\title{
SPIRALS
}

\section{IN NATURE AND ART}




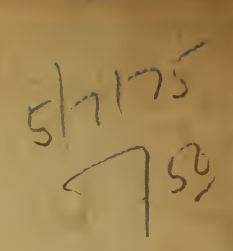

Cooper-Hewitt Museum Library

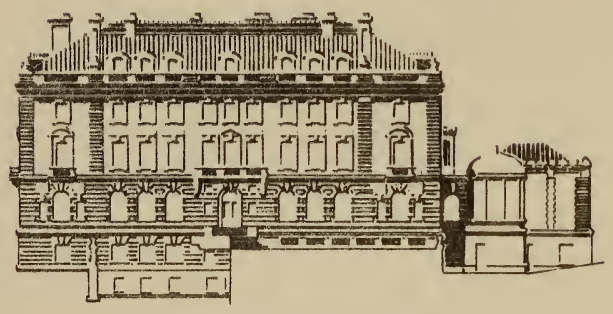

Smithsonian Institution Libraries 




SPIRALS IN NATURE AND

ART 


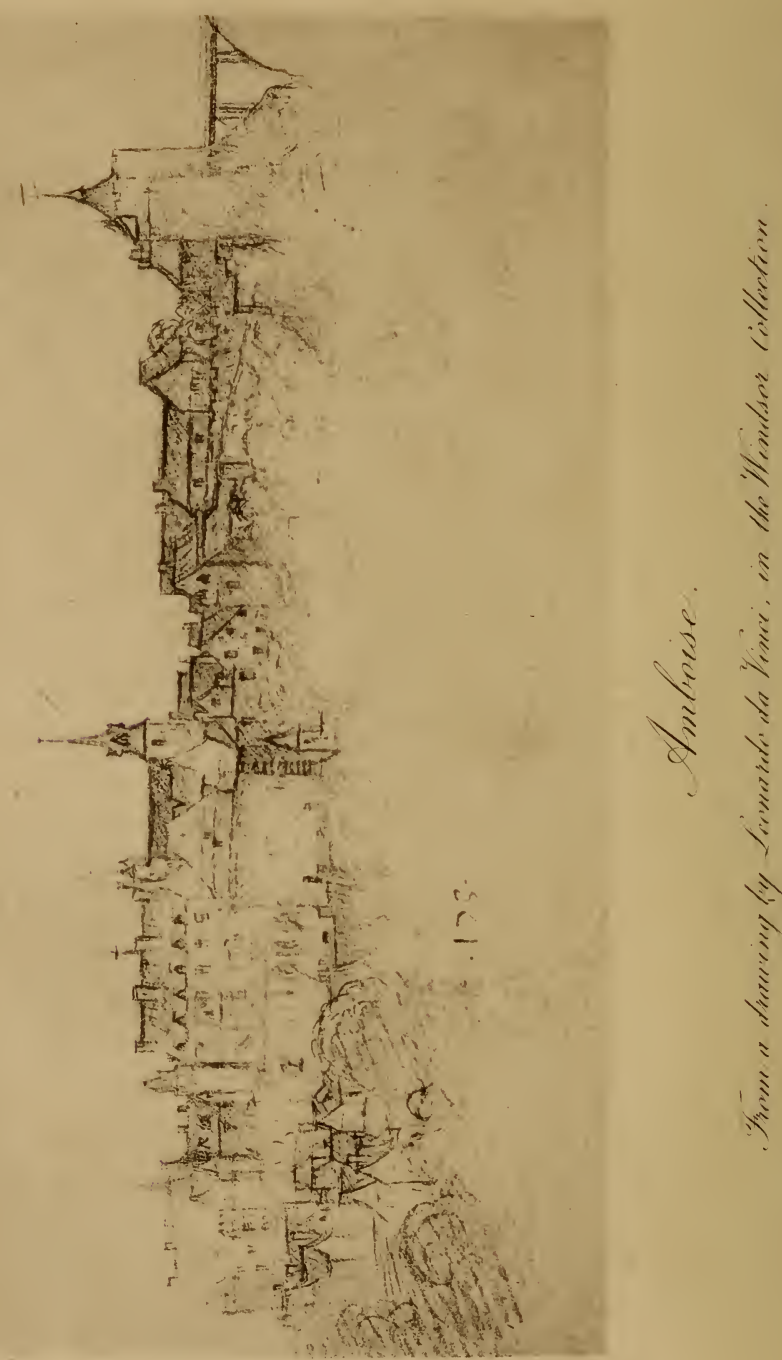


\section{SPIRALS \\ IN NATURE AND ART,}

A STUDY OF SPIRAL FORMATIONS BASED ON THE MANUSCRIPTS OF LEONARDO DA VINCI, WITH SPECIAL REFERENCE TO THE ARCHITECTURE OF THE OPEN STAIRCASE AT BLOIS, IN TOURAINE, NOW FOR THE FIRST TIME SHOWN TO BE FROM HIS DESIGNS, BY THEODORE ANDREA COOOK, M.A., F.S.A., AUTHOR OF "OLD TOURAINE," "ROUEN," ETC., ETC., WITH A PREFACE BY PROFESSOR E. RAY LANKESTER, F.R.S., ETC., DIRECTOR OF THE BRITISH MUSEUM OF NATURAL HISTORY

\section{WITH ILLUSTRATIONS}

LON D ON

JOHN MURRAY, ALBEMARLE STREET, W. 1903 


$$
\begin{aligned}
& \text { NA } \\
& 2840 \\
& \text { CrY } \\
& \text { cHM }
\end{aligned}
$$

Purchase 


\section{CONJUGI CARISSIMAE}





\section{P R E F A C E}

I HAVE often thought that if the public knew more of the real beauties of Nature, our Museums would be far more thronged with visitors than is the case at present. Every effort is made in many of them to display the. various specimens to their best advantage, and to explain clearly what they are. But something more is often needed, and the man who knows most about these matters is not always the man who has time to write about them. Moreover, the writings of the specialist are too often necessarily expressed in language that is fully intelligible only to a few. Yet if the energetic worker in other fields will pause a while to consider what he can learn from biology or botany, he will, I think, be rewarded far beyond his expectations.

Leonardo da Vinci was one of the few men 
who can be great in several directions. His painting would have sufficed alone, and by it alone he is too often judged. But he was a man of science, an engineer, a mathematician, a biologist, as well; and his leisure was given to sculpture and to architecture.

Never has so much talent been united in one man. Yet modern men of art and science, who have specialised on their own subjects, may derive great benefit from the work of other specialists in these days when it is practically impossible to keep abreast of one line of research without an exclusive devotion to its progress.

As far as I am aware, Mr Theodore Cook has not specially devoted himself to any of the scientific subjects which come under the scope of his present inquiry. He is perhaps known to a few as the historian of some districts in France. But his name is unfamiliar to students of biology and mathematics. The training which he received in Paris-a training which I could wish were more appreciated at our own Universities - has emboldened him to enter upon a course of speculative generalisation which a more restricted method of study might have prevented. He looks, in fact, 
upon the results of others' labour with a mind that is more ready to perceive its general value than are those intellects which have concentrated a unique energy upon a single set of problems.

I have perused with the greatest interest many of those manuscripts of Leonardo on which Mr Cook's work for this Essay has been primarily based. I also know many of the steps he has taken to arrive at his conclusions, and among them I would point out the comparisons suggested in the growth of horns, as shown in figs. 17, 18, 19 and 20 ; and the collection of various shells, made to investigate the growth of plaits upon the columella, as seen in the series illustrated by figs. 52, 27, 30, $7,53,31,32$, and 33 . These, it seems to me, will be distinctly useful to the biologist, apart from any connection in which they may be found in these pages.

The hope that mathematicians may in time produce a system of definitions that will be of use both to the biological and to the artistic morphologist, is by no means new. But every fresh instance that tends to make it more probable must contribute to the advantage alike of science and of art. I am perhaps not so 
much interested in the attribution of a certain staircase to Leonardo as I am in the steps by which Mr Cook seeks to enforce a theory that is, after all, susceptible neither of proof nor of disproof. Yet I feel that architecture, if it is to appeal to all of us, as it should do, must, in the end, be based upon some general morphological principles. I have long looked in vain for any architectural hand-book that would not merely suggest the foundations on which building and ornament finally rest, but would also lucidly explain to the untechnical observer the reasons, the faults, or the virtues of any architectural example with which he might be brought in contact.

That there are certain natural laws which bind the work of the architect as they must bind the growth of all organic structure, is evident. Mr Cook has suggested one of them, and his suggestion involves, it seems to me, a course of inquiry that would prove as serviceable to the builder as it should be fruitful to the biologist.

The scientific reader will not need to be warned against certain generalisations which $\mathrm{Mr}$ Cook has formulated upon what are confessedly insufficient data. But I am not aware 
that he has indicated anything that is in itself improbable, or that may not be eventually rendered possible when the scope of our experience and knowledge is enlarged by further study. The investigation of spiral forms in Nature is itself a department of scientific inquiry that is still very incomplete, and I believe I am correct in thinking that neither in mathematics nor in architecture has the last word yet been said upon this interesting subject. There are many gaps in Mr Cook's argument which may doubtless be filled up by existing knowledge; but there are many more which await investigation, and he has at least indicated one way in which their value may be at once put to a practical test.

The example of Leonardo will be difficult to follow until a man like Leonardo reappears. Nature seems to have broken the mould, and its fragments have been buried beneath competitive examination papers. But when to a creative imagination which approaches his, shall be added a knowledge of Nature that may well be greater, then every branch of intellectual activity will benefit, even if the immediate result be not all that Leonardo hoped for when he wrote, so many centuries 
xiv

PREFACE

ago: "In this the eye surpasses Nature, inasmuch as the works of Nature are finite, while the things which can be accomplished by the handiwork, at the command of the eye, are infinite."

E. Ray Lankester. 


\section{CONTENTS}

Preface. By E. Ray Lankester . . . vii

\section{CHAPTER I}

THE ARGUMENT.

Sympathy with many things as essential as specialism in a few-The secrets of Voluta vespertilio-Architectural theory-The Open Staircase at Blois-The Manuscripts of Leonardo-The "Italian brother of Faust"-Rodin's Creed-Discoveries of Leonardo

\section{CHAPTER II}

\section{OF SPIRALS.}

Right- and left-handed spirals-The Prentice's PillarColumns at Canterbury-Screws and shavingsCeltic torques-Left-handed men-Narwhal's tusks -An Elephant's tusk-Helicoprion-Turbinella rapa, the Indian Chank shell-Spiral ornamentHelicteres ixora-Lanistes-A return to Nature 


\section{CHAPTER III}

OF PLANTS.

"Lady's Tresses"-Pine cones-Palms-The Devil's Corkscrews-Twining plants-Tendrils-Mr A. H. Church and Phyllotaxis-The Logarithmic Spiral

\section{CHAPTER IV}

OF SHELLS.

Vorticella-Stentor-Dr George Wherry and the growth of horns-Errors in argument-Spiral twists and spiral curves-Bypaths of research-Spiral growth in shells-Sinistral, dextral, and "ultra-dextral" shells-Ammonite and Nautilus . . . .

\section{CHAPTER V}

\section{COMPARISONS.}

Scalaria scalaris and the Palazzo Contarini, VeniceWrong uses of spiral-Mitra papalis and Escalier de la Reine Berthe, Chartres-Telescopium telescopium and the old Staircase at Blois . . . . . .

\section{CHAPTER VI}

\section{A VANISHED ART.}

Constructive and deliberate "asymmetry"-Delicate irregularities in line-Discovery of curves in Egyptian and Greek Architecture-Evelyn in old St Paul's-"Symmetrophobia" according to Professor Goodyear - The Campanile at Pisa not accidental-What we lose by mathematics . 


\title{
CHAPTER VII
}

THE NAUTILUS.

Plaits on the columella of shells-Tracheæ of insects and spiral tubes in plants - A series, to show the formation of the columella, from Turritella lentiginosa to Voluta musica-Sir John Leslie, Canon Moseley, and the Nautilus-Professor Goodsir and the Logarithmic Spiral-M. Vial de Saint-Bel and the race-horse "Eclipse"-Professor Weldon and Clausilia laminata-Pasteur . . . . .

PAGE

\section{CHAPTER VIII}

\author{
OF MASONRY.
}

Evolution of the spiral staircase in the Feudal KeepThe steps that lead to Hell-Appearance of the central shaft-Tower-houses and Newel-staircasesA delicate problem in construction-The jest of Chambord-Left- or Right-handed, "dexiotropic" or "leiotropic?" . . . . . . . . .

\section{CHAPTER IX}

\section{THE EXILE.}

Leonardo da Vinci at Amboise-Ludovico Sforza at Loches, and Cæsar Borgia at Chinon and BloisClos-Lucé-The grave at Amboise-Researches of Leonardo-Botany-Architecture-Flight of birds -Hydraulics-Head-dress for "Leda"-ShellsThe Amboise Stair and Turritella-The Blois Stair and Telescopium . . . . . . . 


\section{CHAPTER X}

THE SHELL OF LEONARDO.

The Open Staircase in the wing of Francis I. at Blois -Its exterior and interior-Voluta vespertilio-Its exterior and interior-Its rare and common forms -Agreements and differences-The staircase a deliberate copy of the shell-The marvellous construction and fine decoration of the staircaseWhy it is left-handed-Its date-Its architect was left-handed-Advantages of the left-handed formation-The double spirals of Chambord built later -Creative Imagination-The Search for BeautyThe Logarithmic Spiral-The foundations of Taste - The Ionic volute - "Majestati Naturae Par Ingenium" 


\section{LIST OF ILLUSTRATIONS}

FIG.

Amboise, from a Drawing by Leonardo da Vinci

PAGE (photogravure)

- Frontispiece

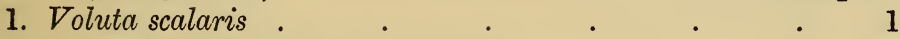

2. Solarium maximum . $\quad$. $\quad$. 7

3. Example of a right-handed and of a left-handed spiral 26

4. The "Prentice's Pillar" at Rosslyn . . . 29

5. Narwhal's tusks . . . . To face page 41

6. Elephant's distorted Tusk . . . . . , 41

7. Turbinella pirum . . . . . . 44

8. Turbinella rapa . . . . . . . 44

9. Postage Stamp now used at Travancore . . 45

10. Helicteres ixora (Seed-Pod) . . . 50

11. "Lady's Tresses" (Neottia spiralis) . To face page 55

12. Pine Cone . . . . . . . 54

13. Wax Palm-Date Palm . . . . $\quad 56$

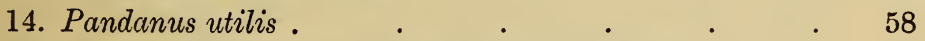

15. Case made by larvæ of Caddis-fly (enlarged) . . 73

16. Capsule of Shark's Egg . . . . . 75

17. Bush-buck shot by W. Brodrick Cloete in South Africa . . . . To face page 77

18. Tragelaphus angasi . . . . .

19. Spiral Twist : $A$. Angora-B. Markhor . $\quad 80$

20. Spiral Curve; $A$. Highland Ram-B. Merino Ram

C. Alaskan Bighorn (Ovis nivicola)-D. Pamir

Sheep-E. Argali . $\quad$. $\quad$. $\quad$. 82

21. Spiral Staircase, Palazzo Contarini, Venice To face page 95

22. Scalaria scalaris . . . . . . . 95

23. Scala del Bovolo, Palazzo Contarini, Venice To face page 96

24. The Tower of Pisa . . . . " " 96 
FIG.

25. Escalier de la Reine Berthe, Chartres

To face page 97

26. Mitra papalis . . . .

27. Telescopium telescopium . $\quad$ - $\quad$. $\quad$. $\quad$. 98

28. Staircase in the Old Wing of the Castle of Blois . $\quad . \quad$. $\quad . \quad$. $\quad$ To face page 98

29. Ceritheum giganteum . . . . . $\quad$. $\quad . \quad$. 115

30. Voluta solandri . $\quad$. $\quad$. $\quad$. $\quad$. $\quad$. 119

31. Voluta pacifica . $\quad$. $\quad$. $\quad$. $\quad$. $\quad$. 119

32. Turbinella fusus . . . . . . 120

33. Voluta musica . $\quad$. $\quad$. $\quad$. $\quad$. 120

34. Nautilus pompilius (section) . . To face page 123

35. Logarithmic Spiral . . . . . " 123

36. Ammonites (arielites) obtusus. From the Lower Lias, Lyme Regis . . . . . To face page 124

37. Argonauta argo . . . . . . . . $\quad$. 125

38. Operculum of Turbo marmoratus . $\quad$ " 124

39. Primitive spiral staircase, with plan of one step . 137

40. Elaborate spiral staircase with plan of improved stonework . . . . . . . 142

41. Two floors of the Château of Chambord, showing the interlacing spirals of the double staircase To face page 143

42. Central wooden shaft of the staircase in the College de Montaigu . . . . . . 144

43. Study for the "Leda," by Leonardo da Vinci, showing spiral form of head-dress. (From the Windsor Collection) . . . . To face page 146

44. Study of the spirals formed by smoke and dust. By Leonardo da Vinci (From the Windsor Collection) . . . . . . . To face page 152

45. Spiral motion of the tips of a bird's wings , 154

46. Professor Marey's photographs of a flying pigeon, taken at the rate of fifty a second. (From Pearson's Magazine for May, 1902) . . . To face page 154

47. A page of Leonardo's handwriting, from Leonardo's Manuscript Note-book on the Flight of Birds. The transcription of Giovanni Piumati and an English version of the translation by Charles Ravaisson Mollien 
FIG.

48. Study of the growth of flowers. By Leonardo da Vinci. (From the Windsor Collection) To face page 156

49. $A$. and $B$. Study of the spirals formed in water. By Leonardo da Vinci. (From the Windsor Collection) To face page 157

50 Longitudinal section of intestine of Raia . . $\quad 159$

51. Turritella lentiginosa $\quad . \quad$. $\quad . \quad$. $\quad . \quad 159$

52. A uricula auris-midac . $\quad$. $\quad$. $\quad . \quad . \quad 159$

53. The common form of Voluta vespertilio (section) . 165

54. Rare form of Voluta vespertilio (section) . . 165

55. Escalier à Jour, Château de Blois, Touraine. The Central Shaft . . . . To face page 165

56. Common form of Voluta vespertilio . . . 166

57. Rare form of Voluta vespertilio . $\quad . \quad . \quad . \quad 166$

58. Escalier à Jour, Château de Blois, Touraine. The exterior . . . . . To face page 166

59. Vaulting and steps of spiral staircase in the wing of François I., Château de Blois . To face page 170

60. $A$ and $B$. Left-handed screws from Leonardo's MSS. in the South Kensington Museum-C. (From the $W$ indsor Collection - D. Signature (from the Windsor Collection) . . . . . To face page 175

61. Method of describing the Ionic Volute by means of a common whelk shell.

(1) Shows tape entirely wound round shell, and pencil in position to start.

(2) Shows tape almost unwound, after nearly completing its guidance of the pencil.

(3) Capital of an Ionic Column.

(4) Chrysodomus antiquus, the shell used to describe the volute reproduced To face page 188 

SPIRALS IN NATURE AND

ART 




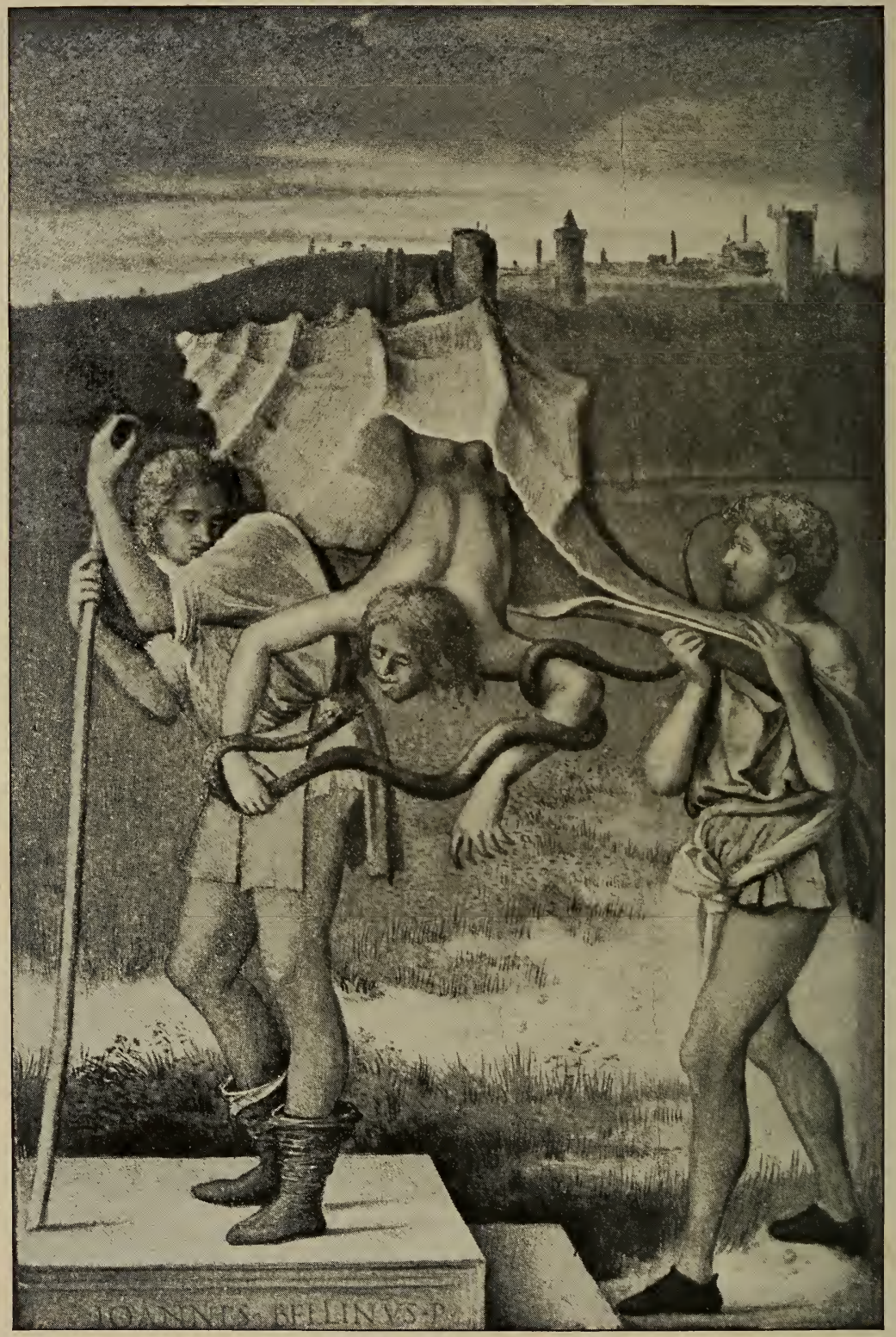

Giovanni Bellini's Allegory of the Shell, painted for the owner of the "Staircase of the Shell," in the Palazzo Contarini, Venice (see page 95).

[To face page 1 . 


\section{CHAPTER I}

THE ARGUMENT

"Ihr durchstudiert die gross' und kleine Welt

Um es am Ende gehn zu lassen

Wie's Gott gefällt.

Vergebens, dass ihr ringsum wissenchaftlich schweift

Ein jeder lernt nur, was er lernen kann." "-Mephistopheles.

"Il pittore deve essere universale."-LEon. DA VIncI.

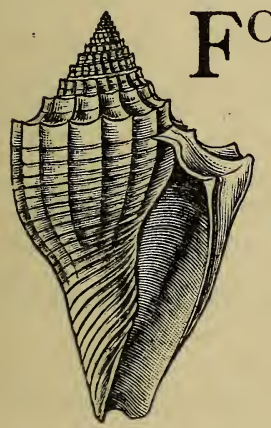

FIG. 1.

FOR the existence of an Essay upon Spiral Formations in Nature and Art, no better apology can be offered than the interest and beauty of an inquiry which has hitherto only been suggested in a few scattered pamphlets and disconnected Voluta scalaris. references. But an excuse is certainly needed for the fact that this

1 "'Tis best to study all things-everywhere-

Nature and man-the great world and the small, Then leave them at haphazard still to fare,

It is, you see, plainly impossible

That one man should be skilled in every science,

Who learns the little that he can does well."

(From Goethe's Faustus. Translated by JoHn ANsTER.) 
inquiry was undertaken by one who knew little history, less architecture, scarcely any mathematics, and no morphology or botany whatever. A deep knowledge of all five seemed indispensable. But as the most profound acquaintance with only one, or even only two, was useless, I have ventured, perhaps too boldly, to believe that to have specialised in none, and to have the keenest sympathy with each, is as good a qualification for the task as may, for the moment, be attained. My belief is all the easier because it is accompanied by the confidence that every specialist will delightedly correct those errors which occur in ground familiar to him, while he may perhaps be tempted-by their mere proximity - to consider questions which he has hitherto too often set aside as being beyond his special province.

In either case I shall be sufficiently rewarded. But I would not have it thought that I have approached these matters lightly or suddenly. They have been constantly in my mind for thirteen years, and if $I$ at length presume to offer the result of my endeavours to the public, it is because many of the questions to which an intelligible reply is sought have not yet been answered in any of the five divisions of intellectual research already mentioned, though distinguished exponents 
of each are firmly convinced that a reply might be furnished by the others. It is in the hope of eliciting such replies that these tentative pages have been published. To remain silent for lack of perfect detail in each part, were but to strengthen the negative gloom of the narrow specialist, whose motto might well be the warning placed at the head of this chapter, the lines that were spoken by "The Spirit who Denies."

I do not give the names of many who have offered me the kindest and most generous assistance. ${ }^{1}$ They are all aware of my gratitude; and none of them might wish to be made even remotely responsible for suggestive generalisations that are unfettered by too keen an appreciation of difficulties in detail. Though I have been at great pains to verify the facts here recorded, I will therefore beg that the architect will particularly scrutinise my biological statements; the

1 To helpers of a different kind I must express my thanks by name, for without the careful drawings made by Mr T. Green of Wallington, and the no less skilful wood engravings of Mr Butterworth of Savoy House, my argument would have entirely lost some of the most convincing of its aids. The design of the twining hop-plant on the binding, and the drawing of "Lady's Tresses" in the text, are my mother's work. Messrs Sowerby and Fulton of Kew have been of great assistance in choosing some specimens of shells for me. 
[CHAP.

mathematician my excursions into art; and that the historian will look indulgently upon one result which seems to flow from arguments based alternately upon both-a result which, in the absence of all documents, does not admit of perfect proof.

With this modest study in spiral formations the great name of Leonardo da Vinci has been connected on my title-page for reasons that will soon become evident. But the incident that first associated the two in my own mind deserves recording, both as an explanation of these pages and as an example of scientific insight.

Just thirteen years ago I was dining at Oxford, in company with some distinguished biologists. Each seemed to have something of value either to relate or to display, and the unlearned guest was feeling a little at a loss for any topic of discourse in a conversation which ranged so far beyond his own experience and knowledge. At length he ventured to produce for general inspection a proof engraving upon Indian paper of a certain staircase (see fig. 59), built by an architect whose name has been hitherto unknown in the early sixteenth century at Blois. I had but just returned to Oxford after a long visit to the banks of the Loire. I had endeavoured to investigate the historical and artistic associa- 
tions of that wonderful valley for a book, ${ }^{1}$ to whose publishers I felt deeply indebted for thus bringing into greater prominence a miracle of design which now seemed to promise even greater fascinations than those discovered in it already.

The little picture was indulgently received; and the joy of its humble possessor may be imagined when one of the party loudly proclaimed his recognition of the spiral curve therein depicted. No sympathy was suggested with any architectural problem; but the critic who now held the picture of the spiral staircase in his hand announced to his comrades that the curves upon its central column were identical with those of Voluta vespertilio (see fig. 56).

Abashed, befogged, but keenly interested, I hinted at my ignorance of what Voluta might be. The shell was fetched. Still I remained unmoved and unilluminated. Finally the Professor had pity upon me. A longitudinal incision was made, and the fourfold spiral stood revealed within upon the columella (see fig. 53).

Every one was soon talking of other subjects, but I could think of nothing else. In spite of many other conflicting interests and duties I have thought of that chance 1 "Old Touraine" (Rivingtons, 1892). 
[CHAP.

discovery ever since. If a biologist could recognise the lines that are hidden within a certain shell as soon as he saw them reproduced in a French staircase, there was also the possibility that the staircase had been originally suggested by the shell. This idea turned my thoughts to other spiral staircases and other shells. I found that a Scala della conchiglia and a Scala del bovolo (fig. 21) were to be seen in Italy; and that in the Natural History Museum at South Kensington there were a Voluta scalaris (fig. 1), a Solarium maximum (fig. 2), even a Scalaria scalaris (fig. 22). The connection between shells and staircases was evidently present in the minds both of those scientists who had bestowed these names on shells, ${ }^{1}$ and of those persons who had seen and admired a building sufficiently to recognise the natural objects it recalled. This by no means involved that certain architectural forms could be explained on a conchological basis, or that conchology should ever be considered from an architectural point of view. But it certainly did suggest that a staircase whose form and

1 The name Voluta was given by Linnæus. The species Scalaris was described and named from the Barton Beds (Middle Eocene) by J. de C. Sowerby in 1843. It may be noted that fossils in these beds are wonderfully preserved, even in colour, and include a very large number of columellar spirals. 
construction recalled a natural growth would more probably be the work of a man to whom
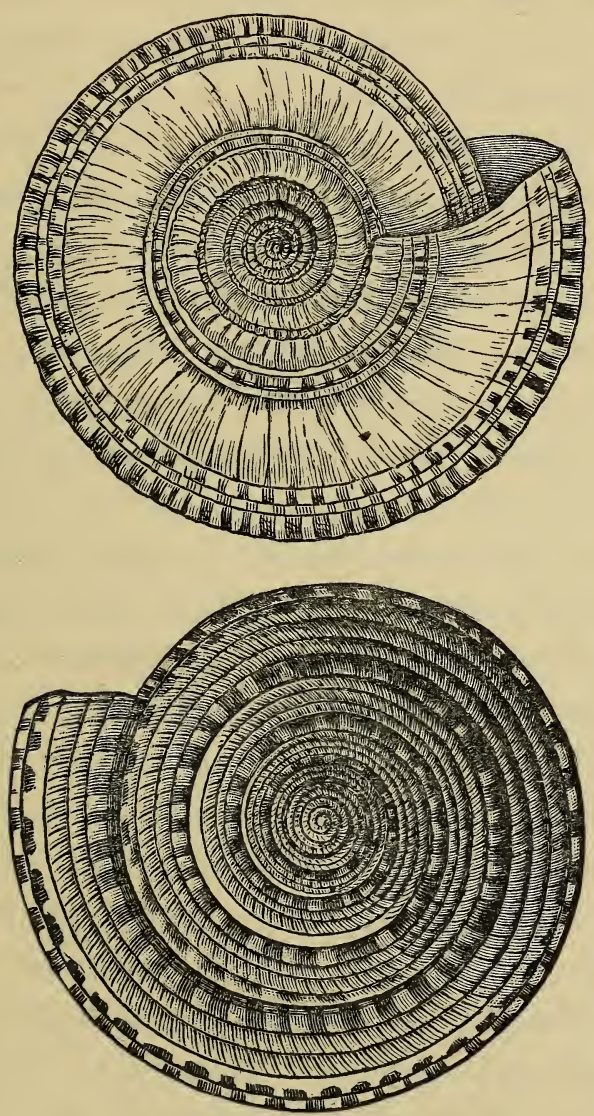

FIG. 2.

Solarium maximum,

biology and architecture were equally familiar than that of a builder of less wide attainments. It would, in fact, be likely that the design had 
come from some great artist and architect who had studied Nature for the sake of his art, and had deeply investigated the secrets of the one in order to employ them as the principles of the other.

It seems difficult for many architects, when they commit their thoughts to paper, to express their views moderately, so deep are their personal convictions of what is right and wrong. Some critics objected so vehemently to one portion of these pages in their earliest form ${ }^{1}$ that they apparently refused to consider any other.

As a matter of fact, I most thoroughly accept the commonplace, that Art is one thing, and Nature is another, ${ }^{2}$ and that mere unintelligent copying of natural phenomena will never be artistic, however faithfully performed. Structural forms in architecture - it is as great a platitude as the other-are usually the result of direct problems in building. Yet I do not hesitate to say that the philosophy of Architecture must finally be based on general principles which will appeal to other intelligences than those of

${ }^{1}$ In The Monthly Review for April and May 1902.

2 "Nature," wrote Whistler, "contains the elements, in colour and form, of all pictures, as the keyboard contains the notes of the piano," but, "to say to the painter that Nature is to be taken as she is, is to say to the player that he may sit on the piano." 
the strictly professional architect. On the other hand, though natural forms, unmodified and unrestrained, can never become architectural ornaments, yet it is not necessary to lose all the charms of natural beauty by exaggerated convention, or by too rigid application of the $T$ square and the ruler. Indeed, I shall show in later pages that it is only by appreciating the irregularities of Nature that beauty can ever be artificially attained (see p. 185).

Language is not literature; nor is mere verse poetry. Style is not attained by overelaborated exactness, nor is industrious reproduction an attribute of genius. Architecture should take her right place at the head of all the Arts, because she can most clearly manifest that divine attribute in man which is connoted in Creation; and the creative imagination is no more concerned with fancies only than it is with facts alone; it deals with the material of scientific knowledge, and with the causes that underlie phenomena, in order to evolve new combinations of its own.

No one has yet been able to say who designed the open staircase in the wing of François I. at Blois, which is reproduced in figs. 55, 58, and 59. If it were really the conscious copy of a shell, the first step towards a discovery of its designer would be to find a man who lived near Blois between 
1515 and 1520, who was a friend of François I., who was something more than a mere master-mason, and who was likely to have studied shells not merely as a biologist, not merely as an artist, but also as a scientist and a philosopher, who was in search of those hidden natural causes which might be applied to the products of human handiwork. To all these somewhat general qualifications there is but one man who can justly lay claimLeonardo da Vinci, that great Italian artist, mathematician, scientist, and engineer, who died in exile within a few miles of this very staircase a year or two after it had been begun.

The main impression produced by this building is its spiral formation. It is therefore likely that its builder would have given particular attention to spiral formations in Nature, with the object of discovering the principles involved in them. I shall hope to show that this was one of the many problems to which Leonardo turned his extraordinarily original and acquisitive intellect; and in the various instances of natural spirals which I have collected I would also point out that the original indication was given me, in almost every case, in his manuscript notes. These manuscripts suggest many problems which even the present advanced 
state of scientific knowledge is unable as yet to answer; and therefore my original voyage of discovery in search of the designer of a particular staircase has led me, by natural and unavoidable paths, into an inquiry which ranges far beyond either the building or its builder, and leads towards those ultimate principles of construction and of growth which Leonardo did so much to discover, and which his successors are still endeavouring to grasp.

Though lessthan a dozen undisputed examples of Leonardo's paintings exist, it is chiefly as a painter that he is known to general fame. The bulk of his sketches and manuscripts in this country exceeds by many times the whole of those possessed by other nations, yet the value and contents of these do not seem to be so well appreciated in England as they are elsewhere. They have been investigated by Venturi, Libri, Govi, Richter, Ravaisson-Mollien, Beltrami, Müntz, MüllerWalde, Uzielli, Sabachnikoff (fig. 47), Piumati, Duval, Séailles, and the editors of the facsimile edition of the Milan manuscripts, to name no more. Apart from the actual drawings and studies they contain, these manuscripts are very much like the notes that might be made by an exceptional Professor for a course of very extraordinary lectures. 'They display a gift of literary expression and construction which lags very 
far behind the ardour for discovery that inspired them. For this reason their writer remained almost unheard by his contemporaries, and is scarcely yet appreciated by his posterity. His arguments are not presented in that logical form which helps a reader to understand their drift. His discussion of the connection between the Scriptural Deluge and the fossil shells found upon a mountain-top is one of the few cases in which the literary form of the inquiry is complete. It is therefore only natural that the isolation of his own intellectual life should have been almost reproduced in the comparative neglect of his manuscripts in later years. It was one of his favourite sayings that the strength of the painter was in solitude:- "Se tu sarai solo, tu sarai tutto tuo."

Another drawback is the material one of the difficulty in deciphering his writing. Whether it be true or not that it was owing to travels in the East that he took to writing from right to left, it is certain that he largely employed a caligraphy which can best be read in a mirror (see fig. 47), and which was also an easy accomplishment for a left-handed man. ${ }^{1}$

1 A landscape drawing in the Uffizi-the authenticity of which has never been called in question-is dated "The day of S. Mary of the Snow, the 5th day of August, 1473," when Leonardo was just twenty-one ; and Mr M'Curdy has 
If the shading of his drawings had not revealed the peculiarity, we should have known that Leonardo was left-handed from the statement of his friend Fra Luca Pacioli, for whose book, "De Divina Proportione," he designed the figures.

These are some of the reasons why the secrets of a man who spent the last years of his life in exile at the beginning of the sixteenth century remained his own until the last years of the nineteenth. Yet his fame is only strengthened by that long oblivion. For the laws which he established or divined have been independently discovered and proved as advancing knowledge made researches easier; and the reputation of his successors remains untarnished; for though their discoveries must now be antedated by three or four centuries, they made them in their turn while Leonardo's manuscripts were still unknown. A sower of ideas of which he never saw the harvest, he jealously guarded them from intrusion during his lifetime, and they never came to light till long after his death.

pointed out that this inscription shows Leonardo had already adopted the method of writing from right to left; so that I prefer the theory that this was the natural method of the left-handed man, rather than the acquired result of any possible travels in the East. 
Before me as I write are some five hundred careful photographs of the originals existing in England, to which it may be hoped that a fuller justice will some day be done than I can now find to be the case. Though it was necessary to examine all of them, only a very small fraction bore upon the special subject of this work, and only a very few examples have been chosen out of these to indicate the kind of material available (see figs. 43, 44, 47, 49), and to produce the barest essentials in the progress of this argument. ${ }^{1}$ 'They embrace drawings of landscape and figures, which are evidently studies for pictures; anatomical drawings of great beauty and skill; botanical sketches, architectural plans, biological notes, numerous engineering problems, many mathematical inquiries, the whole dashed down without much order, in a very fervour of investigation. ${ }^{2}$.

Carrying as he did, in that brain which

1 I have also examined the MSS. in Paris, Venice, and Milan, where the numbering of the great "Codice Atlantico" has been corrected by the Abbé Ceriani, and the whole is being reproduced at the cost of the State.

2 Though many pages that have survived cannot, under any hypothesis, be considered as prepared for publication, there is some evidence in others that Leonardo not only wrote for a public, but was conscious of his literary shortcomings. "Blame me not, 0 reader," he says, for instance, in one note-book, "for the subjects are numberless, and my memory is weak, and I write at long intervals. . . ." 
bore so many images of beauty, not only all the science known at the beginning of the sixteenth century, but almost half of the attainments that the years since then have brought us, Leonardo lived of necessity a lonely life; and with advancing years it is known that his thoughts turned more and more from painting to problems of natural science, and to vast collections of natural objects. His quest was that of Goethe's Faust:-

"Das ich erkenne, was die Welt

Im innersten zusammenhält

Schau' alle Wirkenskraft und Samen

Und thu nicht mehr in Worten Kramen." 1

It was a characteristic of his genius that the patent phenomena of life did not content him. He insisted on going deeper. " $M a$ tu che vivi di sogni," he writes in the Treatise on Flying (fig. 47), "ti piace piu le ragion soffistiche e barerie de palari nelle cose grande e incerte, che delle certe, naturati, $e$ non di tanti altura." 2 His intellect was as

I " $O$ for a glance into the earth !

To see below its dark foundations

Life's embryo seeds before their birth. . ..."

(Goethe's Faustus, trans. by JoHN Anster.)

2 "But thou who livest in dreams art more pleased even with the sophistical reasonings and theories of philanderers, when they deal with great and unknown matters, than with researches into things certain, natural, and of a lower interest." 
[CHAP.

sincere as it was sagacious. He penetrated the secret hiding-places of truth with a passionate industry that never shrank from toil. "Truth," he cries, " is so excellent that by her praise the very smallest things attain nobility." His method was that of Darwin, proceeding by an analysis which does not fear to be diffuse; grouping isolated pieces of evidence, attaining at last a final law, or at least a hypothesis that would explain the facts. His anatomical drawings, apart from their exquisite draughtsmanship, contain so many keen parallels and suggestive indications that the author of the "Origin of Species" would have perused them with delight. ${ }^{2}$ It is perhaps a loss both to Science and to Art that the majority of Leonardo's manuscripts do not seem to have been known, as far as we are aware, either to Darwin or to Ruskin.

I shall have occasion to mention several instances of Leonardo's use of that experi-

1 The passage begins as follows: "Ed è di tanto vilipendio la bugia, che s'ella dicessi be'gran cose di dio, ella to' di grazia a sua deità; ed è di tanta eccellenzia la verità ...."

${ }^{2}$ In the manuscripts at Windsor, for example, there are careful drawings to show that the tail in other animals existed in a modified form in man. Huxley's manuscript memoranda are, I am informed, full of delicate drawings, and in other ways somewhat similar to those of Leonardo. 
mental method which Humboldt recommended and Galileo used. He understood to the full the definition of Science as "the

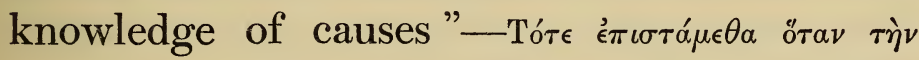
airia $\epsilon^{\prime \prime} \delta \omega \mu \epsilon \nu$. He realised even more keenly the necessity that Science should be largely occupied with speculations, with hypotheses, with imaginations, with what Müller in 1834 called "Phantasie." " Nature must be interrogated in such a manner that the answer is implicit in the question. The observer can only observe when his search is guided by the thread of a hypothesis. It is the thread of spiral formations that has guided these chapters. It was the manuscripts of Leonardo which inspired them.

The laborious collection of facts alone is powerless if it does not go further. The imagination, unrestricted, can neither convince nor gratify. But in combination the

1 "Die Phantasie ist ein unentbehrliches Gut; denn sie ist es, durch welche neue Combinationen zur Veranlassung wichtiger Entdeckungen gemacht werden. Die Kraft der Unterscheidung des isolirenden Verstandes, sowohl als die der erweiternden und zum Allgemeinen strebenden Phantasie sind dem Naturforscher in einem harmonischen Wechselwirken nothwendig. Durch Störung dieses Gleichgewichts wird der Naturforscher von der Phantasie zu Träumereien hingerissen, während diese Gabe den talentvollen Naturforscher von hinreichender Verstandesstärke zu den wichtigsten Entdeckungen führt."-JoH. MÜLLER, Arch. für Anat. 1834. 
[CHAP.

- two can do what, for want of a better word, we call "create."

This was Leonardo's meaning when he said that "the works of Nature are finite." They move along those orderly, those vast, processes of time and space which can be realised by that human intelligence which is a part of them, if only it will work hard enough to collect the details.

"Ich stand am Thor; ihr solltet schlüssel sein;

Zwar euer Bart ist kraus, doch hebt ihr nicht die Riegel.

Geheimnissvoll am lichten Tag

Lässt sich Natur des Schleiers nicht berauben

Und was sie deinem Geist nicht offenbaren mag,

Das zwingst du ihr nicht ab mit Hebeln und mit Schrauben."

This, then, is to "know"; but to "create" is greater, for creation takes that further step which is beyond knowledge, yet must ever be based on knowledge; and this is the truth which the great Italian expressed in that hard saying of the eye surpassing Nature; for he realised that "the things which eye and hand

1 "I stand before the guarded door

Of Nature, but it bids defiance

To latch or ward : in vain I prove

Your powers-the strong bolts will not move.

Mysterious in the blaze of day

Nature pursues her tranquil way. . .."

(Goethe's Faustus, trans. by JoHn ANsTER.) 
can create are infinite." "All things are artificial," said Sir Thomas Browne, "for Nature is the art of God."

Michelet described Leonardo, in a thoroughly characteristic phrase, as "the Italian brother of Faust"; but there is an even closer parallel between the Italian and Faust's great creator, Goethe. For the genius of the German shone not merely in the poetry and prose of which he is the acknowledged master, but in osteology, in botany, in morphology, in anatomy, in optics, in the theory of architecture. His name will indeed be connected with some of these as long as it is honoured in the language he immortalised. Like Leonardo, Goethe projected a mind that was primarily artistic into all those scientific problems which the errors or inadequacy of his time had left incomplete. Such prophetic insight as was theirs is never understood in the age of which it is a part. But when their day has itself become a portion of the past, then their own value emerges clear, in its true perspective, above the many-headed ignorance that once shrouded them ; for " it is not the intelligent man, but Intelligence, that rules." "There is no such thing," cried Goethe, "as a patriotic art." Like all else that is great and good and true, Art and Science belong to the whole world. It is 
[CHAP.

only by constant reference to our great inheritance, and by a constant interchange of ideas between every contemporary worker, that we can advance at all. This, therefore, is another reason why I have ventured to ask the architect to consider the biologist in a kindlier light, and invited the mathematician and the botanist to lie down together.

It is only by such intercommunication as modern inventions and modern tolerance have rendered possible that any of us can ever approach that large point of view which, in the case of Leonardo, was possible to a single man. "La Nature," said Rodin, "c'est le modèle variable et infini qui contient tous les styles. Elle nous entoure, mais nous ne la voyons pas." The ideal of the sculptor speaking at the dawn of the twentieth century was that of the artist working in the fifteenth. As has been finely said of the Frenchman, he knew "all there is to know of the aptitude of clay to receive, of marble to declare, his own intimate interpretation of those large secrets of the Universe which escape the narrow definitions of logic and of language." 1 But Leonardo went further than this; for he possessed to an extraordinary degree that masterful quality of the human mind which Goethe called "das Dämonische," that power

${ }^{1}$ Rt. Hon. George Wyndham, 15th May 1902. 
which makes and transforms ideas, that living and constructive energy which flings itself into the future while it assimilates the present.

"Ich, mehr als Cherub, dessen freie Kraft

Schon durch die Adern der Natur zu fliessen. . . ." 1

It must be remembered, too, that Leonardo lived and laboured in an age when what we may call "the scientific sense" was far less developed than it is now, and when the multitudinous possibilities of the printing press, the camera, and the telegraph were either unknown or unappreciated. In his library, biology was represented by Pliny, John de Manderville, and "a lapidarium." Yet he suggested the theory of the eye, which was slowly elaborated from Leonardo to Kepler, from Kepler to Helmholtz.

"Il Moto," he wrote, "é causa d'ogni vita." "Activity," said Professor Clifford four hundred years afterwards, "is the first condition of development." Leonardo was the first to propose a division of animals into vertebrates and invertebrates. He guessed that the blood circulated, but could not explain the mechanism. "The heart," he

1 "High above cherubs-above all that serve Raised up immeasurably-every nerve Of Nature's life seemed animate with mine. . . .

(Goethe's Faustus, trans. by JoHN Anster.) 
wrote, "is a muscle of great strength ... the blood which returns when the heart opens again is not the same as that which closes the valves."

Long before Bernard Palissy he studied the fossil shells on mountain tops, and showed that "the Deluge had nothing to do with them," and that they were remains of living organisms, left there by water, "Nature's Charioteer," in the course of prolonged changes in the surface of the earth, and revealing in their fossil state the circumstances of their far-off existence. He thought that "the sandy desert beyond Mount Atlas" had formerly been "covered with water," and anticipated Cuvier by showing that the level of the sea's bottom is continually rising, sometimes rapidly, sometimes by lengthy accumulations of débris, and pointed out the strata in the stone of the Apennines revealed by the cutting of the river Lamona. He gave as long as two hundred thousand years for the accumulations formed by the river Po; and in geology his investigations directly foreshadow in other ways the work of Lyell, who established geology as a science by showing that the causes which had produced the past were still at work producing the future, just as Darwin not only explained the biology of 
vanished forms, but gave the reasons for further development, and assigned living things to their right place in the great order of Nature.

Besides founding the study of anatomy Leonardo was the first to investigate the structural classification of plants, and (in the fourth book of the "Trattato") to study the system on which leaves are disposed and arranged about their stalks, and laid down laws which were re-discovered independently in the seventeenth century. He explained the suspension of bodies in the air, and experimented on the consistency of the atmosphere at various heights, besides going far towards a solution of those problems of flying which still occupy us to-day. "Il sole non si move," he wrote, anticipating Copernicus in propounding his theory of the movement of the earth round the sun, and explaining to the dogmatists of his day that "the supreme; wisdom of Grod ${ }^{1}$ guided him to choose those laws of movement which were in closest agreement with abstract and metaphysical reasoning."

He laid the foundations for those laws of the movement and equilibrium of fluids

${ }^{1}$ Compare the "Digression of the Wisdom of God in the Site and Motion of the Sun" in Sir Thomas Browne's "Vulgar Errors," VI. v. 
which were completed by Pascal, D'Alembert, Bernouilli, and others. He proved that water in communicating vessels remained at the same height in each, which was the theory of the hydraulic press of 1653. Attracted irresistibly by the practical problems of the Scriptural "Deluge," he covered innumerable sheets with studies of the movement of water under the stress of such a sudden cataclysm. The canals and irrigating works already existing in Lombardy were enormously improved by his hydraulic knowledge, and his contrivances were still employed by the Milanese at the end of the seventeenth century. He experimented on the lines which subsequently produced the "camera obscura," and initiated the theory of complementary colours which was carried on by Chevreuil.

Of his numberless mechanical inventions, it will be sufficient to say that he designed a breech-loading cannon which propelled its ball by steam, that he invented paddle-wheels for boats, and that he suggested the use of parachutes and of screws turning on a vertical axis as a means of aërial locomotion. Other details will appear in their right place, when I come to point out more emphatically those investigations into spiral forms in Leonardo's manuscripts which are especially appropriate to the subject of this book. But I have said 
enough already to remove any improbability from the suggestion that as an architect Leonardo would be likely to show traces of his studies in other directions, and I can now pass on to consider more closely the form and meaning of various kinds of spirals.

Besides collecting and examining some spiral formations in Nature, with the object of discovering, if possible, any principles that may underlie their existence and construction, I shall call attention to those formations in Art which may appear to be more particularly connected with this subject; and it will thus be possible to realise a little better the full value and meaning of the architectural example with which this book concludes. The attribution of a certain staircase to a certain master may not interest many beyond a restricted class of readers; but the steps by which that attribution is arrived at, and the artistic principles of which that staircase is a type, are matters that should appeal to the far larger audience to whom questions of taste and of abstract beauty are not limited by the requirements of a single profession or a single branch of knowledge. 


\section{CHAPTER II}

\section{OF SPIRALS}

"Search where thou wilt and let thy Reason go To ransome Truth even to th' Abyss below ; Rally the scattered Causes, and that line Which Nature twists, be able to untwine."

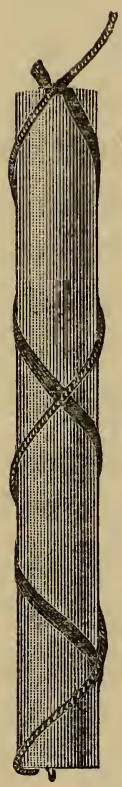

BEFORE me as I write is a plain B cylinder of wood, nine inches high, 蛋 with a diameter of just over one inch (fig. 3). I have taken a piece of string eighteen inches long and nailed it to the bottom edge, in order to wind it round the cylinder to the top edge. In doing this, I find it easier and more natural to make the first turn of the string towards the right, with the result that the three visible lines of the string made by its ascent upon the cylinder are all curves which move upwards towards the right, and these curves are in the form of what is called a spiral, and sometimes a helix. 
When I rotate the cylinder on its axis they remain the same. In this instance I have formed a right-handed (or dextral) cylindrical spiral (see fig. 27). When a watch-spring lies flat upon the table it forms a plain spiral (see figs. 34, 35). If you fix its largest circle to the table, and raise up its innermost point, you find that a conical spiral has been formed; and a good natural example of this is shown in Mitra papalis (fig. 26).

At the same point on the bottom edge of the cylinder where I had fixed my string, I now fix a piece of flat narrow tape of precisely the same length, so that I can wind it round the cylinder to the same point on the top edge reached by the string. I had naturally wound to the right before, because my right hand (being that of a righthanded man) always finds it easier to make a circle towards the right than towards the left, just as every right-handed fencer knows that the contre-sixte is an easier parry than the contre-quarte, because the circular movement of the hand is towards the right, whereas ${ }^{1}$

${ }^{1}$ In driving, the instinctive movement of the hand would turn a horse to the right when passing an obstacle in its way, and most nations are content that this should be so, although the coachman's seat is placed over the right wheel. The English, however, have logically overcome their instincts and drive to the left; they prefer to see where their right wheel is going. 
[CHAP.

Kirchhoffer, a left-handed man, is celebrated for his contre-quarte.

I now begin by turning my tape to the left, and when it is fixed at the top, I find its three ascending curves go up by a different and symmetrically opposite path to that taken by the string; I have made, in fact, a cylindrical spiral, which is not of the usual dextral or right-handed form, but sinistral or left-handed. The difference seems very simple when it is expressed in simple language, but it will have to be kept very carefully in mind in the course of these pages, for a good deal will be found to depend upon it. So much, indeed, is this the case, that I find it impossible to proceed without placing my cylinder upright on the table before me, with the two different threads of string and tape clearly showing the difference between the two forms of spiral; and I notice it does not matter which end of the cylinder is at the top, for the spirals remain the same if I stand it upside down; and this may also be prettily demonstrated by reversing this book and looking at the staircases shown in figs. 28, 55 and 59, from the top instead of from the bottom, a point of view which will indeed only emphasise the complicated beauty of their construction.

The beautiful effect obtained in what is 
known as the "Prentice's Pillar," in Rosslyn Chapel (fig. 4) is due to the fact that its separate right-handed spirals (proceeding from their separate points) envelop in their long and slender ascending curves a pillar which is artfully grooved in perpendicular lines, so that full value may be given to the encircling decoration. In Nature the ascending curves of spiral growth are nearly always, like these, towards the right, as shown by the Pillar and by the string upon my cylinder, when observed at right angles to its elevation. Either very rarely in a "sport," or with some definite reason in artificial examples, the ascending curves are those towards

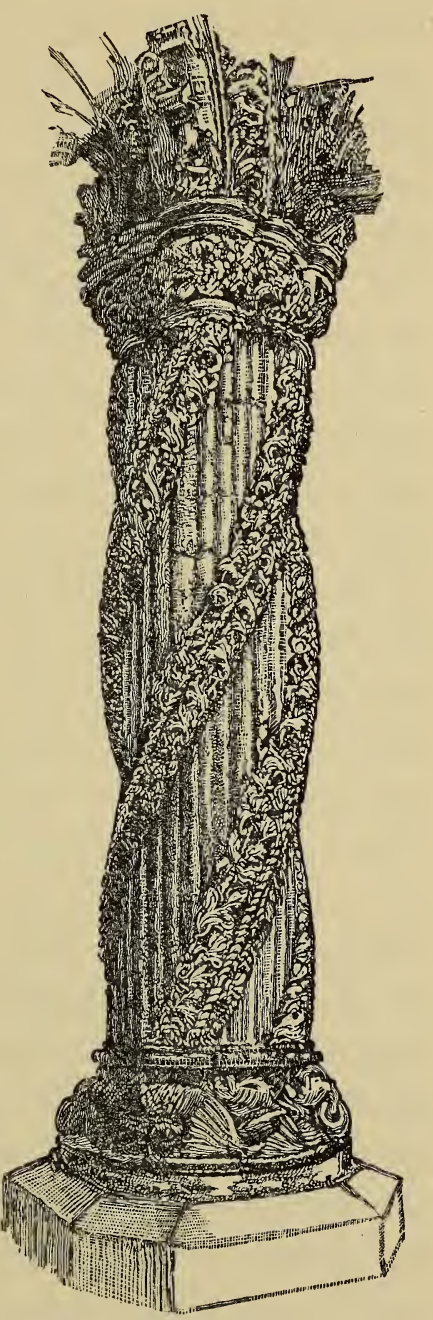

FIG. 4. the left, as shown by "The "Prentice's Pillar" at Rosslyn. the tape when its course is followed from the 
[CHAP.

bottom of the cylinder upwards. Such reverse curves a right-handed man makes with conscious effort either with his right hand or right foot; they seem in fact to be chiefly connected with descent, and may be observed, under certain circumstances, in the fall of a strong stream of water from a height. We should not expect them, therefore, to occur in architecture, because man builds upwards, and his upward spiral movement would be instinctively to the right as it is in the "Prentice's Pillar."

In the Chapel of the Holy Innocents in the Crypt of Canterbury Cathedral (beneath St Andrew's Chapel) there is a short column, with a shaft four feet in height, showing spiral bands running upwards to the right with very fine effect; and it is curious that the same crypt provides an interesting example (in St Gabriel's Chapel, beneath St Anselm's Tower) of a column with a shaft five feet in height, which begins with a left-handed spiral in its grooved decorations, but, half way up, these grooves are changed to a right-handed spiral, with a band of irregular incised diamonds to mark the transition, as if the workman had felt that the design had been begun wrongly, and had therefore corrected its direction. This was built in 1103, and in 1121 a further development in spiral decoration is observable in the same 
building. If you stand in front of the Lady Chapel in St Ernulf's Crypt, and look westwards down the central alley, you will see eight pairs of columns, of which the second, fourth, sixth, and last exhibit a spiral arrangement of grooves. In the first two a right-handed spiral is elaborately decorated throughout. In the next pair, the bands of decorations are cut alternately in right-handed and left-handed spirals, and end in straight fluted grooves. The left-handed arrangement is never permitted to stand alone; from which we may perhaps infer, that if there was one left-handed man among the masons, his right-handed comrades took care that he should never complete a design which did not fall in with their idea of what was appropriate to the principles of growth, support, or strength, typified by a column (see p. 96).

The commonest instance of a cylindrical spiral is the homely corkscrew, which may be placed for comparison beside our cylinder of tape and string, and it will be seen that its masculine strength of penetration is expressed by the same right-handed curves as those of the string. ${ }^{1}$ If you place it upright

${ }^{1}$ I need hardly perhaps remind the traveller that he would never have got across the Rocky Mountains in a railway train if the track had not been planned on a feasible gradient by the scheme of spiral tunnels gradually ascending like a corkscrew. 
upon its point, you will observe that an insect ascending to the handle would be perpetually turning to the left, so conchologists call this spiral "leiotropic," for they seem to have connected shells and staircases together as soon as scientific terminology became common.

If you imagine that the string surrounding our cylinder is made of the same substance as the cylinder, and projects a little further from the surface, you will have an example of the ordinary screw. The coffin-screw, on the other hand, is that fortunately rarer variety which only penetrates when it is turned in the unusual direction, to the left. In these military days it is also possible to point to a sinistral spiral which has become a common object of admiration, and that is the rifling in a Lee-Metford, which is made to turn to the left in order to counteract the pull of the average right-handed soldier. It is curious that all left-handed spirals look as if they were at almost double the pitch of the corresponding right-handed spirals; perhaps because they are less familiar to the eye.

A screw may be defined as a cylinder of wood or metal having a spiral ridge ("the thread") winding round it, usually turning in a hollow cylinder, in which a spiral channel is cut corresponding to the ridge. The 
distance between the medial lines of any two successive threads of a screw, measured in a direction parallel to the axis, is called "the pitch" of the screw. A "screwstone" is the name sometimes given to one of the joints of the stem of an encrinite, or "stone-lily," a Palæozoic crinoid plentifully found in marble, and belonging to a class of animals (echinodermata) which are stalked, or fixed like a plant for some or all of their lives. A "Portland screw" is a similar name bestowed on the fossil cast of the interior of Cerithium Portlandicum. The name of "Augur-shell" has for the same reason been given to a toxoglossate gastropod called Terebra (Bullia) semiplicata, and more especially to $T$. maculata.

As we shall see when we come to consider the origin of spiral shells, the force which determines the original direction may be very slight and subtle, yet is invariably "good evidence." The shape of the shavings at a carpenter's bench, for instance, might furnish another Sherlock Holmes with the proof he required that his murderous mechanic was either left-handed or a Japanese; for one of these two he must have been if the shavings exhibit a sinistral spiral. The right-handed screw which is usual in the innocent shaving is produced because the right-handed carpenter 
invariably drives his plane a little to the left. Orientals seem always to prefer a left-handed spiral, just as they write from right to left, and a common example may be found in those silver-headed walking-sticks of blackwood which, in all instances I know, are carved in left-handed spirals, where a Western workman would naturally have turned them to the right. ${ }^{1}$

Many of the walking-sticks sold to our officers in South Africa, and made by Zulus, are carved into a sinistral spiral, but it is impossible for me to say whether this is owing to left-handed workmanship, or to imitation of a climbing plant which coils (like our own hop) in a left-handed spiral. I was at first inclined to think that the persistence of the lefthanded twist in prehistoric Irish torques, as may be seen from examples from Dublin, and in the British Museum, was due either to the predominance of left-handedness in Ireland, which is shown by the use of the light lefthand axe mentioned by Giraldus Cambrensis, or to the fact that the most skilful artificers were developed from left-handed men. But nothing is so strange about spiral formations as the results of practical experience, and I

${ }^{1}$ An interesting comparison may be found in the spiral twist which forms so common an ornament in Swedish silver spoons. 
soon found that the flat ribbon of soft gold from which the earliest torques are made, would naturally become a left-handed spiral if twisted by a right-handed man, for he would hold down one end with his left hand, and would twist the other end outwards with his right hand, with the result that the spiral of the twisted gold would be left-handed, as may be proved by any one with a long piece of narrow paper. This may account for the fact, that from the many torques I have examined, all the gold examples were left-handed, the only right-handed spiral shown being a silver specimen in the Germania Museum at Nuremberg, and another silver specimen now in the Society of Antiquaries. The five-coiled armlet in the British Museum, exhibits the usual left-handed twist, but has the additional charm of showing four distinct spirals, which has resulted from the use of four flat ribbons of gold united, the combined section being cruciform before the process of twisting had begun.

The use of this spiral formation as an honourable ornament is certainly as old as the golden collar promised by Belshazzar as a reward, the Chaldee name for which was Menéka, transliterated in the Septuagint (Dan. v. 7), as Mavıáк $\eta$ s. From the Chaldæans this form passed to the Persians, and the mosaic 
pavement from Pompeii, now in the Naples Museum, represents Darius and his officers at the battle of Arbela, wearing torques which end not in the usual cones, but in snakes' heads. 'The crest of the Manlius family in Rome had its origin in the prowess of $\mathbf{T}$. Manlius Torquatus, who beat a Gaul in single combat, and took from him the torque which had descended to his nation as an honourable symbol from Chaldæan sources, and which passed on to Druids and Celts in the British Islands in the various forms that are now discovered in their tombs. The collar itself (though not its spiral form) continues to be a mark of honour to the present time, among Knights of the Garter, or the Golden Fleece, and even among provincial Mayors. Indeed, the phrase "Collar-day," as an ordinary concomitant of courtly ceremonial, is to be found in almost any issue of the Lord Chamberlain's instructions for "red-letter" days, when there are special Collects, Epistles, and Gospels said in Church, and when the judges wear red in the Courts. The only difference between the modern insignia of rank and the Celtic torque, is the loss of the significance involved in the spiral form of the primitive decoration.

The Investigations of the Anthropological Society of Washington (May 1879) go to 
show that though left-handed workmen existed in the Palæolithic Age, prehistoric man was as a rule right-handed. The buttons of our own dress, like the hooks and eyes of our ladies' attire, are now expressly adapted to the right hand. So are the adze, the plane, the gimlet, the cutting end of the augur, the scythe, the fittings of a rifle, scissors, snuffers, shears, and other mechanical tools which must be used by one hand or the other; or, when used by several men at once, must be used by the same hand in each man. All this, however, will not prevent one who is naturally lefthanded from continuing his natural practice, though it is attended by great mechanical inconvenience in all the instances mentioned.

A man with only a slight bias towards his left hand will readily become ambidextrous owing to the many right-handed conventions and appliances which occur in everyday life. But the instinctively and strongly left-handed will never change, and is usually distinguished for his skill, as Sir Daniel Wilson has pointed out in his interesting monograph on the subject. When Gideon discomfited the hosts of the Amalekites, the seven hundred Benjamites he selected for their superior skill in slinging were all left-handed. ${ }^{1}$ Only the

${ }^{1}$ Compare the chapter on "The Right and Left Hand," in Sir Thomas Browne's "Vulgar Errors," IV. v. 
[CHAP.

best, in fact, of the left-handed men can survive in the struggle against the vast majority of right-handed influences around them, and their skill will go on increasing, as may be seen in the case of left-handed fencers who have far more opportunity of practising against right-handed men than we have of getting used to them.

It is worth noticing in this connection that when Londoners had an opportunity, in March 1902, of seeing eight of the best fencers in the world, of whom four Italians were pitted against four Frenchmen, the pair who did best of all were the two famous French lefthanders, Louis Mérignac and Kirchhoffer. Indeed, instead of starting at a disadvantage, as is too often assumed, a left-handed artist has generally the advantage of his righthanded rivals, for he is usually ambidextrous by education, besides being possessed of a high degree of congenital skill in the hand he prefers, as may be seen in the instance of Leonardo da Vinci or of Hans Holbein.

It is probable that when it was not a matter of importance for a helix to be either dextral or sinistral, the first sketch for such a helix made by a left-handed man would more often exhibit a sinistral than a dextral spiral; but when we come to an example of a sinistral 
helix which may have been designed by Leonardo da Vinci, I do not, therefore, wish to argue that his skill in drawing with his left hand was alone responsible for the rarer formation. The fact that he was left-handed may certainly have suggested the original form of the left-handed helix which he eventually elaborated for other-and more potentreasons.

Dr Wherry has pointed out that righthandedness or left-handedness sometimes leave definitely traceable effects in the works of early or unskilled artists. In the archaic bust of an Apollo forty-seven curls out of sixty-one turned the way of the clock-hands. In another statue, dating before the Persian war, the curls are arranged in right- or lefthanded spirals, according to the side of the head on which they grow, not as in Nature.

I have mentioned the slight causes which may give an apparently accidental origin to a spiral. The follicle of hair is a good example of this. In Western peoples it is generally straight, but in the negroid races the follicle is bent, and the result is the spiral shown in curly hair. The socket of a tusk or the base of a horn has much the same effect on growth. The two examples of narwhal's tusk (really his front tooth), which I have chosen from the Museum of the Royal College of Surgeons 
(fig. 5), show excellently the rare sinistral spiral, and the variation shown by the additional curves in one of them is no doubt due to a slight variation in the socket. Every narwhal tusk I have ever seen (and there are six now in one naturalist's shop in Oxford Street) has a left-handed spiral, including a sixteenth century carved specimen, now in the Sala dei Stucchi of the Doges' Palace, and another still older tusk, preserved in St Mark's 'Treasure, in Venice. But they exhibit an even more extraordinary partiality to this formation. There are seven examples known of narwhals with a double tusk. One of these is in the British Museum of Natural History at South Kensington. Instead of following the examples of the horns I mention later (p. 80), and showing different spirals, this pair of tusks exhibits two spirals of the same kind, and each of them is sinistral ; and though I only speak of what I have myself examined, the statement has been made that whenever a narwhal has two teeth their spirals are identical, instead of exhibiting symmetrically different spirals about the middle plane of the body, as might have been expected. Dr Wherry thinks that as an unerupted tusk exhibits a perfectly straight fibre, the direction of the spiral is formed after it leaves the bone and 


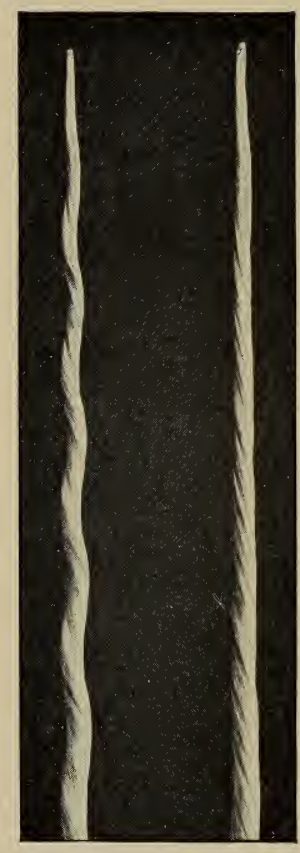

FIG. 5.

Narwhal's tusks.

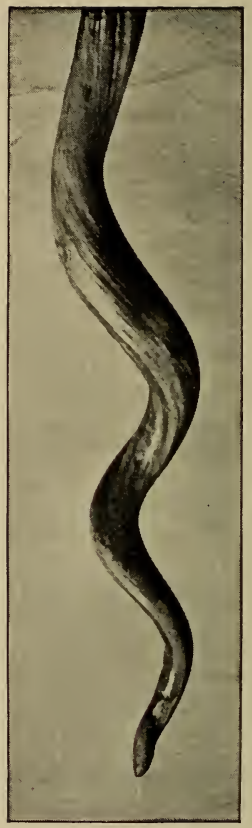

FIG. 6.

Elephant's distorted Tusk.

[To face page 41 . 
becomes opposed to the waves during growth, owing to the fact that the creature "plays" to one side as it ploughs through the water; and when by a rare chance two tusks are developed, the creature preserves the habit of carrying its head on one side and so gives both tusks the sinistral twist it gives to one. In the Museum of the Royal College of Surgeons I found an elephant's tusk (fig. 6) which exhibits a very abnormal form indeed, for, instead of being the usual segment of a circle, the tusk has grown into a sinistral spiral, so much accentuated by causes latent in the socket that the whole thing has taken a complete corkscrew formation. ${ }^{1}$ That an alteration in the socket is quite sufficient to control the formation of a growing spiral may be proved by placing one of the eggs called "Pharaoh's serpents" in a small tube. As soon as the spiral begins to come out of the egg it will exhibit a dextral helix if the tube is dented slightly on the left, and a sinistral helix when the orifice of the tube has a dent upon the right.

Another example of the spiral arrangement in teeth is so curious that it must be inserted

${ }^{1}$ Frank Buckland had certain rabbits' teeth in his collection which had grown into a spiral form owing to an injury at their base from a stray shot or some other accident. 
here. In the Imperial School of Mines at St Petersburg is a fossil which has been given the misleading name of Helicoprion. A cast of it is placed among the fossils at the British Museum in South Kensington. In general shape it very much recalls the form of the section of the Ammonite shown in fig. $36 \mathrm{~b}$, but a closer examination shows that it is really a row of sharp teeth set upon a ribbon which is spirally constricted into that form. On the drawing of the logarithmic spiral in fig. 35, 1 have placed letters that will explain the growth of this queer fossil, which has now been proved to be a single transverse row of teeth from the jaw of an Elasmobranch fish. The new growth comes from the point A; the teeth are used for biting at the point B; and as they become worn out they move back in a spiral direction, the small teeth of the young fish being naturally in the centre of that spiral at $\mathrm{C}$, and the larger teeth of the growing fish being at $\mathrm{A}$.

An analogous case of this strange folding-up of disused teeth is to be found in Cochliodus contortus, a shark-like fish from the carboniferous limestone, with crushing teeth instead of the pointed teeth of Helicoprion; and a very similar arrangement of growth may be observed in the teeth of the Skate, which grow at $\mathbf{A}$, are used at $\mathbf{B}$, and, after beginning a 
spiral curve, fall away before reaching anywhere near the point $\mathbf{C}-\mathbf{a}$ much more convenient arrangement, it would seem, than that of carrying disused teeth coiled up somewhere in the head, as must have been the case with Helicoprion.

The difference between such dextral and sinistral spirals as we have now seen artificially constructed, "from the outside," will become more and more suggestive when we investigate a few examples of spiral growth "from within " in plants and other natural objects; and we shall find that when objects which usually display a dextral helix are found to show a sinistral helix, some peculiar value and often some supernatural signification is attached to them by the primitive races who make the first discovery. The delight in such rarities of Nature, and the instinctive use of them as ornament, was shown by Schliemann to be at least as old as ancient Troy; for he found that an inland people had used the echinus or seaurchin as a model for the bosses which they set round the circle of their shields.

A still more interesting example, which has left easily verifiable traces at the present time, is the belief of the inhabitants of Travancore that the sacred shell called "Sankho" is a manifestation of the god Vishnu, because its internal spiral does not turn to the 
right (with its "entrance" therefore also to the

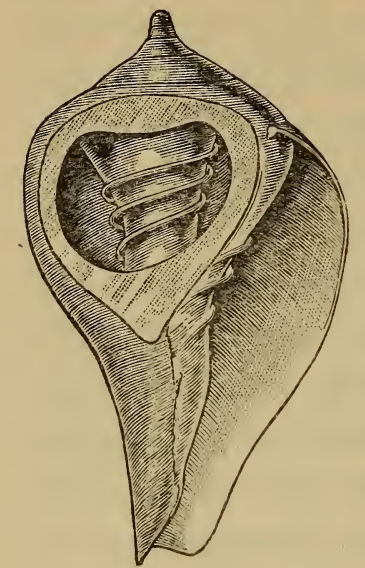

FIG. 7. right), as in the case of the shell Turbinella pirum (fig. 7), and in a million other examples, but turns to the left (with its "entrance" also to the left) as in Turbinella rapa (see fig. 8) with the rare sinistral helix ; and this belief survives in the drawing, conventionalised though it be, of this sacred shell (with its opening to

Turbinella pirum. the left) which is to be seen upon the postage stamps now used in Travancore (see fig. 9). This Turbinella rapa, called the "chank shell," is represented in Hindoo religious art as held in the hand of Vishnu. It is fished for at Tuticorin on the Gulf of Manaar from October to May, and in 1887 a good sinistral specimen found at Jaffna was sold for Rs.700. Nearly all the shells brought up are

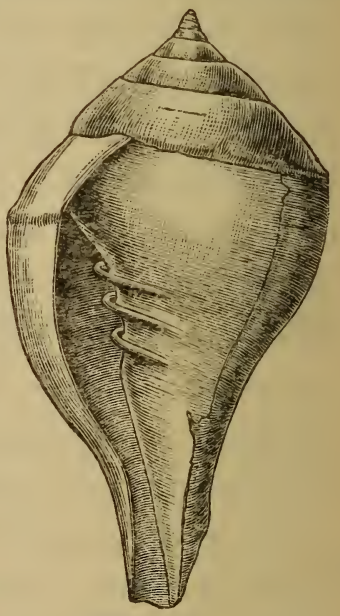

FIG. 8.

Turbinella rapa. sent to Dacca to be sliced into bangles and anklets for Hindoo women; and this use of 
shells as ornaments among savage inland races, and more civilised dwellers by the sea, may be paralleled in every quarter of the globe in the earliest periods of time. In the Indian Ocean Cypraea moneta (the "moneycowry") has for ages been employed as a medium of exchange, as is Cypraea annulus in the Pacific. In Bengal in 1854, the value of 5,120 cowries came to one rupee. In Egypt the same shell is still considered to be a preservative against the "evil eye."

The use of the spiral in ornament goes back to prehistoric times in other instances. In the work of the Bronze Age flat spirals are found hanging to the side of Postage Stamp now used a shield as decorations, just as on an ancient Pile-Hut-Urn (which is mentioned in Sir John Lubbock's "Prehistoric Times," and is thought to come from Melos) the walls of the house are represented as being decorated with large spirals; and Mr Arthur Evans found a frieze of spirals and rosettes painted on the walls of the Palace of Minos at Knossos in Crete. From the well-known fact that the mediæval monks used to say their prayers within a maze, to escape the pursuit of the 
Devil, the spirals tattooed upon a Maori's face may have the same object of confusing the Evil One, though it may quite as possibly be a result of his inborn sense of the adaptation of ornament to form; for his spirals admirably express the feature decorated, and seem to do so in a way which concentric circles never can. Spirals are found in the decorative art of such different peoples as the natives of New Guinea (especially where Melanesian influence occurs), of Borneo, of ancient Peru, of Central Africa. Sometimes the form is connected with the manufacture of pottery or basketwork, and it is then definitely suggested by the structural lines of the object. Often the spiral seems the genuine expression of artistic feeling or fanciful imagination. But in no case do we find a savage making an abstract pattern that does not go back to Nature by a series of conventional variations. All forms of the spiral in Polynesia, for instance, can be traced to a Malay centre, and that centre took its ornaments from Hindoo or Phœnician sources.

No doubt the discovery of bronze was a most substantial step in the progress of civilization, inasmuch as this discovery enabled the men of the Stone Age in Northern Europe to learn such patterns as the chevron, the meander, and the spiral scroll, at the same 
time as they learnt the arts of metal-working. Patterns grow: they are not made. They are evolved from pictures, and from those pictures which most often occur, and are most easily repeated. Among such pictures, those which represented the lotus would be as significant and as sacred as any known to the earliest periods of Egyptian art. The earliest pictures were not done for their own sake, as "works of art." They were meant to convey an idea; they were even supposed to retain some of the powers and qualities of the original. So the lotus, as the emblem not of one god but of all, not of one sacred animal but of all, embodied an enormous amount of ancient and popular symbolism, and supplied patterns to paleolithic peoples, whose pictures we know to have been life-like representations of the incidents of the chase.

Spiral scrolls have been found on pottery in Schliemann's "First Tomb" at Mycenæ; on scarabs of an Egyptian dynasty which existed three thousand nine hundred years before Christ; on bronze axe-heads from pre-historic Sweden. Mr Henry Balfour possesses many examples in the Pitt Rivers Museum at Oxford. At Leyden the representative exhibit for the Malay Archipelago is unique. The ethnographic collections in Washington, in Rome, and Amsterdam, are also full of similar 
[CHAP.

specimens. Throughout, the theory of spontaneous generation falls to the ground. The rule of historic development and tradition shows no exception; and Professor W. H. Goodyear has very carefully investigated the whole subject as suggested to him first by the geometric lotuses upon the Cypriot vases. He showed that all the Arab and Mohammedan spirals came from the Byzantine Greeks; that they are not found at all in barbaric Africa, and that, on the other hand, they are the foundation of Malay ornament; they reached Alaska, however, by means of Buddhist influence, along the Amory valley, through the Yakoots to the Aleutian islands. When it is realised that fivesixths of the ornamental patterns of ancient Egyptian art were based upon the lotus and its spiral derivatives, the number of spiral traditions which spread from the Nile valley all over the world will be better understood. The oldest forms of the spiral associated with the lotus are found in Egyptian tomb-ceilings. The Greeks and Assyrians, who found the flower already conventionalised almost out of knowledge, took the spiral accompaniments and developed them in turn to their highest pitch. The Assyrian idea of the organic connection of repeated units of design by linked curves, ending in spiral volutes, was 
immeasurably improved by the genius of the Greeks, which seized on elements of beauty that had hitherto remained unproductive, and gave them not merely new life, but measureless scope.

I have thought it well thus early to suggest that the widespread value attached to the spiral formation as a decorative pattern has been very largely owing to the fact of its origin, and of its association with the lotus, the symbol of creative power or energy, of the strength and divinity of the sun, of the sun's birth from moisture, and of the many sacred phenomena of life. The lotus was used for the first time in the decoration of the English throne in Westminster Abbey in 1902 ; and it will be seen in later pages that modern research has largely justified a symbolism which was based rather on faith than knowledge (see p. 189).

But we have found that escape from danger, as well as ascent into new being, has been associated with the spiral; and one of the most delightful forms in which the idea occurs, has been told me by Mr George Calderon, whose knowledge of the folk-lore and magic of Eastern Europe seems as inexhaustible as it is interesting. It appears that at the baptism of a Lithuanian infant the parents bury one of its little curls at the bottom of a Hop-pole, so 
that the child may "twine out of danger" in its lifetime, just as the spiral tendrils of the plant twine upwards to the light. Another strange fancy is the use to which the spirally twisted seed-pods of Helicteres ixora have been put by certain races, who assumed (by the "doctrine of signatures") that their peculiar, shape (see fig. 10) would make them an admirable medicine for "twisted bowels," or

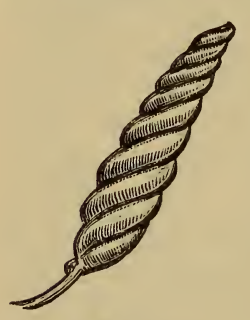

Fia. 10.

Helicteres ixora (Seed-Pod).

colic. It was similarly believed that the plant called "Jew's Ear" was a good remedy for earache.

It is quite possible, therefore, that the sinistral spiral for many ages had a deep signification as a symbol, and that any specimens in shells known (for example) in the early sixteenth century would be brought home, if possible, by travellers, and valued by collectors, for this extraneous reason, quite apart from the biological problem they present. The four great columns set up behind the High Altar in St Mark's at Venice, are all carved in left-handed spirals; and some special value connected with that formation is suggested by the tradition that they originally came from the Temple of Solomon in Jerusalem. The same spiral was carved on the pillar of St Bernwand at 
Hildesheim in 1022. I think, too, that any one who had ever studied the laws of organic structure would be particularly attracted by shells. The "Allegory" painted by John Bellini (in the Academy at Venice), may well indicate that shells were as full of legend and interest in his time as they are to-day, when greater knowledge has only brought the certainty of far more complex causes.

There are some divergences in "natural" spirals which are inexplicable on the theory that one kind is normal and the other very rare. On the beach at Felixstowe, for instance, you may pick up specimens of shells which exhibit dextral and sinistral curves in about equal proportions; but after a little investigation it appears that all those with the sinistral curve have fallen out of the cliffs, and are in fact the fossil Fusus antiquus of the Red Crag Sea; while modern whelks of the same kind in the North Sea apparently all possess the dextral curve. The spiral horns of fossil animals, however, do not differ from those of living creatures. Near Lake Tanganyika there is an amphibious mollusc with a large shell, called Lanistes, which in that locality always exhibits a spiral of the left-handed formation. The same shell when it is found at Lake Nyassa or the Victoria Nyanza, exhibits a dextral helix. Is this difference 
connected with the fact that, as the recent Biological Expedition seems to show, Lake Tanganyika has had some past connection with the ocean, whereas the others are freshwater lakes ? ${ }^{1}$ There is another strange beast within its waters which exhibits one kind of spiral externally, and another internally, but it still awaits a more precise examination.

The development of microscopical and photographical research has put before our designers many beautiful forms in Nature which older workmen never knew. In such organisms as Hexacoralla, the diatoms, the calcispongiæ, and snow-crystals, the most exquisite combinations are to be found, which should alone be sufficient to inspire a new school of design in ornament; and though I am here chiefly concerned rather with structure than with decoration, these examples are all germane to the general principle of this Essay, which aims, in the humblest manner, at suggesting a return to Nature by our craftsmen, fortified as they now are by the enormous advances in scientific knowledge since the days when the old workmen drew their inspiration from the things they saw. In the Past, men worked well because they worked

${ }^{1}$ See "The Tanganyika Problem," just published by J. E. S. Moore. (Hurst \& Blackett.) 
in one style. Now the majority of our architects copy bits from every previous style, and lose all originality. The best style of the thirteenth century, for instance, may be almost entirely explained by that illuminating flash of light in which men saw the true proportions of Nature, the unsurpassable beauty in the structure of her forests, the moulding of her flowers, the living grace of her animals and plants. We know far more to-day. Will it not be worth while to try if we cannot create something for ourselves a little better? 


\title{
CHAPTER III
}

\author{
OF PLANTS
}

"As woodbine weds the plant within her reach, Rough elm, or smooth-grained ash, or glossy beech, In spiral rings ascends the trunk and lays Her golden tassels on the leafy sprays."

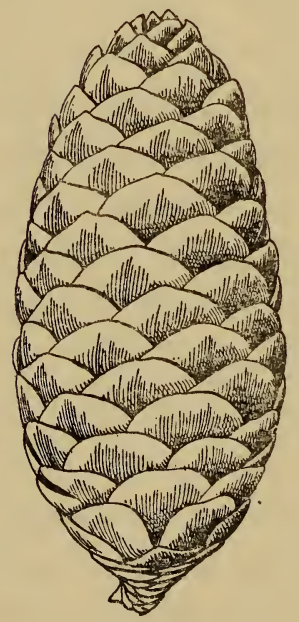

FIG. 12.

Pine Cone.
IN plants many particularly beautiful examples of spiral formations and growth are to be found, and it will not be forgotten in this connection that the structural classification of plants owes as much to the researches of Leonardo da Vinci as does the science of anatomy; and it is not generally known that Leonardo also carefully studied in the fourth book of the "Trattato" the system on which leaves are disposed and arranged about their stalks, long before Bonnet's 



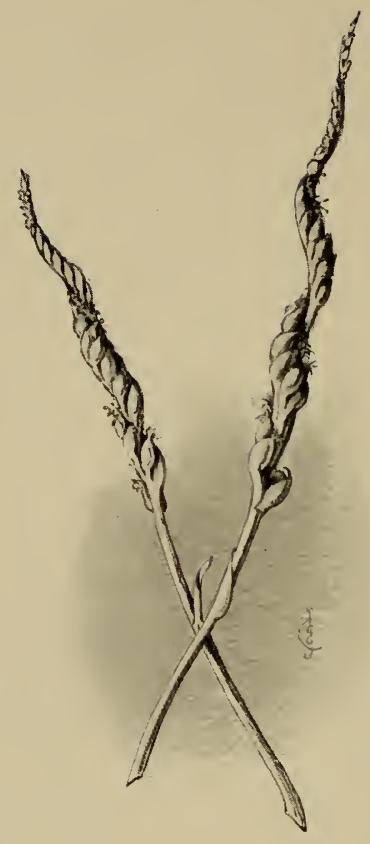

FIG. 11.

"Lady's Tresses" (Neottia spiralis.)

[To face page 55 . 
"Spiral 'Theory" (to which I shall refer later on) had been published in 1754. One of his many beautiful drawings of botanical subjects from the Windsor Collection is reproduced in fig. 48. $\mathrm{He}$ was especially fond of the many exquisite spiral lines exhibited in the growth of the Cyclamen. Since his day the subject has been investigated by many great observers, and the mere facts of spiral growth would take too long to enumerate here.

A very peculiar effect is observable in the growth of an Orchid, called "Lady's Tresses" (Neottia spiralis), found for me in North Devonshire. It is not a climbing plant at all, yet its buds are arranged to catch the light in an exquisite spiral of the rare sinistral form, which can almost be seen to move as the plant stands by a window in a glass of water. The drawing in fig. 11 was an exceedingly difficult piece of work, so often did the plant slightly alter its surfaces during the hour it was being closely studied.

In the cone of Pinus smithiana (fig. 12), the spiral arrangement of the overlapping leaves is very distinct. The economy of space ensured at the points of growth is as observable as the curious manner in which each of these leaves is enabled, by its special relation to 
its neighbours, to obtain the maximum of light with the minimum of shade. In this instance, it should be noted that the true growth is a right-handed spiral. In this cone the lines of a left-handed spiral (in which the beginning of each line is on the left, and the lowest point on the right) may also be observed, but in them it will be seen that

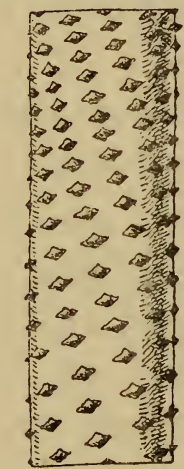

Wax Palm.

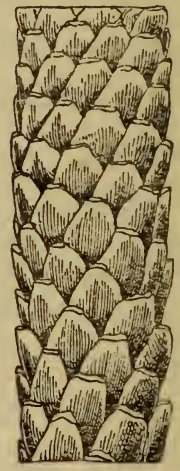

FIG. 13.

Date Paln.

the scales are intersected by other scales from the row above, whereas in the true spirals the scales grow round and round, overlapping each other, but never interfered with by a scale from a different line.

In Museum No. 2 at the Royal Botanical Gardens, Kew, is a section of the trunk of the Carnauba Palm from Brazil, sometimes called the Wax Palm (Copernicia cerifera), 
which shows very clearly the left-handed spiral exhibited in the example of the same tree in the British Museum of Natural History, drawn in fig. 13. But there is another example of this same Wax Palm in the same room at Kew, which is no less clearly arranged as a right-handed spiral. The Date Palm (Phoenix dactylifera), also shown in fig. 13, was drawn from an example in the Museum at South Kensington, and shows a righthanded spiral; but in Museum No. 3 at Kew, the same tree exhibits a left-handed spiral. If the common Chestnut Tree be carefully compared to the Horse Chestnut, it will be seen that the spiral growth of the bark on their straight stems is set in different ways.

Of all the plants I examined at Kew, the various kinds of Pandanus in the large Palm House afforded the most beautiful instances of this remarkable form, and their growth is extraordinarily like that of a spiral staircase. But here, again, we get the same puzzling divergencies. Pandanus vandermeschii, a maritime variety of this "screw-palm" from Madagascar, is arranged in a right-handed spiral, as is Pandanus utilis (fig. 14). But the left-handed spiral is found both in Pandanus sylvestris, from the Isle of Bourbon, and in Pandanus millore, from the Nicobar Islands. The plant called "Rata," which 
[CHAP.

climbs up the New Zealand Gum-Tree, is an example of another kind of spiral growth. A visit to Kew Gardens will reveal many

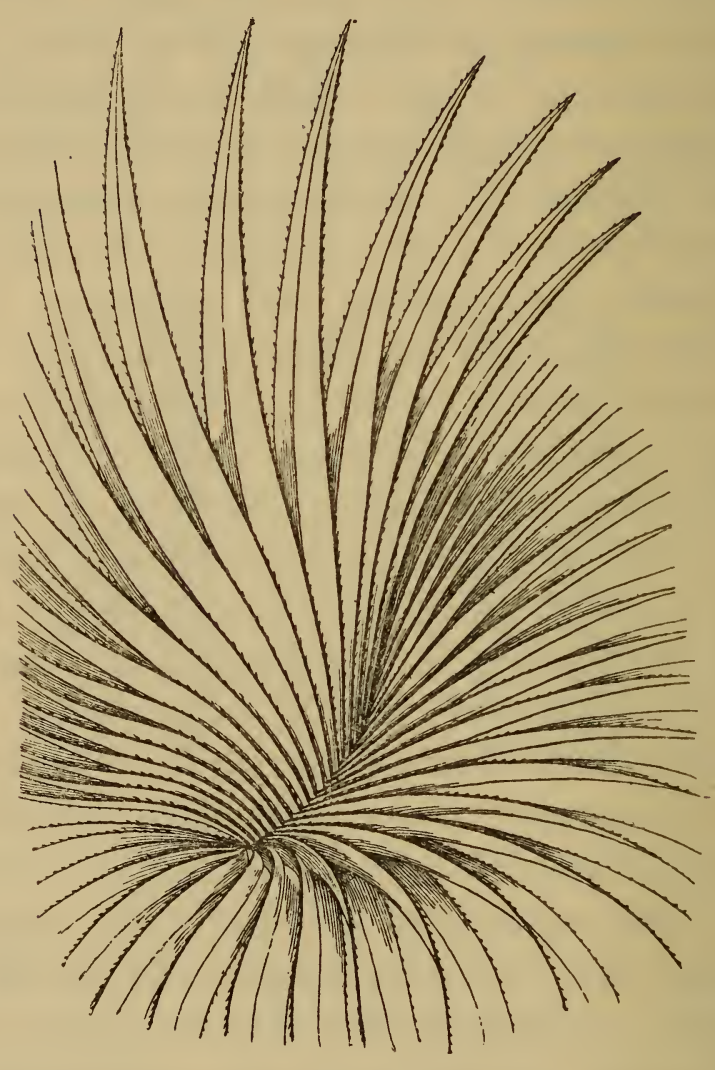

Fig. 14.

Pandanus utilis.

more instances of the same formation. In the flower of the white Water-Lily the various organs will be found to be arranged in a 
continuous spiral, and the Egyptians, noticing a similar formation in the Onion, often used that plant to typify eternity. In all the more primitive flowers a spiral formation is exhibited, as opposed to the concentric circles in the "floral diagrams" of more highly developed species. This spiral arrangement also seems to me to be not only nearer to primitive Nature, but also more beautiful and suggestive; for the spiral begins in the centre with the carpels, and the various organs in the course of their growth gradually slide out of one formation into another, until they become the sepals on the outside, which are often green and leaf-like.

The bud of the Convolvulus closes and opens with a spiral twist, and it may be noted that the Byzantine builders of St Mark's were peculiarly fond of the beautiful lines of the Water-Lily and the Convolvulus flowers, as motives for the decoration of their columns; not, perhaps, taking these forms consciously, but producing the same effects by the careful modelling and the artistic proportions of their convex and concave capitals. In all ordinary Yews the leaflets grow opposite each other, but there is now a variety in which the leaflets are set in a spiral, and the name by which they are distinguished is a record of the fact that all were grown from a 
single "sport" which occurred at Florence Court.

Some very extraordinary spiral fossils, found in the Bad lands of Nebraska, have only just had attention drawn to them by the scientific world; and by the kindness of $\mathrm{Dr} \mathrm{W}$. H. Drummond, of Montreal, a specimen will, it is hoped, soon be placed in the British Museum at South Kensington. 'Their exact origin and nature are still the subject of discussion, but as the balance of expert opinion inclines to the belief that they are not only organic, but also plants, I have inserted what is known about them in the present chapter.

Professor Erwin Hinckley Barbour has published an illustrated description of many examples of these "Devil's Corkscrews" or "Fossil Twisters," called in more scientific terminology, Domonelix, which he found in large quantities at Eagle Crag, on Pine Ridge, near Harrison, in Sioux County, Nebraska. These peculiar structures, as anomalous as they are unique, are found over an area of some 400 square miles, between the White River and the Niobrara River, and to a depth of about 200 feet. They are corkscrew-shaped columns of quartz, sometimes embedded in sandstone, sometimes "weathered out" quite clear of the original matrix. The spiral varies in length, but sometimes is as much as twenty 
feet long, and perfectly regular throughout. At the lower end is a large transverse attachment, not spiral but smooth, and roughly cylindrical in shape, as large round as a hogshead, and longer than the spiral growth above it. The surface of these spiral fossils is a tangle of ramifying, intertwining tubules about an eighth of an inch in diameter, which thicken inside into a solid compact wall showing (under the microscope) plant tissue arranged in fibres. Every microscopic section, without exception, shows unmistakable plant structure.

An immense lake of fresh water, in long distant periods of time, once covered the great basin east of the Rocky Mountains, of which the sand-rock of the modern district, all sedimentary and of aqueous origin, is a relic. In the course of ages this lake became filled up by detritus poured in from the rivers, and its water-plants were buried in sand. By degrees these plants decayed, and, particle by particle, were replaced by silica, the material of quartz; and in this manner the huge corkscrews of quartz now found on Pine Ridge have preserved the shape, the spiral growth, and the huge roots, of the vast water-weeds which flourished long ago at the bottom of the lake, and persisted in growing at various levels, one above the other, as the filling-up process went 
on, until at last the lake became dry land, and its weeds vanished - to reappear as Dcemonelix. The spirals are both right-handed and lefthanded, and their symmetrical arrangement round a vertical axis is alone sufficient proof that they are not the remains of any animal or of any animal's abode.

Other strange hypotheses have been put forward to explain these odd formations; but this is not the place to enlarge upon them; for the theory that they are the fossil stalks of giant water-weeds, explains all the facts as known at present; and though the skeletons of animals have in two cases been found in connection with them, I cannot believe that Domonelix was ever a rabbit-burrow.

The phenomena of climbing plants are among the most interesting of all spiral developments in Nature; the subject of their right- and left-handed spirality is now being investigated, I believe, by Francis Darwin, who should produce some very valuable results. In most observed instances, the Hop and the Honeysuckle twine to the left, but the majority of twining plants exhibit a righthanded screw, contrary to the sun, as in the case of the French Bean, the Convolvulus, the Pea tribe, and the Passion-flower. Charles Darwin once examined seventeen plants of Loasa aurantiaca, and found that eight showed 
the dextral formation, five preferred the sinistral, and four reversed their spiral after a part of their growth had taken place in one direction. Plants became climbers, he thought, in order to expose their leaf-surfaces to as much action of light and air as possible, and to do this with the least possible expenditure of organic matter. The facts observable in their growth certainly make it very difficult to accept the phrase "the power of movement" as a differentiation between animals and plants.

In examining those plants which twine spirally round a support, Charles Darwin found that in two hours and eight minutes the shoot of a Hop made one complete revolution to the left with the sun, and that the tip of a 31-inch shoot of Ceropegia Gardnerii made a circular movement to the right at the rate of 33 inches an hour, contrary to the sun, in search of an object round which to twine. Every part of such a revolving shoot in a twining-plant has its own separate and independent movement, described by Sachs as "revolving nutation," a movement which appears to be due to the more rapid growth of cells on one aspect or edge than on the other, which makes a curve in the shoot, and rotates it, as the growth alters and alternates. The result of this is that when a revolving shoot 
meets with a support, its motion is arrested at the point of contact, but the free projecting part goes on revolving. As this continues, higher and higher points are brought into contact with the support and there arrested, and thus the shoot winds round, just as a swinging rope which hits a stick coils round the stick in the direction of the swing.

"Irritability" has nothing therefore to do with these phenomena. The shoot twines round its support rather more slowly than it would revolve by itself (the difference being about $1 \frac{1}{2}$ to 1 ), owing to the continued disturbance of force by arrestment at various points. But when the shoot has made its first, close, firm spiral, it slips up the support in more open spirals, because it is freed from the pull of gravity. "The majority of twining plants," says Dr Wherry ( "On Spiral Growth," 1898), "are no longer able to climb actively, if their support forms a smaller angle with the horizon than forty-five degrees; and the influence due to gravitation is such that if the pot containing a plant which twines round a rod is inverted, so that the twining apex is lowermost, the youngest coils of the shoot will loosen themselves, the free terminal bud will erect itself, and will again grow upwards close to the rod."

After carefully investigating the growth of 
Hops up a straight meshed-wire fence, set up round a Berkshire tennis-lawn, I found one example of the twining apex having got lowermost, owing to some interference by the gardener during the growth of the plant. In the course of the next twenty-four hours the free terminal bud had erected itself again, turned upwards, and twined to the left up its own pendent shoot, taking three spiral twists completely round, before allowing the new extremity to grope freely in the air after a fresh support. ${ }^{1}$ In this instance, there was not only the spiral curve to be observed, but also a very clearly marked spiral growth in the fibre of the plant itself, which, in four out of five observed cases, was strongly sinistral. In the fifth case it was nearly straight, but whenever any inclination was observable, it was to the right. The reason for this exception I was not able to discover. Indeed, the whole question of torsions in the true axis of a spiral twist revealed a serious complication for so unskilled an observer as myself. Fortunately, however, a reference to Charles Darwin's experiments showed that the axis is twisted, in all cases, owing to the roughness of the usual natural support, and the rough, glutinous

1 This hop-branch was the model for the conventional design (by J. E. Cook) of the binding on the back of this book. 
surface of my Hop-shoot is a good example of this. He even trained some Kidney-beans up a smooth glass rod, to prove that they scarcely showed any twisting at all. No doubt the twist provides an additional strengthening of the fibre, which enables the plant to surmount inequalities, and the spiral twist (as opposed to the spiral curve) in the horns of goats and antelopes, and on the columella of certain shells, may be an evidence of a similarly necessary strengthening process.

A different class of climbing plants is that which possesses "irritable" organs, such as tendrils, which clasp any object they touch. These can grow horizontally, or up and down, in distinction to those twining plants which can only coil themselves round and climb up supports that are almost upright. Whereas these latter always go round a stick in the direction of their own revolving movement of growth (which may be either to the right or the left, as we have seen), tendrils can curl indifferently to either side, according to the position of the supporting stick, and the side first touched, the clasping movement of their extremity being undulatory or vermicular. The tendrils of all tendril-bearing plants contract spirally after they have caught an object-with about four exceptions, of which Smilax aspera is one; and this contraction, 
says Charles Darwin, is quite independent of that power of spontaneously revolving which is observable (by "nutation") in the apex both of the shoot and the tendril; for Ampelopsis hederacea does not thus revolve at all. The use of the spiral contraction of a tendril is to drag up the shoot by the shortest course towards the object clasped without any waste of growth. This same spiral contraction also makes the tendrils highly elastic, and therefore stronger to resist the wind, so that the Bryony, for example, will outride a storm like a ship with two anchors and a long range of cable that serves as a spring.

In the Bryony a filiform organ grows out from the plant, as Dr Wherry observed, and becomes "irritable" in such a fashion that, while revolving at its free end exactly, as if groping for a prop, when this free end touches a twig, it coils round it at once. The coiling tendril then develops a corkscrew spiral twist in one direction in one part, and in another direction in another part, with a short straight portion between. This reversal of the spirals after fixation sometimes occurs only once, sometimes as much as seven or eight times, but the number of times it appears in one direction is always equal to the number of times in which it appears in another. 
The reason for this is to be found in the mechanical necessity for preventing excessive torsion. We have seen that a twining plant, as it binds its spiral curve round a support, develops a spiral twist also. This twisting involves a twisting of the axis in the same direction, which, if persisted in for too long in the same direction, would ultimately burst the tendril. But if just as many turns are subsequently taken by the spiral in the opposite direction, the strain involved by the twisting of the axis is removed.

I can the more cheerfully leave this part of my subject somewhat incomplete, because the vast majority of twining and tendril plants still await investigation by more competent observers; nor does it seem possible to explain their ways until we understand a little better how the forces of gravity and light act upon processes of growth. In many instances the resulting spiral may have originated in what we should call " mere accident," or, as Darwin expressed it, in "causes which are not apparent to us." But several of the problems presented seem to go much deeper, and even to touch those elemental laws which govern universal life and strength and movement, and give their final proportions to the handiwork of man.

The investigations into the system on 
which leaves are arranged upon a stem, begun by Leonardo four centuries ago, have only just arrived at something approaching to an intelligibly philosophical explanation. For a hundred and fifty years, what is known as the "Spiral Theory" of Bonnet, formed the foundation of all studies in phyllotaxis ; that is to say, in the consideration of a stem bearing leaves as an axis and its appendages. In 1754 Botanists were still dominated by the doctrines of Constancy of Species, and as morphology dealt solely with adult structures, it arrived at the very simple ideal of a formal account of the framework of the fully matured stem, leaves, flowers, and fruit; developmental stages, and buds, being considered as unessential. Bonnet therefore took a mature stem, and chose upon it a leaf (A), which came exactly above another (B). He then showed that the intermediate leaves were arranged as a spiral, exactly as if (B) were the bottom point on the cylinder in fig. 3, and the intermediate leaves were arranged along the string until they reached (A) at the topmost point of the cylinder. In this way he determined what is known as the "two-fifth spiral," in which the sixth leaf is inserted exactly over the first of a spiral series, which makes two complete revolutions of the stem. By the help of the mathematician 
Calandrini, he formulated a correct geometrical conception of a helix, with parallel screw-thread winding round the cylindrical stem. This mathematical conception was arranged to fit certain definite facts, and with this as a basis, Schimper and Braun (1830-35) raised "an enormous edifice of beautifully precise nomenclature."

But by degrees appeared the results of such ideas as were contained in Goethe's Theory of the Metamorphosis of Leaves, in Lamarck's Researches into Development and Heredity, in Von Mohl's Discovery of the Growing Substance in Plants, in Darwin's great Hypothesis of Evolution. By degrees the type plant of the new morphologist became the growing body, as seen in the growth of the members, growth of the axes, growth of the whole individual, growth of the race. But while critics exclaimed that Bonnet's mathematical conception had been gratuitously introduced into the plant, and was "mere playing with the properties of numbers," they did not apparently realise what Bonnet himself thoroughly understood, that, being ignorant of protoplasmic growth, he dealt solely with adult structures which had ceased growing.

At last Mr A. H. Church, a well-known and distinguished botanist in Oxford, came 
forward with a new mathematical conception, founded on the new mathematical data afforded by the transition of the morphological standpoint from that of adult construction to that of growing systems. As a starting-point for such a conception, $\mathrm{Mr}$ Church very properly propounded a certain ideal condition. Just as, in the consideration of the Newtonian laws of motion, the purely abstract and mathematical conception of " uniform motion" precedes that of varying motion, so the growth of a mass of protoplasm may be conceived as a "uniform growth," expansion taking place around a hypothetical central point. From this, Mr Church deduces the hypothesis that logarithmic spiral curves (see fig. 35), with the straight line and circle as limiting cases, are the sole curves of uniform growth expansion. Spiral phyllotaxis must, in future, therefore be based on a logarithmic spiral on a plane surface, and not on Bonnet's old idea of a helix winding on a cylinder, which is merely the expression of the attainment of uniform volume by members in a spiral series, and which, if carried on to a plane as a spiral with equal screw-thread, would become a spiral of Archimedes.

Of course, when applied to the living, and admittedly irregular, growing plant, the conception of a logarithmic spiral would be as 
difficult to prove by actual measurement as was Bonnet's theoretical helix. But now the standpoint is changed, it becomes possible not only to deal with uniformly growing systems, to deduce mathematically their various properties, to watch them (as it were) grow on paper, but also (as soon as the properties of uniform growth are ascertained) to study the possibility of varying rates of growth, and to state the growth of an irregular body in mathematical terms as precise as those which indicate the erratic orbit of a comet.

We shall find that the logarithmic spiral occurs again in connection with organic growth in later pages of this book, and I shall have occasion, ${ }^{1}$ before the end, to consider some further results which follow from $\mathrm{Mr}$ Church's valuable and intricate researches. For the present I must conclude, with this brief notice of them, that portion of my subject which has to do more particularly with Botany.

1 See pages 124 and 185. 


\section{CHAPTER IV}

\section{OF SHELLS}

"Year after year beheld the silent toil

That spread his lustrous coil ;

Still as the spiral grew.

He left the past year's dwelling for the new,

Stole with soft step its shining archway through,

Built up its idle door,

Stretched in his last-found home and knew the old no more."

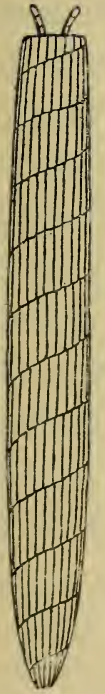

VERY early in the chain of animal creation the spiral arके rangement makes its appearance. ${ }^{1}$ The cilia on the top of ${ }^{1}$ Though I have purposely refrained, for the present, from introducing pictures ㅇ. 유 of microscopical specimens into this of 4 Essay, I must refer the biological student L. illustrations in Dr Friedrich Ritter v. S Stein's "Der Organismus der Infusions\% thiere" (fol. Leipzig, 1867). In the second Division, he will find left-handed of spiral lines on the body of Spirostomum ambiguum (Taf. III.); a beautiful spiral curve in the filaments surrounding the head of Stentor Polymorphus (VI.); and spirals of a distinctly logarithmic character in Stentor coeruleus (VI.), S. Roeselii and S. igneus (VIII.), and 
[CHAP.

Vorticella are set in a spiral, possibly with the object of creating a vortex in the water that would suck food towards the mouth. In the tube-building worm called Sabella, the gills are set in a very beautiful spiral, no doubt with much the same effect of converging currents. This organism is mentioned by Herbert Spencer, but the best picture of it I have seen is in the Atlas to "Le Règne Animal," by G. Cuvier, edited by a number of his disciples (Paris: Fortin, Masson et $\mathrm{Cie}$ ), which gives a very beautiful drawing of Sabella unispira on Plate IV. in the section "Annélides." An instantaneous photographic record of the spiral movement of the cilia of Vorticella was published by E. J. Marey in "Le Mouvement" (Paris, 1894), since translated by Eric Pritchard.

The case made by the larvæ of the Caddisfly (Phryganeida) is beautifully formed by a ribbon twisted up into a right-handed spiral. In the enlarged drawing of this in fig. 15 the creature's antennæ are seen protruding from the top of its case. In some sharks the egg-capsules show a spiral, of which I S. multiformis (IX.). In the third Division of the same work, "Der Organismus der Flagellaten" (Taf. XX.), a good example of right-handed spiral lines on the body is shown in Euglena oxyuris (figs. 4 and 5), while an especially well-marked specimen of the left-handed spiral is to be seen in Euglena spirogyra (fig. 7). 
reproduce an example (of a dextral helix) in Cestracion philippi (fig. 16); and the queer spiral arrangement of certain sharks' teeth has been already noticed on p. 42.

The spiral of the cochlea hidden in the ear is an unmistakable proof that the bone containing it belongs to a mammal, and it is thus that ambitious lizards are unmasked. Hermann von Meyer once accidentally dropped a skull which he thought belonged to a lizard, and the breakage revealed the cochlea, proving that the bones belonged to a mammal which was christened Zeuglodon. The same arrangement has an even more intimate connection with the most important organ in the human body, for Pettigrew showed that the process of the fibres in the ventricles runs in spiral lines

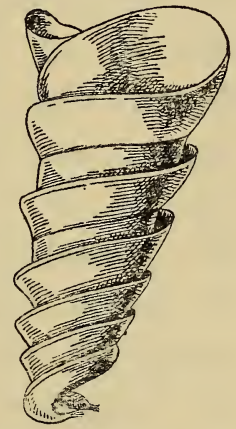

FIG. 16.

Capsule of Shark's Egg. from the tip of the base of the heart, so that the muscular constriction of the systole is of the nature of a twist or screw. There are, in fact, certain vital forces in Nature which are invariably expressed in a spiral. It has, for instance, been shown that the relation of the direction of the magnetic force due to an electric current to the direction of that current itself is the relation involved in 
a right-handed screw. Astronomers, too, are now aware that the spiral nebulæ, though generally discredited when originally announced by Lord Rosse, were photographed between 1880 and 1890, and usually exhibit left-handed whorls.

Some of the most beautiful and interesting spiral formations in Nature are, as Leonardo knew, to be found in horns, a pretty pair of which (from a Bush-buck, shot in 1878) is shown in fig. 17. It will hardly be believed that in the year these were brought home, and for twenty years longer, there existed no proper scientific terminology for the direction of the spirals in horns, found in both fossil and living animals. In a pamphlet on "Spiral Growth," published by Dr George Wherry in 1898, it was first pointed out that the horns of the Koodoo exhibited a right-handed spiral on the left side of his head, and a left-handed spiral on the right side of his head. In February 1901 another leaflet by the same writer noticed that "the spiral horns of animals, such as the Koodoo, are symmetrically arranged, are right and left by certain rules to which few exceptions only are found." A good deal of somewhat nebulous newspaper controversy arose on the subject; but as many statements were made without sufficient proof, 


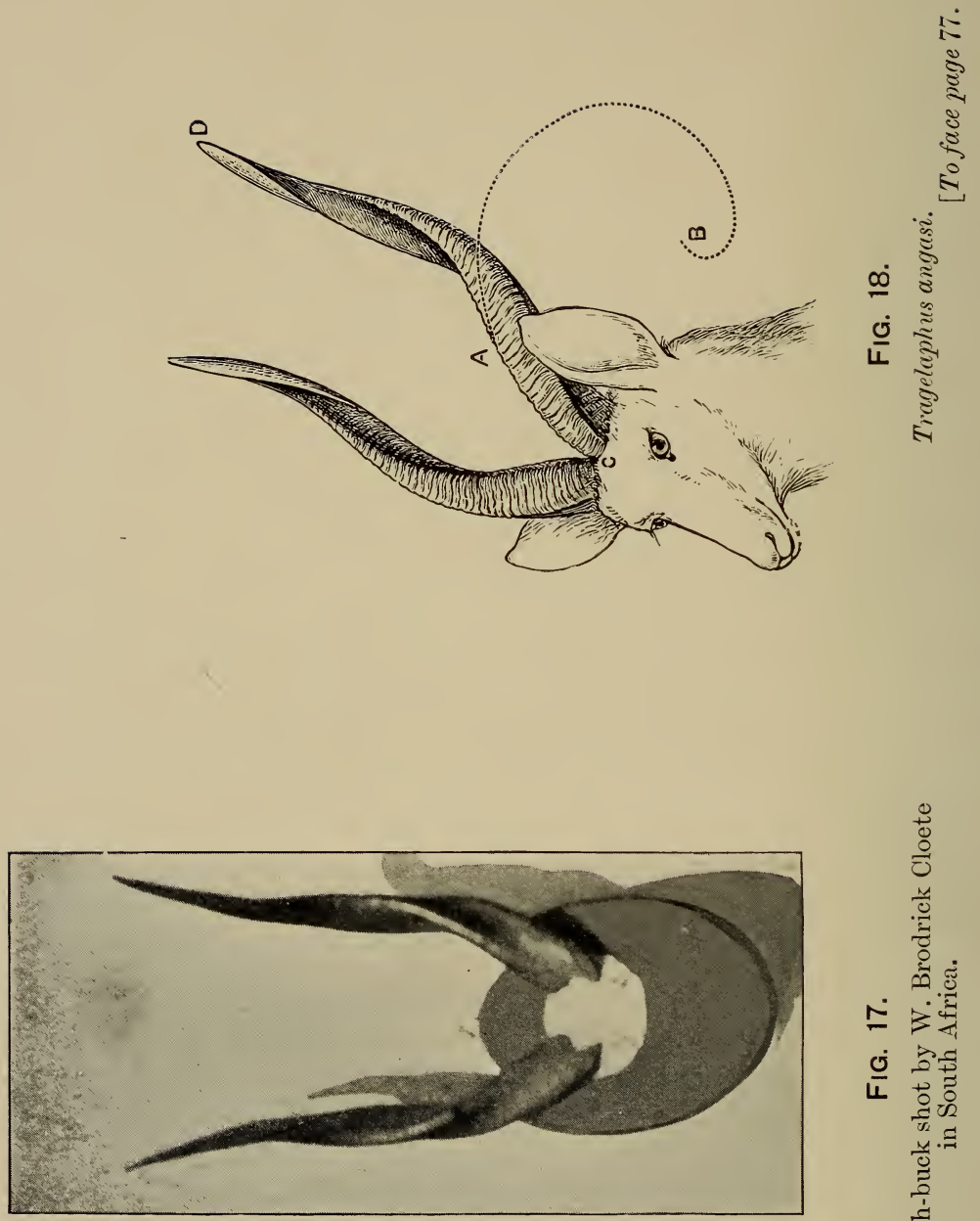

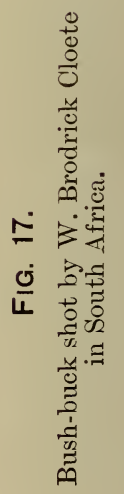


and many words were used without any proper definition of their meaning, it may be as well for me to give a few facts and illustrations here of what is only one branch of my subject, but is none the less deserving of far more extended study than I can give it in this place.

Even from the little already said as to spiral formations in Nature or Art, it must be obvious that the word "spiral" cannot be used in any argument unless it is carefully qualified and defined. It is obvious, for instance, that no critical comparisons are possible between such a conical helix as that exhibited in fig. 26, and such a spiral curve as that shown in fig. 34. We might, indeed, compare the twisted horns of a Markhor (fig. 19b) to such a conical helix as that in fig. 27 ; but the horns of the Highland Ram (fig. 20 $\alpha$ ) are evidently a different kind of spiral, which can better be compared to such a mathematical curve as that which has been drawn in fig. 35. In other words, we must carefully distinguish between the spiral twist, about an axis which coincides with that of the horn; and the spiral curve, about an axis which would be perpendicular to that of the horn, if the horn were a flat spiral. In fig. 18 these two different forms of spiral can be seen in the same pair of horns. From C to D 
[CHAP.

runs the spiral twist about the axis CD. But in the growth of the horn from C, there is a point $\mathbf{A}$, up to which a curve only is apparent, and if this curve were produced, it would show the spiral $\mathrm{CAB}$, about the axis CB.

It will save our space considerably, if we adopt the suggestion that horns exhibiting right-handed spirals on the right side of the head, and left-handed spirals on the left side of the head, should be called " homonymous." The obvious corollary is that horns which exhibit right-handed spirals on the left side of the head, and left-handed spirals on the right side of the head, may be described as "heteronomous." Owing to a lax use of words, it has been thought that all wild animals prefer the heteronomous arrangement, while all tame animals show a homonymous formation. You may, for instance, see a pair of Elands (Taurotragus oryx) at the present time in the Zoological Gardens in Regent's Park. One of them was bred in South Africa, the other in France. Both of them show clearly the heteronomous arrangement which is observable in a Sing-sing Water-buck (Cobus unctuosus) not far off them. So far, therefore, they support the suggestion described above; and as the animal bred in France exhibits a spiral with a slightly longer pitch, 
it is conceivable that this spiral may straighten out before beginning to turn the other way. This would mean that the effect of domesticity upon spiral horns would be that the heteronomous arrangement of the wild varieties became in time the homonymous arrangement suggested as proper to tame animals. Such a result is not only based on an incorrect use of language; it is also contradicted by the facts.

In the head of Tragelaphus angasi, shown in fig. 18, it would be correct to say that the right-handed twist on the left horn (from $\mathrm{C}$ to $\mathrm{D}$ ) is an example of the heteronomous arrangement of spirals in a wild animal. But if we imagine the curve $\mathrm{CA}$ to be continued to $\mathrm{B}$, we find that it would form a left-handed spiral, and that, being on the left side, it would exhibit the homonymous arrangement. If the same horn, therefore, may exhibit a right-handed twist and a lefthanded curve, the argument concerning the effects of domesticity in horned animals must be limited either to the twist or to the curve in dealing with the same kinds of animals, and should hold good in both, if it is to be accepted at all.

Taking the spiral twist first, we find it most often in goats and antelopes, and the most markedly heteronomous arrangement exists 
in the Markhor (fig. 19b) of which I have reproduced a drawing of the Pir Panjal race (Capra falconeri cashmiriensis). Compare the horns of this wild goat with those of the domesticated Angora (fig. 19a). Here we

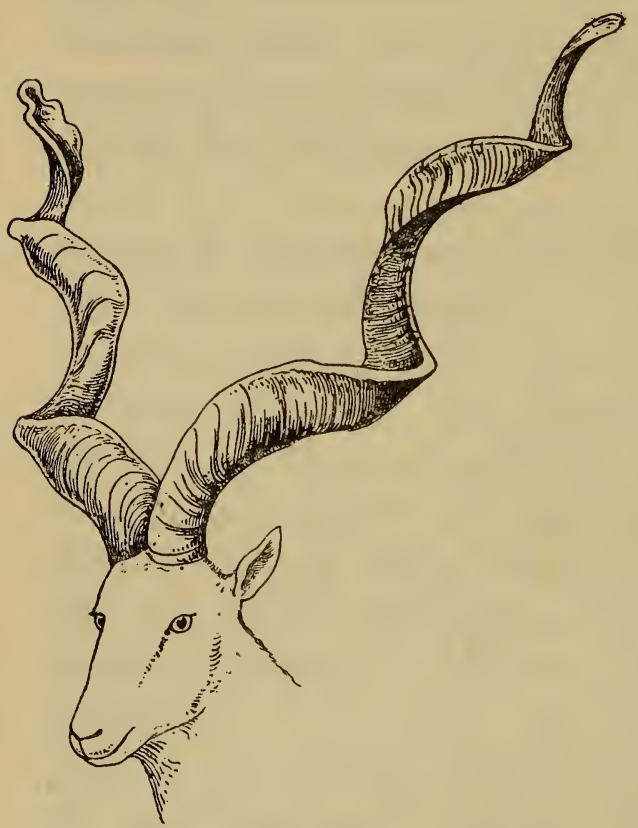

Fia. 19.

B

Markhor.

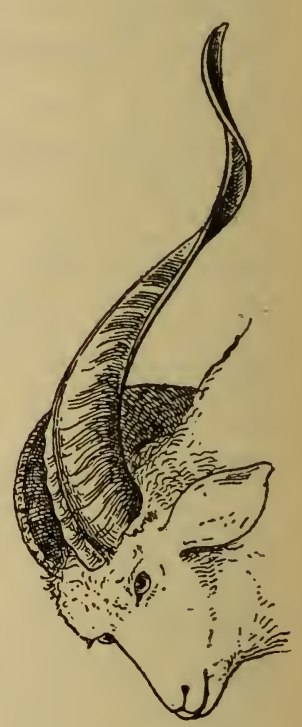

A Angora.

find an arrangement which is just as clearly homonymous; for the twist on the left horn is a left-handed twist, and the curves are homonymous as well. So far then as the twist is concerned, we do find that all wild 
animals enjoy the heteronomous arrangement, and some tame animals show homonymous spirals.

But when we examine horns in which the prominent feature of the spiral is its curve, as is the case with nearly all sheep, we find that no wild varieties exhibit the heteronomous formation, for the homonymous arrangement, which is convenient and necessary, is common to both wild and tame, to Alaskan Bighorn, Argali, and Pamir sheep (fig. 20, $c, e, d$ ) as well as to the Highland and the Merino Ram (fig 20, $a, b$ ). Evidently, when horns grow in curves, the homonymous formation is the best, inasmuch as a left horn which produced a right-handed spiral curve would not only be quite useless, either for offence or feeding, but would become positively dangerous to the animal when the ingrowing horn began to penetrate its skull, or even its back, a freak of nature which has been observed to occur when normal growth has been affected by injury of the base, as we noticed in the case of the elephant's tusk in fig. 6 . In the few cases in which the curves exhibit heteronomous formation, the horn is prevented from doing harm by being given a twist as well, which carries the dangerous point off in another direction. It would be 


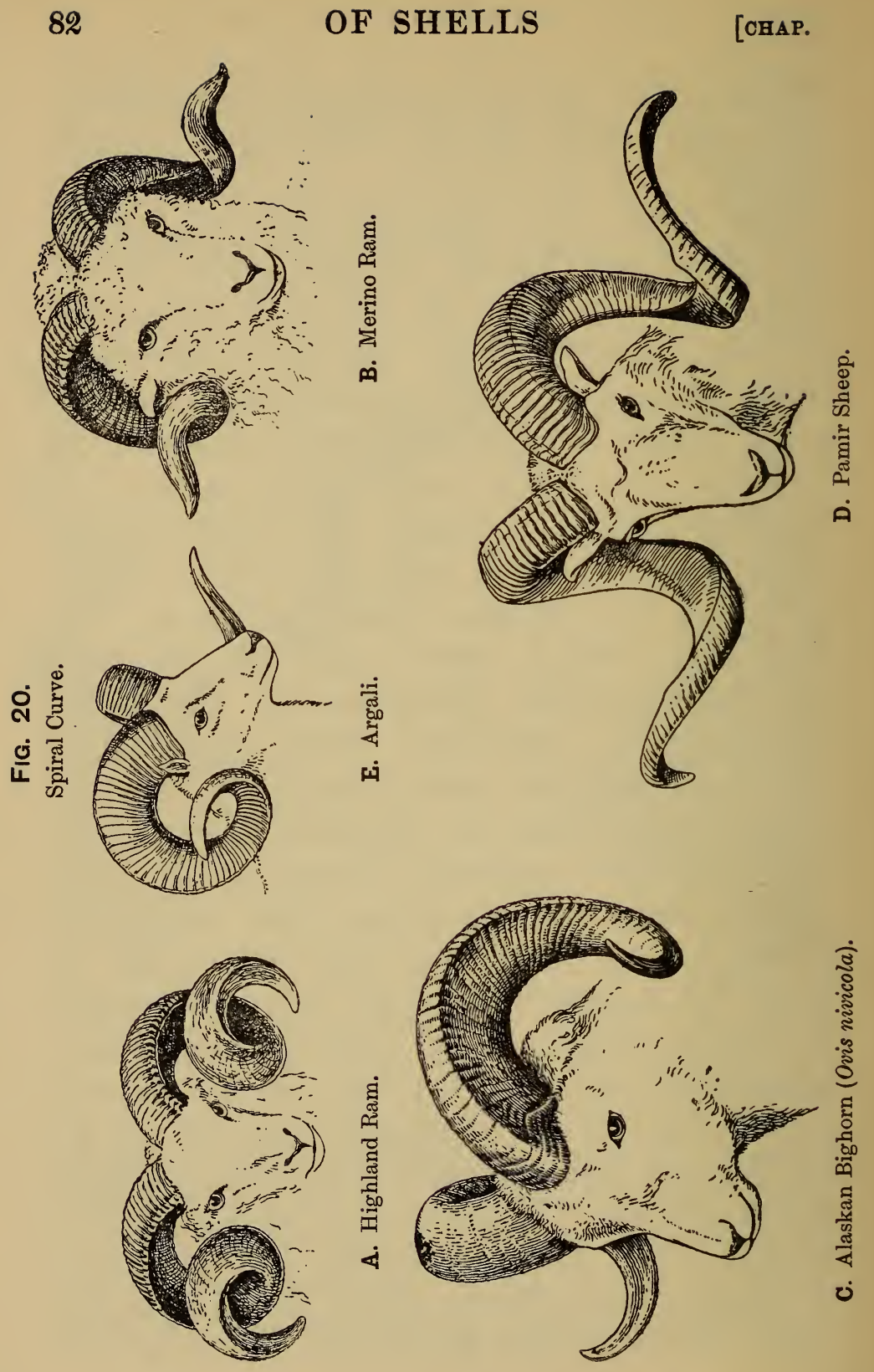


interesting if it could be established that this latter peculiarity was exhibited by animals which were midway between sheep and goats, and therefore possessed a little of the peculiarities of both. There is no doubt that a horn with a spiral twist would be stronger mechanically than either a plain cone, or a spiral curve, as may be seen by the twisted plaits on the columella of a shell, or the twisted fibre in a twining plant. So a curved horn may very possibly develop a twist as well, if strengthening were necessary, and it is obvious that the twisted horns of goats and antelopes are stronger than the mere curves usually exhibited in the horns of the less pugnacious sheep.

There is an exception in each class which has come under my observation. The Abyssinian Ibex (Capra walie) has no spiral twist whatever, but only a curve; and the Wallachian sheep with its queer spiral horns is even more peculiar, in that it shows no curve whatever, and has a very strongly marked and close spiral twist like a corkscrew, of heteronomous formation. This animal is found in Crete, Wallachia, Hungary, and Western Asia, and as nothing of it but its horns has yet reached this country, it is actually impossible to say whether it is a sheep or a goat, for the presence or absence 
of certain glands cannot be established. But judging from the model at South Kensington, and from five photographs in the possession of Mr Rowland Ward, I am inclined to believe that these characteristic horns are due to a cross of Markhor blood, more particularly of the Sulieman Markhor (Capra falconeri Jerdoni), which has very closely twisted spiral horns. But one of Mr Ward's "Wallachian sheep" seems to show the probability of this cross even more, for its horns exhibit the true Markhor curve at the beginning, which we noticed in fig. 19b, and continue in a far more open spiral twist.

My last observations in this part of the subject would be that all horns which show heteronomous twists also exhibit the homonymous curves seen in fig. 18. But the Situtunga (Tragelaphus spekei) shows the curves above its forehead to be very clearly heteronomous, and they are completed in heteronomous spiral twists, which gives a shape very much like that of the conventional lyre.

So far, therefore, as I have been able to go, it seems that when the spiral twist occurs, its better formation is the heteronomous formation, and that therefore this is the formation most usually found, even when the twist occurs in an animal which usually exhibits a homonymous curve. In the case of curves, on 
the other hand, the homonymous formation is practically inevitable, and the heteronomous only occurs in combination with a twist. The origin of these two distinct kinds of spirals in horns does not appear to have been investigated. The beginning of the divergence is no doubt to be found in some remote ancestral type, long before Man exercised any influence upon animals whatever, or even appeared upon the earth at all. Since the effects of domestication upon a particular breed would take a very long time indeed to make itself visible in this way, I am inclined to think that these spiral formations are rather the accompaniments of a differentiation in species than the result of any domestication of a breed, otherwise, how is it that differences are observed in the spirals exhibited by closely allied animals? This study of horns, which Leonardo began in one of the Manuscripts preserved at Windsor, on which he has sketched a head, very like that shown in fig. $20 \alpha$, is a bypath in biological research ${ }^{1}$ that will offer results as interesting as an investigation (for instance) into the growth of hair. We do not at present know why the growth of hair in

${ }^{1}$ Another bypath of biology that may lead us to the most unexpected results is the investigation by Professor Poulton and others into animal coloration. It appears that animals are usually dark above and white beneath, 
some antelopes and in all African buffaloes is perfectly normal from head to tail, whereas in other antelopes you find the growth reversed from shoulder to head, and in all Indian buffaloes it is reversed from tail to head. There is a reason, or there would not be the difference. And there is a reason, too, for the spiral formations in horns. In this place, I can but state the facts I have observed, and leave to others, who are better qualified, the task of explanation. I cannot agree with $\mathrm{Dr}$ Wherry's further suggestion that the funnel created by the spiral curve of the great horn of Ovis nivicola enables the small ear (placed " at the apex of the hollow cone") to distinguish sounds better, just as a man often hears more clearly when he places his hand behind and round his ear. Like many other theories of a similar nature, this stands in need of further proof and investigation, though it is a good example of the interest that may be found in any consideration of the causes or origins of spiral growth.

Certain brachiopods contain very beautiful

because this arrangement is exactly the opposite of what happens when light falls upon a solid body which need not be concealed. A normally coloured animal in its normal surroundings will, therefore, not seem to be solid, and will be practically indistinguishable at a short distance against a background of colour and pattern similar to its own. 
calcareous spiral arm-supports, formed by a ribbon of lime, and attached to the dorsal valve. In Zygospira modesta (Hudson River Group), these spiral cones are directed inwards ; in Spirifer mucronatus (Devonian) they are directed outward and backward, and formed of many whorls; in Koninckina leonhardi (Trias) the double arm-supports are flat spirals, instead of cones set on their edge, and are each composed of two lamellae.

In shells I have found the most exquisite examples of spirality in all the natural kingdom, and the formation of spirals by the shell-fish seems to be still in need of a complete scientific explanation.

When an elastic "bendable" substance is growing above an object, and dropping at its end, it might sometimes take the form of a plane spiral. But if, during its growth, it lops over at all to one side, it usually lops over to the left, the result of which (as we observed in shavings) is the usual right-handed spiral, and shells exhibiting this are called by conchologists "leiotropic," because a man walking up a right-handed spiral staircase would be always turning to the left (see fig. 28, and compare fig. 7). Very rarely they lop over to the right, and the result is the rare lefthanded spiral of the "dexiotropic" shell (see fig. 8). 
As an organism of this kind grows, if the new piece were of accurately rectangular formation, thus: $\square$, the result would be growth in a continued straight line. But it never is ; for the dorsal surface of a shell-fish is thin and ductile, while the ventral surface is harder, and contains muscles which continually exercise a certain pull upon the tissue; so that the new growth is usually of this form:

As, therefore, the dorsal surface expands more easily than the ventral, while the creature goes on developing, the result is a continuation and emphasis of the spiral form, thus :

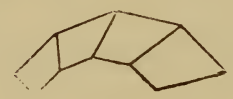

It is only necessary to remember that this spiral is growing vertically while it also grows in length, and you may add the pull of gravity to the other forces at work while the creature increases in bulk and weight, until the spiral formation of the shell-fish becomes a little more intelligible. You may produce the same formation by squeezing paint out of a tube, or by the toy called "Pharaoh's serpents," which is a more exact parallel, because the "growth" comes from beneath, and may be made to exhibit either a sinistral or a dextral formation (see p. 41).

In considering the reasons why a shell 
should be sinistral rather than dextral, I must distinguish between those sinistral shells which are "sports," or rare exceptions to the dextral rule common in their species, and those shells which are sinistral as a rule of their species. There is yet a third distinction, which must be made later.

Turrilites catenulatus always exhibits a conical sinistral spiral. Turrilites costatus, a fossil gastropod, commonly called the "screwshell," is found in the Portland formation as a rule. Other left-handed species are Columna flammea, from Prince's Island in the Gulf of Guinea; Miratesta, a freshwater shell from Celebes; Amphidromus perversus from Java; the pond-snails Physa fontinalis in Europe, and $P$. heterostropha of America.

The sinistral form of Voluta vespertilio (figs. 54 and 57) is, however, the exception to the rule of the species, which is found on the Italian coasts of the Mediterranean, and an Italian collector would be more likely to have the sinistral form of a common shell than its ordinary growth. At the present day, Mr Fulton informs me that specimens of the sinistral Buccinum undatum, though not common, can be bought for a few shillings. A Billingsgate porter thinks he has a rare prize when he finds it, and 
is greatly disappointed when he discovers it is not worth gold. Chrysodomus antiquus, a fossil sinistral whelk, of which Mr Morton Loder, of Woodbridge, has sent me an excellent specimen, is too common to be bought by dealers at all. The genus Amphidromus is about equally divided into dextral and sinistral species. But in cases where a shell only exhibits the sinistral specimens in its fossil form, and is dextral in all living examples, I have been unable to determine, as yet, any reason for the survival.

The third distinction to be made in this matter is in such cases as Spirialis, Limacina, Meladromus, and Lanistes (see p. 51), in which the shell is sinistral but the animal is dextral. Here Simroth, Von Thering, and Pelseneer explain that the shell is really ultra-dextral; that is to say, the whorls have been, as it were, flattened, as in Planorbis, then the spire has been still further pushed downwards, until the whole is turned inside out, becoming sinistral with its original dextral animal. The proof that this queer process has in some way occurred, is arguable from the fact that every dextral shell has a sinistral twist to the operculum, with nucleus near the columella, and vice versâ (see fig. 38); but in "ultra-dextral" shells, the operculum is sinistral, in spite of occurring in what looks 
like a sinistral shell. There are also instances of "ultra-sinistral" shells, which appear to be dextral though their orifices are sinistral, as in the fresh-water Pompholyx from North America, and Choanomphalus from Lake Baikal. Turbonilla is sinistral in its embryonic form, but becomes dextral as an adult.

If we take the Telescopium shown in fig. 27 as an example of a conical spiral, the Nautilus pompilius in fig. 34 will be a good instance of the flat spiral, in which all the whorls are practically in one plane. In this picture, the little projection noticeable in each compartment of the shell is the siphuncle, a membranous tube perforating the septa, which Owen thought was connected with the pericardium, and which may serve to lighten the shell by the passage of some gas into its various chambers. In the Nautilus it nearly always projects backwards, but in the Ammonites it nearly always projects forwards. Among the Stephanoceratidae, Crioceras bifurcatum has disconnected whorls, as if the various coils of an Ammonite had not joined together, and it looks something like a ram's horn, or a rather complicated hook. Oncyloceras spinigerum is a fossil tetrabranchiate cephalopod, in which the whorls are also disconnected. Siliquaria 
[CHAP.

anguina has a shell that begins in a close spiral and ends in irregular separated coils. Cylindrella, the cylinder-snail of the West India islands, a palmonate gastropod of spiral form, has the last whorl detached from the rest, with a circular mouth-opening.

In the British Museum of South Kensington, there are very fine examples of Macroscaphites gigas, and Macroscaphites ivanii, which look like Ammonites beginning to unroll themselves; and if the logarithmic curve in fig. 35 be taken as the expression of " uniform growth" in all organic matter, as Mr Church suggests it may be used in plant-protoplasm, it may be conceived as possible that as the surviving Nautilus (fig. 34) differs from it in taking a wider sweep, while the fossil Ammonite differs in exhibiting a tighter spiral, so the form of Macroscaphites may represent the tendency of a creature more recent than the Ammonite to expand its coil, and get a larger space for the life and growth of the animal it shelters.

The position of the siphuncle may also have some connection with the causes of survival, for while it is on the convex side of Goniatites, and on the concave side of Clymenia, it is placed in the middle in the Nautilus. In "Les Enchainements du Monde Animal dans les Temps Géologiques" (Paris 1883), M. Albert Gaudry shows that Orthoceras (with its 
siphuncle in the middle) is in fact, as Barrande thought, "a straight Nautilus," and the intermediate steps in development may be traced through Aploceras, which shows a slight curvature to the right at the thin end, and Nautiloceras, a hook-like formation with disconnected whorls. In the same way M. Gaudry suggests that Melia (with its siphuncle on the right side) becomes Cyrtoceras when the tip shows a slight curvature, and so may be supposed to pass through such forms as Gyroceras and Ophidioceras to the Ammonite. 


\section{CHAPTER V}

\section{COMPARISONS}

"Small and pure as a pearl. . .

Frail but a work divine

Made so fairily well

With delicate spire and whorl. . .

A miracle of design."

TN such a shell as Solarium maximum (fig. 2, $a, b$ ), the simpler form of spiral arrangement is prettily exemplified, and it is so easy to imagine walking in at the mouth (or entrance), and continually turning to the left until the top is reached, that this shell has been commonly called the "staircase shell."

A connection between shells and spiral staircases, in the minds of those who were responsible for scientific terminology as it is now accepted, has been already indicated in the words "leiotropic" and - dexiotropic," which are otherwise inexplicably the reverse of the spirals they describe. But it is still 94 



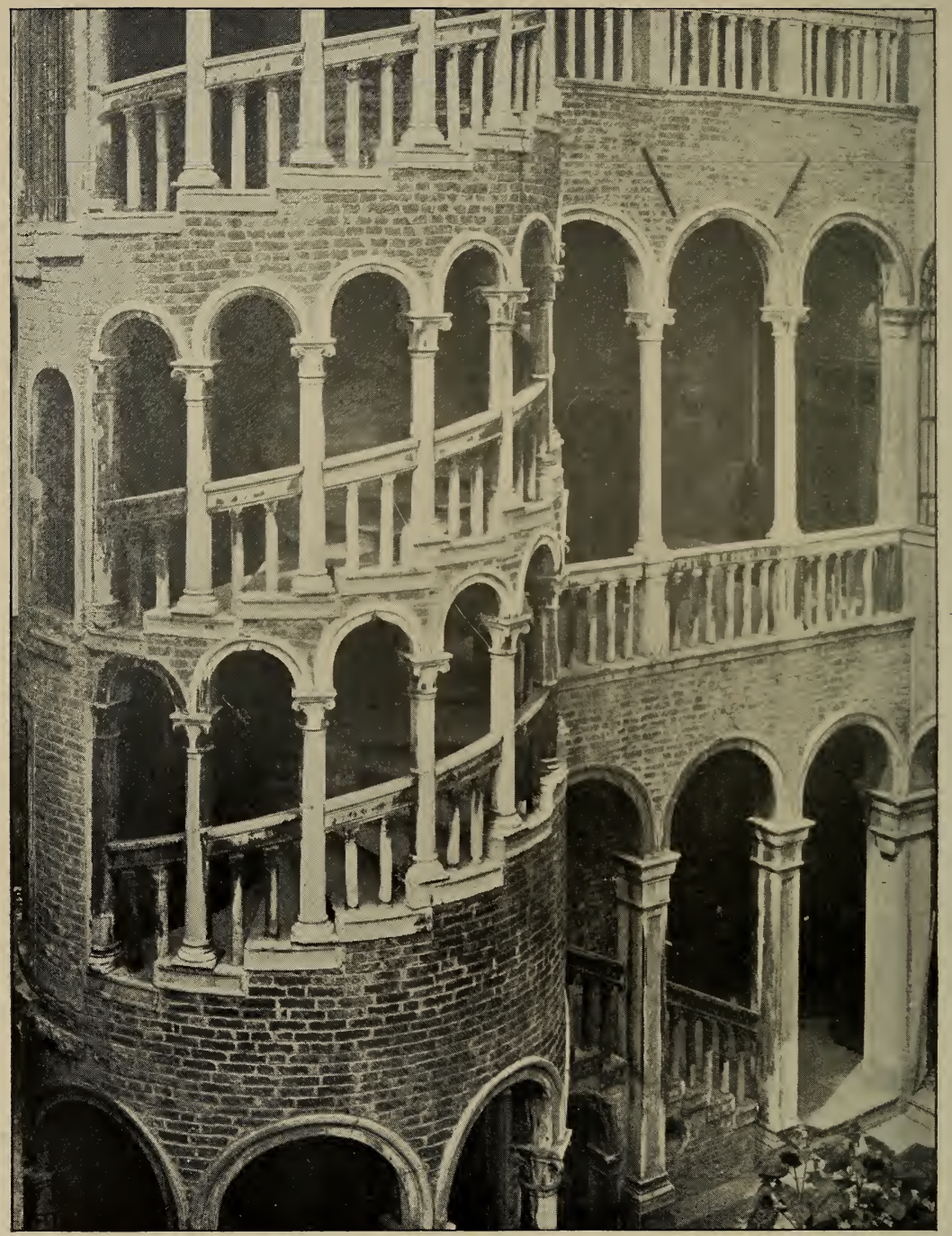

FIG. 21.

Spiral Staircase, Palazzo Contarini, Venice.

[To face page 95. 
further suggested by the nomenclature of some well-known architectural treasures in Italy. At Fiesole, for example, in the convent of San Domenico, there is a flight of eight steps (leading down to the cloister) which is so exquisitely arranged in the form of a shell that the little building is called the "Scala della Conchiglia." At Venice a more famous example may be found lin the Palazzo Contarini, near the "Congregazione di Carita" (No. 4299), which is reached through the Calle della Vida out of the Campo Manin. Its shape has earned it the name of the Scala del Bovolo (fig. 21), and I am tempted to think that the architect of this dextral helix,

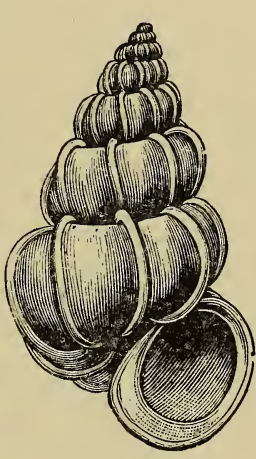

FIG. 22. with its exquisite rising spiral of light archways, may have seen the shell so aptly called Scalaria scalaris (fig. 22), which exhibits exactly the same formation. In this shell the mouth or entrance has gradually grown round and round with the growth of the inhabitant, leaving a little colonnette behind it as it moved, until it reached the place which is equivalent to the door in the staircase to which I compare the shell. How infinitely more beautiful the 
spiral formation of ascending curves in the Scala del Bovolo is than a mere system of super-imposed circles (even when arches and colonnettes are similarly added) may be seen from a comparison of the whole height of this staircase (fig. 23) with the Campanile at Pisa (fig. 24). But the spiral formation itself is not invariably a happy thought in every architectural position. Some such idea of growth, of support, of strength, as is shown in the "Prentice's Pillar," seems as essential to it in Art as in Nature. The staircase of the Rundthor at Copenhagen, is, for instance, a far more satisfactory example than the twisted copper spire in the same locality; or than the corkscrew-shaped spire of Gelnhausen, near Frankfort on the Main; or than the stone spirals in one of the small steeples of the Palais de Justice at Rouen, near the Rue Jeanne d'Arc. ' Mere imitation of externals without structural necessity, is, in fact, as barren here as it must ever be. Perhaps this is why I can never admire the twisted

${ }^{1}$ I am informed that the twisted spire at Chesterfield, which is made of a timber frame covered with metal, was not originally constructed in this screw-like form, but has been twisted into its present shape by the decay and partial failure of some timbers, an accidental origin for an architectural form which must carefully be distinguished from a structural shape intentionally created from the first. 


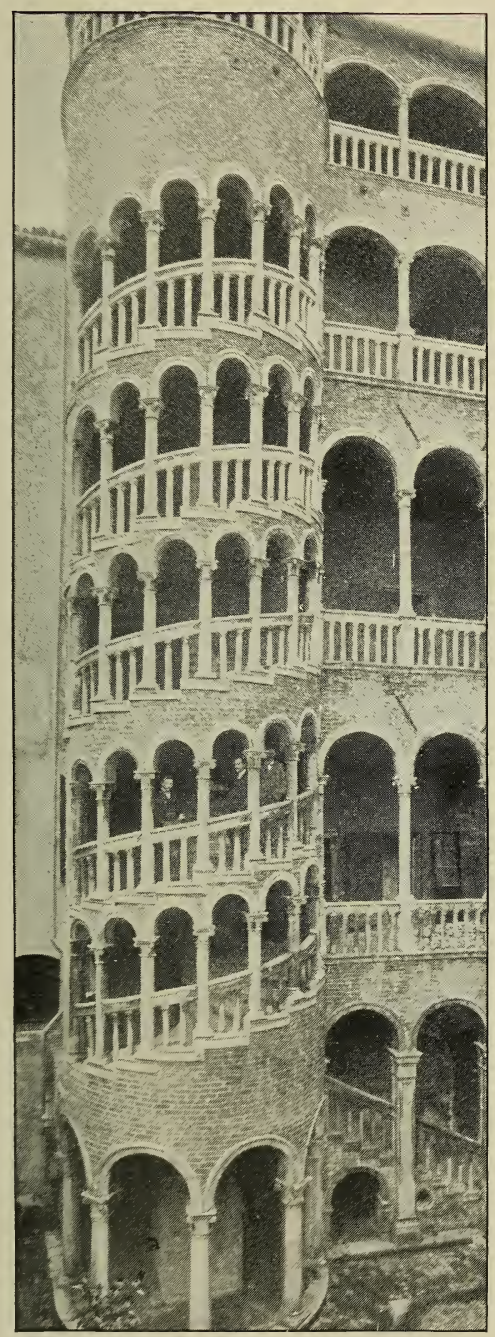

FIG. 23.

Scala del Bovolo, Palazzo Contarini, Venice.

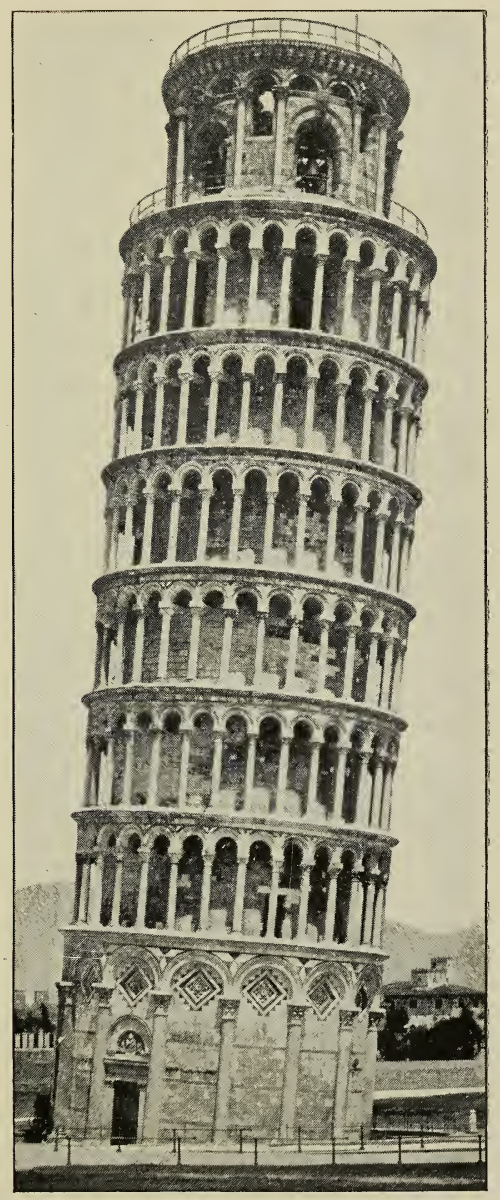

FIG. 24

The Tower of Pisa.

[To face page 96. 




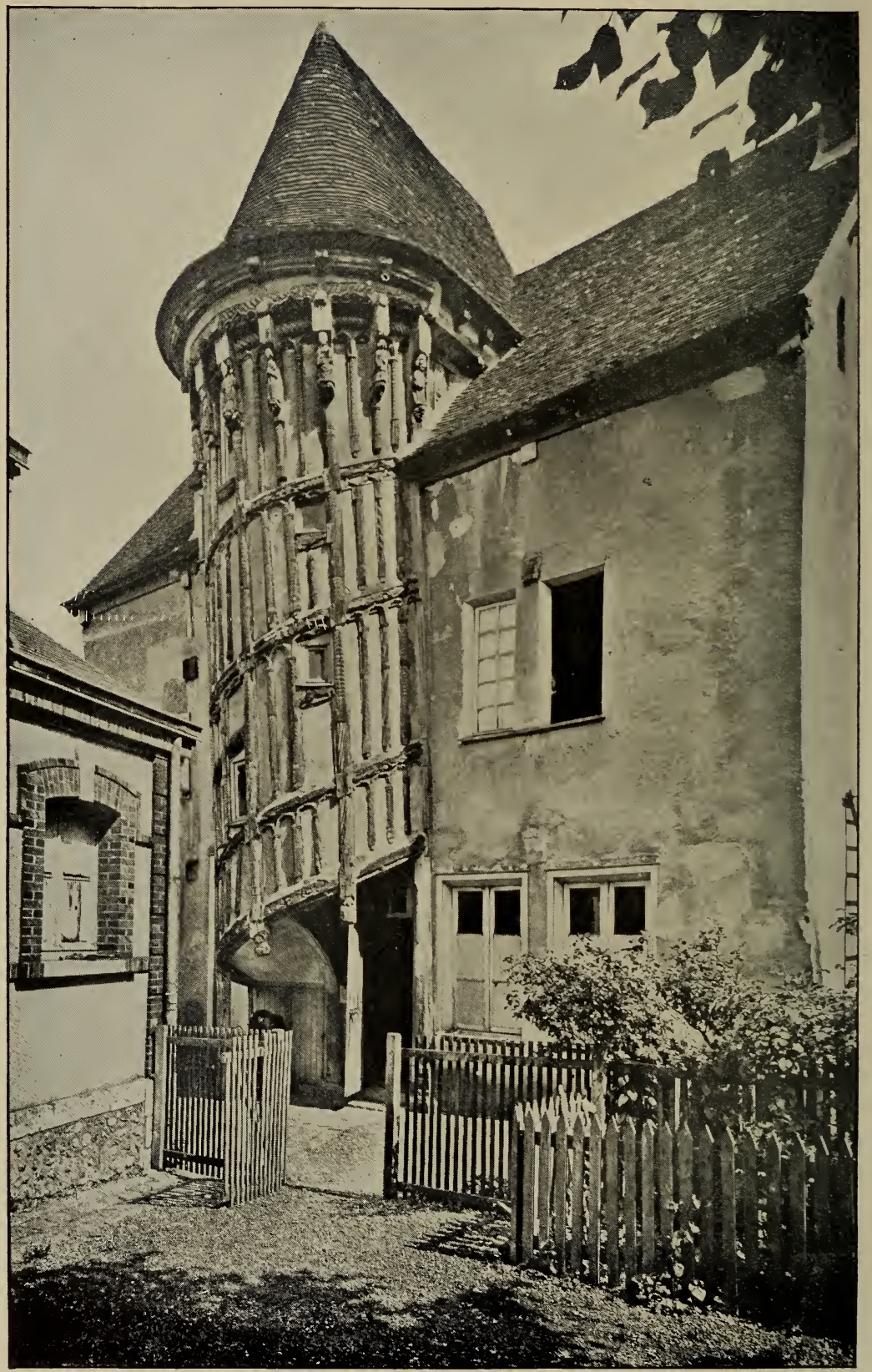

FIG. 25.

Escalier de la Reine Berthe, Chartres.

[To face page 97 . 
chimneys so often seen in Tudor buildings, or even such fine sinistral spirals of brickwork as are to be seen in the chimneys at Framlingham Castle. Even when in its right place, in a staircase, the spiral needs clever handling if it is to be effective, as may be seen in the clumsiness of the brickwork in the house of Tristan l'Hermite at Tours, and the ambitious failure of the clustered sinistral spiral in the stone stairway of the cloisters in the same town. In each case the steps, too, are straight and inartistic.

An even more delightful example of the close connection between a good architect's plans and the exquisite lines of Nature is to be found in the stairway called "Escalier de la Reine Berthe" at Chartres (fig. 25). It exhibits the delicate

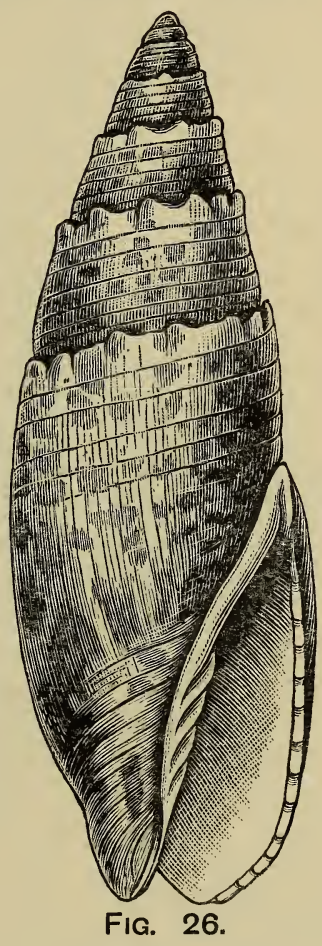

Mitra papalis. exterior ascending dextral helix, and even the top of Mitra papalis (fig. 26) with extraordinary faithfulness, and the parallel becomes even more complete when the position of the darkened doorway is com- 
pared to that of the shadowy orifice of the shell.

In Mitra papalis at this orifice, you will observe the beginnings of three internal spiral lines which suggest that the internal arrangements of a shell have as much to teach us as its exterior forms; and a very beautiful

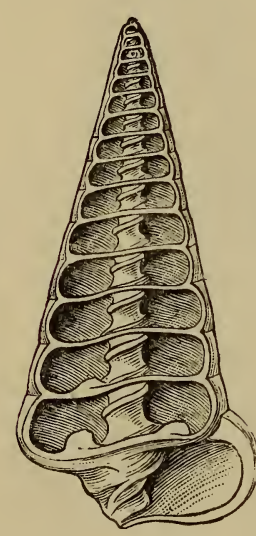

Fig. 27.

Telèscopium telescopium.

spiral may be seen by the aid of the $\mathrm{X}$-rays continuing throughout the whole length of the long-pointed shells so common in the south. The clue is worth following up, and a section cut through such a shell as Telescopium telescopium (fig. 27) actually reveals an exquisitely firm and elegant single spiral (a dextral helix) rising round the columella, that pillar which supports the whole; and this at once reminds me of the spiral in a staircase built in the old part of the Château of Blois many years before Leonardo was in France (fig. 28). But I do not for a moment suggest that there was any conscious comparison in the mind of the fifteenthcentury architect, and this for the very good reason that the curve of his stairway and the beautiful spiral rail (on which the left hand would rest as one ascended) are both 


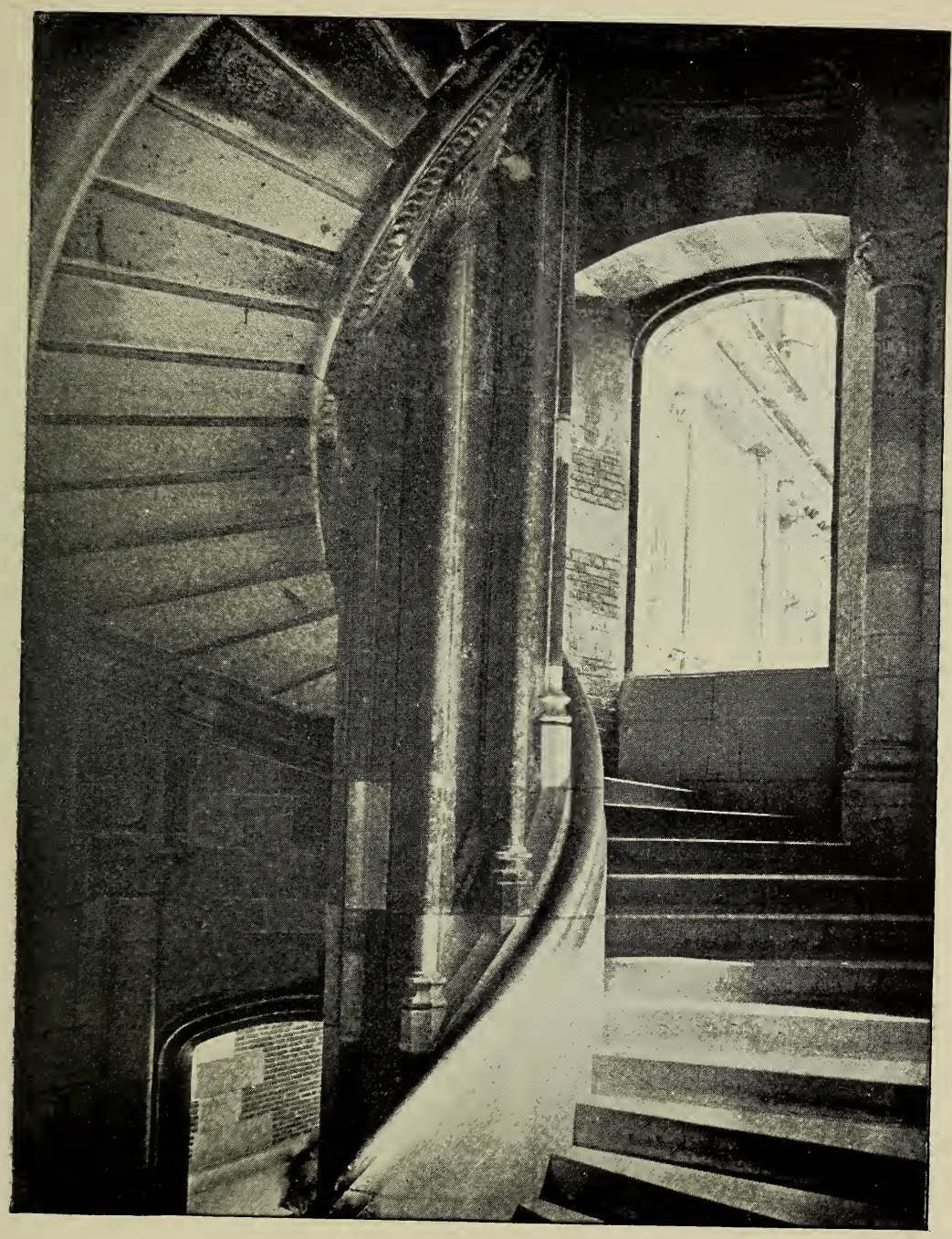

FIG. 28.

Staircase in the Old Wing of the Castle of Blois. [To face page 98.
[ 

susceptible of a simple architectural explanation; so that all I should be inclined to say of this comparison at present is that, as the lines of the architecture are right, and fulfil their purpose exactly, with an economy of space and strength, and a sufficiency of support, they were therefore very likely to be in harmony with those lines which Nature, the best of all artificers, has developed in her shell. I should need more resemblances than this to be satisfied that one might have been taken from the other; but, on the other hand, I shall by no means reject such a possibility, at the outset, as absurd; for architecture is full of such copies from Nature, as every organically beautiful, constructive art must be, and it is full of equally suggestive relics of the simpler forms of shelter from which the palace slowly grew. If the Egyptian pillar is a copy of the lotus-plant, so the peculiar shape of the Moorish and Saracen arch is a survival of that wind-blown tent, with conical top and bagging sides pegged closely in, which was the habitation of the Bedouin. 


\section{CH A P T E R V I}

\section{A VANISHED ART}

"Qual pare a riguardar la Carisenda Sotto 'l chinato, quand un nuvol vada Sovr' essa si ched ella incontro penda : Tal parve Anteo a me. . .."

-Dante.

$\mathrm{N}^{\mathrm{O}}$ one who looks with a seeing eye at the finest of the buildings which Leonardo da Vinci might have known, can fail to detect an intense perception of that difference in detail and harmony in relation to quantities of which Nature is the great exemplar. The "straight lines" of the Parthenon are in reality subtle curves, and recent investigation has detected a similar delicacy of constructive measurement in the great Gothic cathedrals. The influence of the study of flowers and leaves is especially marked when the positions and proportions of the best Byzantine arches are examined in the light of the laws which govern growth. How slight and exquisite were the details on which such laws depended no one could realise better 100 
than the painter who had studied the rendering of expression on a human countenance by lines so delicate that the reason for the effect produced was only visible to the few who knew. The eye is even more influenced by things which are usually "unseen" than by things which are "obvious"; and it is of the essence of Beauty that her origin and cause are hidden from those unworthy to appreciate her.

Some of these origins and causes it may be well to state here, for though they have been emphasised by such acute artistic intellects as Professor William Goodyear and Mr Julian Moore, and though the first announcement of their existence was made many years ago, yet they have never been properly appreciated by a public which must, after all, be the ultimate arbiter of architectural taste, and they are closely connected with those methods of Leonardo with which we are now chiefly interested.

The history of architectural theory has seen a renaissance of the ideals called classical, and a revival of the school known as "Gothic," of which the former was incomparably the more valuable, because the conditions of society which made "the pointed style" possible in England, and gave birth to the "Gothic" school in the Ile de France, could never re- 
appear, and were an essential concomitant of the architecture which expressed them. Yet an omission of equal value was made by the revivalists of both schools. The real "Gothic" preserved certain delicate principles of constructive asymmetry, in the curves and irregularities in the masonry of the old Greek builders, but the "Renaissance" which pretended to go back to ancient Greek and Roman ideals, did not appreciate, even if it saw, these slight divergencies from the rule of thumb which were invisible to any but the trained observer. In the same way, the Gothic Revival, which attempted impossibilities by overlooking entirely the radical changes which had occurred in contemporary life, was fated still more fully to destruction by its complete ignorance of the finer subtleties of mediæval art. We have no actual proof of this lack of appreciation in each case, except the proof provided by the buildings which were themselves the products of these separate revivals. For, apart from Vitruvius and from the invaluable Note-book of the architect Wilars de Honecort (1250), we have no real contemporary record of the growth of architectural principles until these theories concerning slight divergence had been wholly lost. Even the sentence in Vitruvius, which seems directly to refer to them, was never 
understood until the nineteenth century, and then only by the merest chance on the part of an observer whose real work was never recognised. These constructive refinements, however, died out, not merely because no record existed of them, but for the far more vital reason that the public eye was no longer delicate enough to appreciate them, though, as a matter of fact, they are the real cause of beauty in the finest of our old surviving buildings, which owe their charm not merely to the kindly hand of time but to the deep-laid skill of their builders. When constructions have arisen which were designed without that skill, even when they are supposed to be exact copies of the old originals, no lapse of time can ever lend them a beauty which is no concern of theirs, as may easily be seen in many smoke-begrimed atrocities of modern London.

In these days, division of labour has lowered the capacity of the individual artisan; and machine-made work, accustoming the eye to inartistic uniformity of ornamental detail, has also destroyed its grasp of delicate structural effects. In the old cathedrals, the mason and the architect, the artist and the artisan, were one. By the fifteenth century a Florentine, Leon Battista Alberti, had separated the architect from the builder. In England, it was Inigo Jones who first invariably insisted 
that his wood and stone workers should copy his designs instead of following their own fancies. Each was a great man, yet each was the unconscious origin of a great evil which has befallen the art they loved.

The history of the discovery of curves in ancient Greek, even in Egyptian, architecture, is romantic and interesting enough. Every one had read the passage which suggests them in Vitruvius since 1500. Stuart and Revett had measured the Parthenon in 1756. Lord Elgin's workmen noticed nothing. In 1810 Cokerell had established the fact of entasis, and in 1829 Donaldson saw the lean of the columns. But in $\mathbf{1 8 1 2}$ the translation of Vitruvius, by Wilkins, only contained a note that "this great refinement . . . . does not appear to have entered into the execution of the work of the ancients." Apparently it never occurred to the translator that it was worth while measuring "the work of the ancients," before making general statements about it. At last, in 1833, Mr John Pennethorne discovered the undoubted existence of convex constructive curves in the architraves of the second court of the Theban Temple of Medinet Habou. Four years afterwards he stood before the Parthenon, with the passage from Vitruvius in his mind, and saw those delicate irregularities which had remained invisible throughout the passage of 
so many unintelligent years. About the same time two German architects, Hofer and Schaubert, saw them too, and published their discovery in the "Wiener Bauzeitung" of 1838. Save in a private pamphlet, Pennethorne gave nothing to the world till 1878, although in 1851 Francis Cranmer Penrose, helped by the Dilettante Society, published the results of his measurements of the Parthenon in "Principles of Athenian Architecture."

Penrose showed that in this building no two neighbouring capitals correspond in size, diameters of columns are unequal, intercolumnar spaces are irregular, the metope spaces are of varying width, none of the apparently vertical lines are true perpendiculars, the columns all lean towards the centre of the building, as do the side walls, the antæ at the angles lean forward, the architrave and frieze lean backward, the main horizontal lines of construction are in curves which rise in vertical planes to the centre of each side, and these curves do not form parallels. Professor Goodyear, who completed the investigations of Pennethorne at Medinet Habou, found that similar curves existed in the Maison Carrée, and it is clear that while irregularities which would be easily detected or obtrusively conspicuous were avoided, there was also an unquestionable intention of avoiding exact 
ratios or mathematical correspondences wherever such an avoidance was calculated to produce a certain effect. That these deviations were not the result of error in the workmen, or of accidents in the lapse of centuries, is also clear from Penrose's calculation that the maximum deviation of the Parthenon in the case of lines intended to correspond (as at the two ends) is as little as the fiftieth part of an inch, while the refinement of jointing in the masonry is so great that the stones composing the great steps have actually grown together beneath the pressure of the columns they support. It is in fact impossible to explain such asymmetries as these, on the theory of faulty work, of the use of varying materials from different sources, or of subsequent accidents, and the principles thus found to be practised by the builders of the Parthenon, have also been discovered by Professor Goodyear to exist not merely in Egyptian, Greek, and Roman buildings, but in ItaloByzantine, Byzantine-Romanesque, and Gothic buildings, especially where Byzantine influence has been strong, in obedience to laws which fell into abeyance almost completely when the classical Renaissance fully established itself.

Oblique plans are common in old churches, and can easily be seen in such examples as $\mathbf{S t}$ Ouen at Rouen, or the choir arch in the parish 
church of Wantage, where the deflection of the building has been said to represent the position of Christ's head upon the cross. These instances, however, are of a grosser nature than the curves in constructional line, which I wish chiefly to emphasise, and which may be seen in the walls of the nave of Westminster Abbey. These are bent inwards at about the height of the keystones of the arches, and outwards above and below this point, as Mr Julian Moore has shown. They are not only structurally sound to this day, but have retained a greater beauty than exists in any of the numerous ruler-made copies in different modern churches of the country. In Evelyn's "Diary" there is a most interesting indication of similar divergencies in Old St Paul's. "Finding," he writes on 27th July 1665, " the main building to recede outwards, it was the opinion of Mr Chichly and Mr Prat that it had been so built ab origine for an effect in perspective, in regard of the height; but I was, with Dr Wren [Sir Christopher] quite of another judgement, and so we entered it; we plumbed the uprights in several places."

This implies that two English architects of the seventeenth century asserted a constructive existence and an optical purpose for an outward divergence from the perpendicular in the vertical lines of the nave of a Gothic 
cathedral, and favoured the preservation of the Gothic building as far as possible. To Evelyn and Wren, however, the champions of the Renaissance, the old church was "only Gothic." Keen as they were, they had lost something which two lesser men remembered. Similar divergencies in St Mark's at Venice have been equally overlooked by almost every visitor. The piers and upper walls of the nave lean outward to an extent of 18 inches out of the perpendicular on each side, a deviation which, had it been accidental, or later than the original construction, would have disintegrated the arches supporting the dome, ruined the frescoes, and destroyed the building. Again, in the choir of Sant' Ambrogio at Milan, the main piers on the right and left lean out nearly 6 inches from the perpendicular on each side; and a similar lean may be observed in S. Maria della Pieve at Arezzo, where the queer bent column in the choir gallery is a conspicuous instance of the capricious and eccentric forms occasionally developed by the hatred of mathematical exactness.

A much more daring and aggressive instance of divergence from accurate measurements is to be found in the Campanile of Pisa Cathedral, which I reproduced in fig. 24. This astonishing structure is $\mathbf{1 7 9}$ feet in height, and is no less than 13 feet out of the perpen- 
dicular, a peculiarity which has given it the name of the Leaning Tower of Pisa. This lean is more accentuated in the three lowest storeys, and above the third storey there is a deliberate effort to return towards the perpendicular by means of a delicate series of changes in the pitch of the columns on the lower side, and by a slight rise in height of the galleries on the same side. The reasons for this have been somewhat too hastily and generally taken from Vasari's explanation in the "Lives," who attributes it to inexperience of the peculiar soil of Pisa on the part of the architects Guglielmo and Bonanno. They endeavoured, he asserts, to rectify the settlement of the foundations (which occurred, on this theory, just when the third storey had been completed) by endeavouring to build back again to the perpendicular in $\mathbf{1 1 7 4}$.

I cannot accept Vasari's explanation now that Professor Goodyear's researches into what may be called "symmetrophobia" have been published. Vasari wrote some four hundred years after the Campanile had been built, some time after the Italian Renaissance had cast its scorn on what was "only Gothic," and in days when the marriage of a daughter of the Duke of Tuscany was celebrated by whitewashing the Gothic frescoes of the Duomo at Florence. Even if we accept 
Vasari's theory as to the Campanile alone, it will not explain why similar divergencies occur in contemporary buildings. The Baptistery of the Cathedral, begun in 1173, also leans 17 inches out of the perpendicular, and the plinth-blocks of its foundations tilt down evenly and gradually for exactly 9 inches in the direction of this lean. The Campanile of S. Nicolò (built by Nicolò Pisano) leans forward in the same way, and also curves back again towards the perpendicular. The façades of the Cathedral of Pisa, and of its choir, both show a similar forward lean in their original construction, curving back again to the perpendicular.

Its Campanile, in fact, is not the result of accident. It was originally built as it may now be seen, the most remarkable combination of Greco-Byzantine subtlety with mediæval exaltation in the age which enjoyed such tours de force as the bent column of Arezzo, or the Torre del Pubblico of Ravenna, or the Garisenda Tower at Bologna, which is $\mathbf{1 6 3}$ feet high and $\mathbf{1 0}$ feet out of the perpendicular. Goethe, whose Essay on Strassburg Cathedral (about 1773) was a veritable re-discovery of mediæval principles of beauty, explained this leaning tower as intentionally so built as to attract the spectator's attention from the numerous ordinary straight shafts; which 
may well be true, if we are to believe Benjamin of 'Tudela's statement to the effect that there were ten thousand towers in Pisa alone.

I cannot here commend the Campanile of Pisa for its eccentric leaning construction any more than for its superimposed circles (fig. 24), which lose much of their effect by the equality of their vertical divisions, but I quote it as the most intelligible instance I know of the deliberate avoidance of accuracy in construction for deliberate reasons. It is exaggerated, and therefore fails where the more delicate effects of the Parthenon succeed; but its very conspicuous qualities give a very clear example of that intentional mystification by which the old builders strove to get a look of life, of that nature which never grows by rule, of those principles of growth which have brought Nautilus pompilius so near to the logarithmic spiral (figs. 34, 35) without exactly reproducing the mathematical curve (see p.185).

Ruskin noticed some such divergencies from accurate measurement in the old Gothic buildings of Venice, but apparently without appreciating the value of Penrose's work on the Parthenon. ${ }^{1}$ Yet the principles which

${ }^{1} \mathrm{He}$ emphasizes, for instance, the fact that the two Eastern windows in the façade of the Ducal Palace, which overlooks the Riva de' Schiavoni, are lower than the other 
[CHAP.

guided the Greek builders seem to have lasted just as long as building was done from the freehand drawings of the artist-mastermason. No painter, even of to-day, would draw in a door in one of his pictures with a rule and compasses; he knows that there is a quality in the natural work of hand and eye which no artificial aids can give him. The old Egyptians and the Greeks knew that, and the tradition of it lasted on in a few cases of stone construction even when the designs were ruler-made, and when the irregularities of handiwork had become the conventions of a few skilled masons. As we have seen, two English architects in the seventeenth century recognised the existence of deliberate constructional inequalities. As late as the eighteenth century these principles prevailed, as may be seen in the "humped" pediment of the Mansion House in London. Even today the thatcher builds his cottage roof not in straight lines, but in curves, which absorb less rain-water, and he achieves a beauty which is denied to the higher mathematics. four, and his comment is :- "In this arrangement there is one of the most remarkable instances I know of the daring sacrifice of symmetry to convenience, which was noticed in chap. vii. ['Stones of Venice,' vol. ii.] as one of the chief noblenesses of the Gothic schools." But, of course,

- questions of "convenience" do not enter into the "symmetrophobia" discovered by Penrose and Goodyear. 
The old streets were full of beautiful curves which cannot be explained only on the theory that twisting thoroughfares were more easy to defend, or by the suggestion that the houses grew up at haphazard. Neither of these reasons can explain the beauty of the High at Oxford, or the angle at which Magdalen Tower is set to its own quad, or the superiority of Regent Street and Piccadilly to Victoria Street or the Edgeware Road. The "whiff of grapeshot," has Haussmannised modern Paris into a city of straight lines, and the next step is the chessboard of the American city, in which every thoroughfare leads to nowhere in particular. When the divergencies in building and in the laying out of streets were almost forgotten, the principle that underlay them still survived in that more intimate form of architecture which is furniture and domestic decoration. In the best periods of Chippendale, or Hepplewhite, or Sheraton, you find each step in a staircase gently bowed outwards, or given a waving outline (as in fig. 59); you find, too, that the walls of the best rooms are given slight curves horizontally as well as vertically; you find the subtle inequalities of feeling handiwork in settee, and chair, and screen. But the modern "decorator" seems so fond of Euclid, that the joys of the rectangle and the 
parallelogram have swamped the charms of Nature. He forgets that even so common an object of his daily life as the human face has two sides which are quite different the one from the other.

Fortunately for us, Leonardo, that mighty master of the human face, lived when these principles were not so utterly forgotten as they are now. He was indeed a painter of the Renaissance, and the Renaissance influenced all his life and art. But he was a man whose personality broke a way through the limitations of every style. He was a student of Nature who had observed that her divergencies were even more important than her reproductions, and who did not even shrink from saying that the creative imagination of the understanding man was infinite in comparison with her. We shall see therefore that when he chooses his inspiration from such a natural object as one of the shells to which he devoted special study, it is not to imitate it slavishly, but it is to reproduce those essential elements in it which are the causes of its beauty, and to mould them into new forms at the bidding of his own artistic genius. 


\section{CHAPTER VII}

\section{THE NAUTILUS}

"... Wrecked is the ship of Pearl

And every chambered cell,

Where its dim dreaming life was wont to dwell

As the frail tenant shaped his growing shell,

Before thee lies revealed

Its irised ceiling rent, its sunless crypt unsealed."

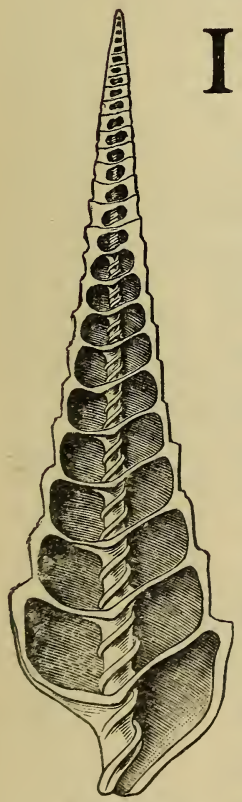

T MUST now return to fig. 27, and endeavour to examine the reasons for that spiral line which encircles the central column of the shell, for the plaits upon the columella, as the conchologist would say; for this is a little structural detail which Leonardo evidently noticed, and which has not been thought worthy of any adequate illustration by later biologists. If it had ever become "necessary" (I can find no other word) to strengthen the central supporting column or columella, FIG. 29. without too much enlarging it Ceritheum giganteum. or adding to its weight, no better formation than this spiral could be conceived, 
and an almost exact parallel to it occurs in the air-tubes or tracheæ of insects and of plants. Though of totally different origin, these airtubes in each case have a spiral thickening of the wall, which strengthens them and keeps them open, just like a spiral coil of wire round a rubber garden-hose : engineers and mechanicians are of course aware of this artful method of strengthening a cylinder by means of a spiral; the cannons made by winding wire round a central core are an obvious example. I have not found any good drawing of this formation in the tracheæ of insects, though I have seen an example under a microscope in the British Museum of Natural History. The tube has a delicate outside coating, and after the death of the insect the spiral (which thickens this coat) can be pulled out and examined. In just the same way the spiral band can be unrolled from the air-tube of a plant, and this is very beautifully illustrated in the "Text-book of Botany," by Julius Sachs (Second Edition, Oxford, Clarendon Press, 1882), which gives on page 114 the longitudinal section of a fibro-vascular bundle of Ricinus, drawn in fig. 95, $s$, and $s^{\prime}$, of that book.

These spiral filaments are also found in double and triple, as well as single, threads. The spiral vessels of the Chinese Pitcher- 
plant (Nepenthes) exhibit a quadruple thread, as in fig. 54, and they have the further peculiarity of being sinistral, like the rare dexiotropic Voluta. These air-tubes are found in the leaf-stalks; they are closed; and their air-contents only permeate their enclosing membrane, which is so delicate that if the thread on the inner surface is uncoiled, no trace of the thin membrane will be seen except at the conical end of the ruptured vessel. The air-vessels of insects are branched and ramified so as to form a set of continuous tubes, and are framed to resist pressure from without by the elasticity of the fibre spirally coiled within them.

It is only in the true spiral vessel that we find air in each case. When plants have long continuous tubes, forming ducts for fluid, the internal strengthening is formed by a combination of broken spirals and rings, exactly as in the windpipe of the Dugong we find a spiral cartilage terminating at intervals in rings.

In Dr Schleiden's “Principles of Scientific Botany," translated by Dr Edwin Lankester (London: Longmans, 1849), the nature and origin of spiral fibres (discovered by Malpighi) is very carefully explained, with diagrams, on pp. 42-47, and to this I must refer my readers, for I have but space here to suggest that the 
same process observable in these tubes may have gone on in the formation of the spiral round the columella of a shell; and if so, it might no doubt be further shown that shells with only a single spiral need such strengthening less than those which possess eight, as may be perhaps observed by a comparison of fig. 27 with fig. 33. Charles Darwin noticed that the clasp of a twining plant round its support was definitely strengthened by the spiral twist of its own actual fibre (see p. 65), and the plaits on the columella may possibly be the result of a similar set of circumstances. In any case, this additional growth has never yet been satisfactorily explained; it may certainly be useful, as in some way assisting the animal to keep firm hold of its shell by means of a muscle specially adapted to hold on by it. But there are many large and thick shells in which the columella is perfectly smooth, so that in their case-whatever may be true in other instances-the mode of attachment must be different. The spiral line which I am now considering begins at the topmost and smallest chamber of the shell, and continues growing with the external growth to the largest chamber at the bottom. It is possible, therefore, that this spiral may have some intimate relation to the body of 
the animal in whose dwelling-place it occurs. But this I am inclined to doubt, for the reason that in Turritella lentiginosa (fig. 52) it does not occur at all (though possibly because the "strengthening" process was not yet advisable), while if we take Telescopium telescopium (fig. 27) with its one spiral as the

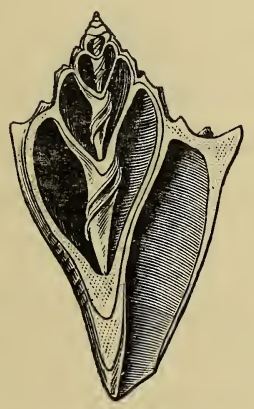

FIG. 30.

Voluta solandri.

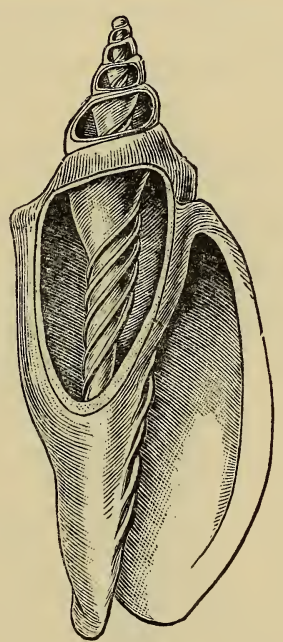

FIG. 31.

Voluta pacifica.

beginning of a series, we shall find Ceritheum giganteum (fig. 29) and Voluta solandri (fig. 30) with two spirals, Turbinella pirum (fig. 7) with three, Voluta vespertilio (fig. 53) with four, Voluta pacifica (fig. 31) with five,

${ }^{1}$ Cymbium, the boat-shell from the African coast, has four plaits upon its columella, but its external formation is entirely different to that of Voluta vespertilio (see p. 167). 
Turbinella fusus (fig. 32) with six, and Voluta musica (fig. 33) with as many as eight, while the number is even greater in Cymbiola tuberculata and Harpula fulminata. Whatever may be the real explanation of these internal spirals which are reproduced in every chamber of the shell, I do not

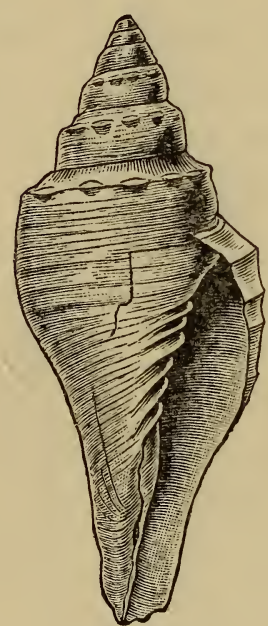

FIG. 32.

Turbinella fusus.

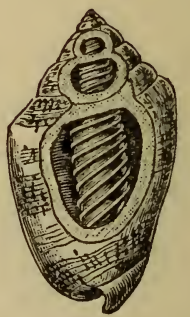

FIG. 33.

Voluta musica.

therefore think that they can be so intimately connected with the anatomy of the living organism as with the structure of the shelter which it fashions for its home; for though it may be true that the number of "notches" in the columella-muscle of these 
shell-fish corresponds with the number of spirals round the columella in each case, the question why these spirals exist remains unanswered.

"It is better to take the line and leave the shell," said Ruskin, forbidding his pupils to admire or use as ornament these "moulds or coats of organism," however beautiful their lines. He had evidently never looked inside them.

But long before Ruskin's criticisms had become an artistic shibboleth, the inside of shells had fortunately attracted the attention of scientific men who possessed a combination of talents as rare as it is fruitful. I think it was Professor Freeman who said once that the true historian should not only know everything about something, but also something about everything. That may be a counsel of perfection; but it is an ideal that is worth remembering in days when too much specialisation sometimes darkens knowledge. The biologist is great, and the mathematician is great; but greater still is the man who can combine some of the knowledge that is in each without losing the accuracy of either. Such a man, to some extent, must have been Sir John Leslie, who was the first to indicate the organic aspect of the curve-line known to mathematicians as the logarithmic or 
equiangular spiral (fig. 35). "This spiral," he wrote, "exactly resembles the general form and elegant septa of the Nautilus" ("Geometrical Analysis and Geometry of Curve Lines," Edinburgh, 1821, p. 438). But Canon Moseley of Cambridge went further. $\mathrm{He}$ made an exact geometrical examination of certain Turbine shells (Phil. Trans., 1838, p. 351) which exhibited a spiral curve wound round a central axis. This curve was found to be logarithmic, and from it could be framed a series of formulæ by which the other conditions could be predicted as they were found to exist. The spires of the shell increased in breadth in an exact successive series, each one of which was a multiple, in a certain ratio, of another. Thus the shell must possess this form and could possess no other, for its spiral logarithmic curve reproduced itself.

Canon Moseley also noticed that the operculum was remarkable for its geometrical symmetry in the shells he examined; and a process which no naturalist had yet discovered was thereupon ascertained by means of a mathematical calculation of the revolution which the operculum of the shell must make round its axis. By cutting any part of the shell in the direction of the plane of its axis, he found that every section gave a form 


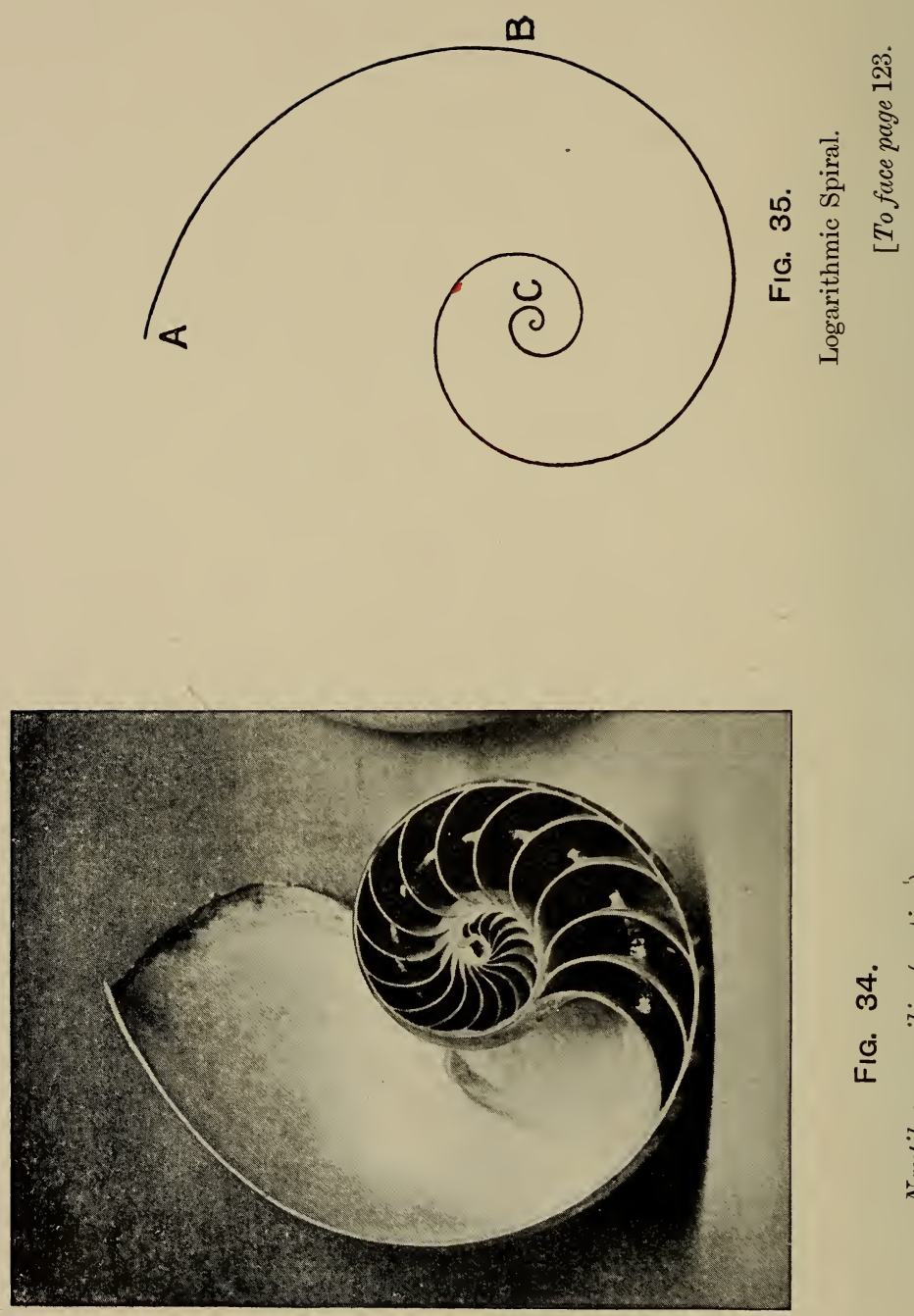

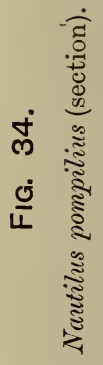


exactly similar to the form of the operculum; and so he proved in this way that the form of a turbinated shell is produced by the revolution of the perimeter of the figure formed by the operculum round the axis of the shell. In the Nautilus this figure is an ellipse which revolves round its minor axis and increases in geometrical progression without ever changing its form as it revolves. The operculum being of a fixed form, as the shell grew it increased in size proportionately, and thus formed a very convenient measure of the shell itself and all its parts, inasmuch as the curve of the shell possessed the peculiar properties of the logarithmic spiral. Nor was the extension of this animal's dwelling formed by merely pushing the operculum forward, as I suggested in speaking of the growth of Scalaria scalaris (fig. 22), but by the more precise method of depositing additional matter along the lower margin of the shell which formed the tangent of the curve. In fig. 34 I have photographed a Nautilus shell cut in two ( $N$. pompilius from New Britain) so as to show the spiral within, and this should be compared with fig. 35, which was drawn for me by a Senior Wrangler as an academic example of a logarithmic or equiangular spiral, without any reference to this paper or to the shell of which it seems so close a copy. 
It will be noticed here that Mr Church's application of the logarithmic spiral, as an ideal formula for "uniform growth" to phyllotaxis, will serve the conchologist equally well in the present instance; for certainly this Nautilus is so nearly a logarithmic spiral that the difference between the two can easily be expressed in a mathematical formula which will give - for the first time - an accurate definition and description of the shell. Professor Goodsir, and $\mathrm{Mr}$ Church after him, have considered that the logarithmic spiral is a manifestation of the law which is at work in the increase of organic bodies: "Spira Mirabilis, as Bernouilli called it (in "Acta Eruditorum," 1691), and gave it the motto-"Eadem Mutata Resurgo"because it reproduces itself both in its involute and its evolute. If they are right, the Ammonite, of which I reproduce an example from the Lower Lias of Lyme Regis (fig. 36), has not survived as a living organism, because the sweep of its curve is not wide enough for truly vital expansion, and does not, in fact, correspond so nearly to their Curve of perfect Growth as the living Nautilus of fig. 35. It may be equally significant that though the more generous outlines of Argonauta Argo (fig. 37) do not correspond to the logarithmic spiral even so 

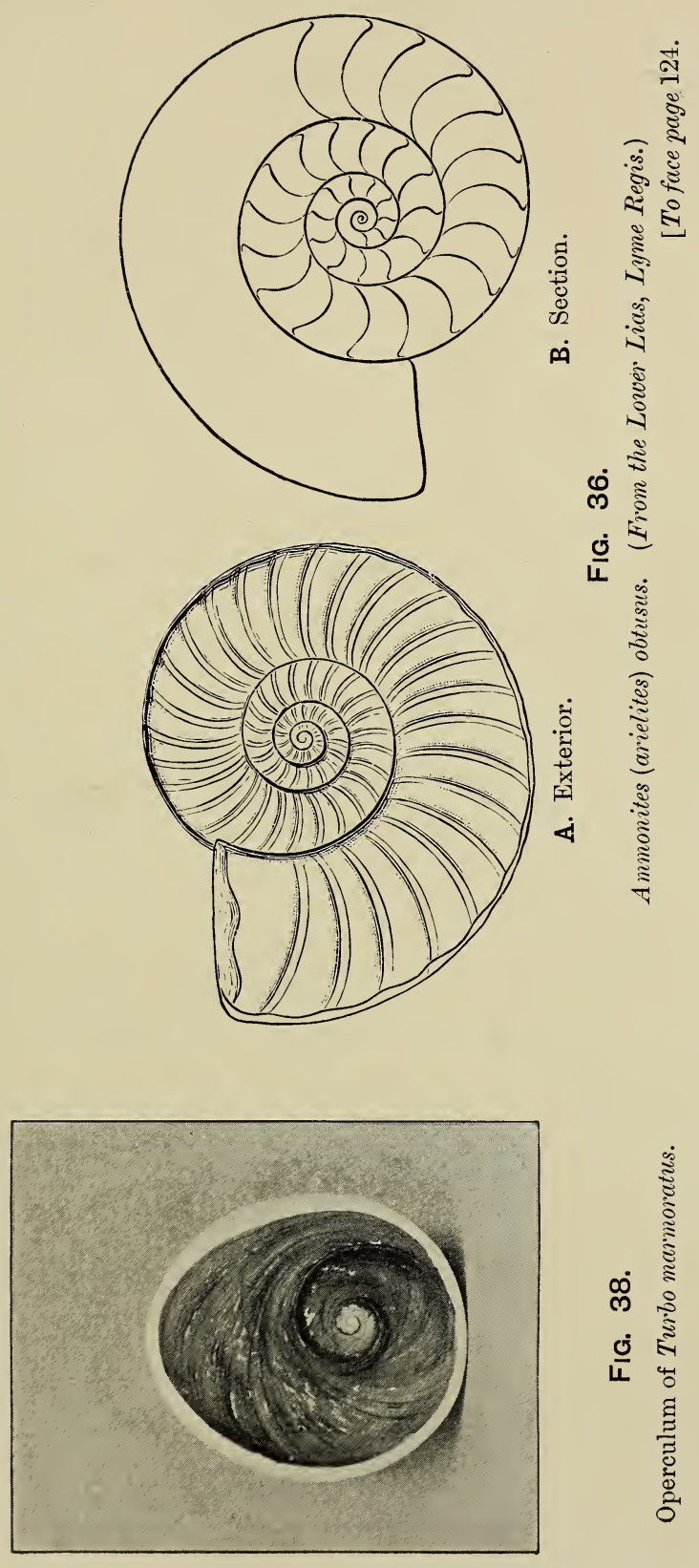

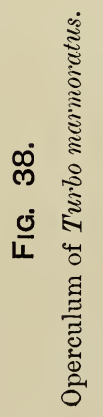






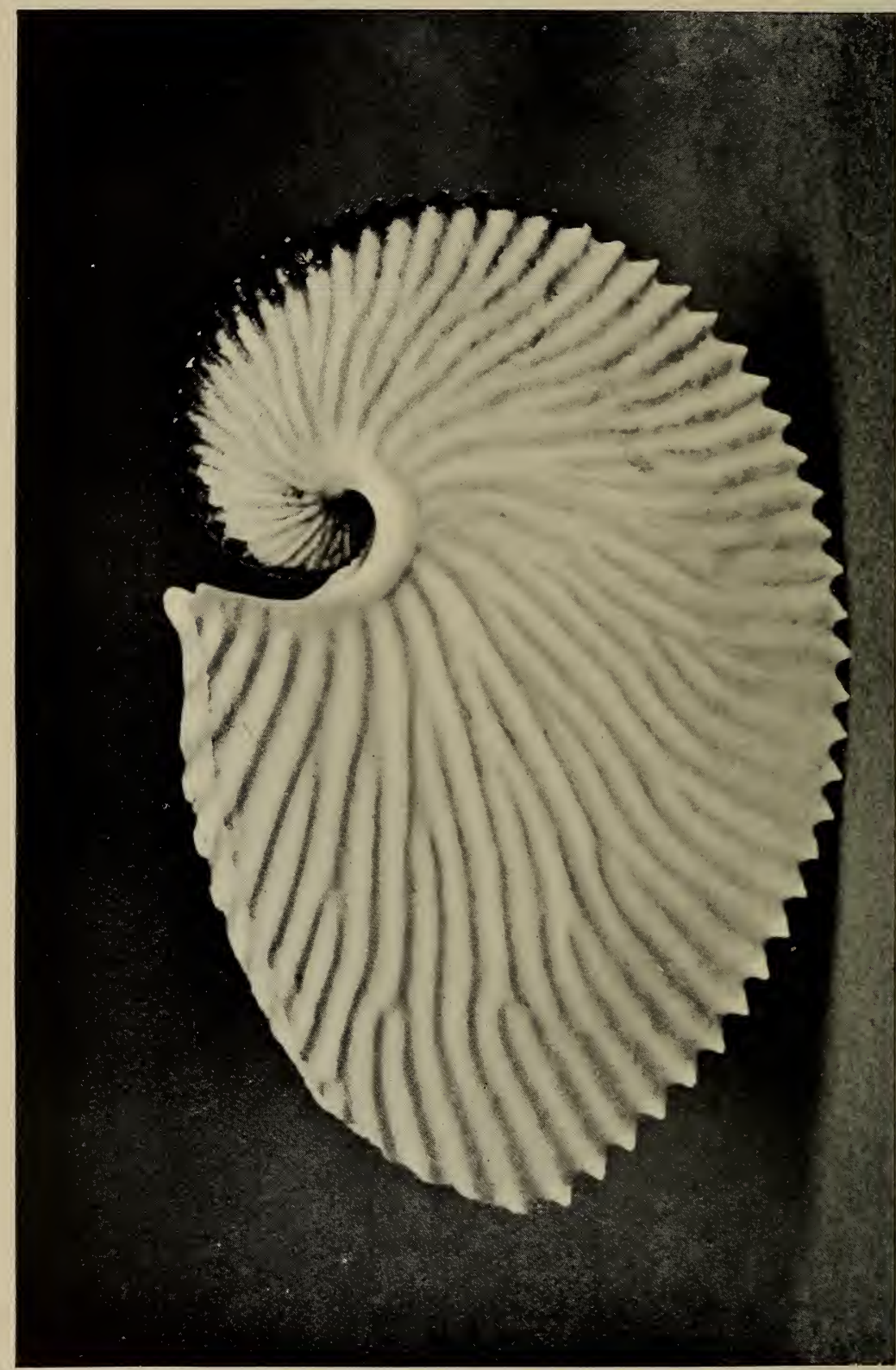

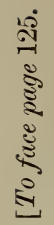

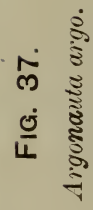


nearly as the Ammonite, yet they err on the side of increase instead of decrease, and may therefore have had a greater chance of survival. Similar comparisons with the logarithmic spiral may be profitably made in the case of the beautiful external spirals clearly marked upon the shells of Haliotida gigantea from the Corean Archipelago; of $H$. cunninghamii from Australasia; and of $H$. midae from the Cape of Grood Hope. The first of these three exhibits an especially wide sweep in its outline after the first curves of the spiral have begun to grow and to expand. It has been already noticed (see note to p. 73) that curves closely approaching the logarithmic spiral occur in such minute specimens of life as the Infusoria, described by Stein, especially in Stentor Coeruleus; so that Sir John Leslie's recognition of the "organic aspect" of this curve was perhaps wiser than he realised.

Biologists may not see anything very profound in the approximation here illustrated of a logarithmic spiral to a shell; for they know that the spiral curves in the Nautilus are due to growth and gravity acting on an elastic substance, and mathematicians tell them that the logarithmic curve merely expresses in a convenient form certain common and usual relations. Still, there is no doubt whatever that the mathematical curve pro- 
vides an interesting definition of the shell, and I have never yet seen the apparently inevitable corollary to this simple fact, which would be to explain what the component factors are which would produce a logarithmic curve in the Nautilus, and how those factors would have to differ in order to produce some other curve. I would humbly suggest this as an interesting thesis to future examiners. A careful inspection of fig. 34 will also reveal the astonishing fact (which is common, I believe, to every Nautilus and Ammonite) that the last compartment in which the creature lived, instead of being the largest of all, is distinctly smaller than the one behind it; a very pretty instance of Nature's unexpected asymmetry, which may be perhaps explained by the results of increasing age in the inhabitant of the shell. This is the only point in which Dr Oliver Wendell Holmes does not seem quite accurate about his biology in the beautiful lines on the Nautilus, from which I have made several quotations.

In fig. $38 \mathrm{I}$ reproduce a photograph of the operculum of Turbo marmoratus. The operculum of turbinidac has been called an "eyestone," and a "sea-bean." It is a horny or shelly plate secreted by gastropods and other molluses, which serves to close the aperture of the shell when the animal is 
retracted. In Trochus the spiral on the inner side is as close as a watch-spring. In Turbo olearius it shows a beautiful figure like a logarithmic spiral with septa like the Nautilus.

I have abridged my description of Canon Moseley's investigations from Goodsir's “ Anatomical Memoirs," edited by Sir . William Turner (Edinburgh, 1868, vol. ii. p. 205 et seq.); and I insert it here in order to lay stress upon the fact that if any particular class of natural objects were to be chosen by a student for the purposes of such a mathematical and creative art as architecture, the class of shells would be the most suitable, inasmuch as they suggest with particular appropriateness those structural and mathematical problems which a builder so often has to face. The deductions made by Professor Goodsir from Canon Moseley's investigations will be mentioned later on in their proper place. It will be appropriate, however, to point out here that M. Vial de Saint-Bel, a famous veterinary surgeon and anatomist of the eighteenth century, made very careful examinations and mathematical measurements of the body and skeleton of Eclipse, the famous racehorse which died in 1789. From these a valuable series of standards and proportions was deduced, 
which I have republished elsewhere ${ }^{1}$ as a method for comparing the developments of the English thoroughbred in the past hundred years, and as some explanation, from the purely mathematical point of view, of a speed which was entirely owing to Eclipse's wonderful anatomical construction. The most interesting result of $\mathbf{M}$. de Saint-Bel's investigations has only recently appeared; for he proved by mathematics that Eclipse must have made certain movements with his legs which nobody could see. Only when instantaneous photography was invented and applied to horse-racing, did these movements actually make their appearance in the photograph of a galloping horse.

Having given an example of "biological mathematics" before Moseley, I will add an example of mathematical biology after his time, from the "First Study of Natural Selection in Clausilia laminata (Montagu)," which was published in October 1901, by Professor W. F. R. Weldon in Biometrika. He pointed out that the problems presented by certain terrestrial mollusca in Europe are of great interest in connection with the theory of natural selection, and that such specific (though apparently "useless") characters as 1 "A History of the English Turf (Illustrated). Messrs H. Virtue \& Co. 
the shape of the spire, the number of ridges and furrows on a given whorl, or the size and shape of the aperture, can often be expressed in such a way as "to admit of numerical comparison between individuals." The shell of an adult Clausilia laminata is essentially a tube coiled round an axis so that the successive coils are in contact, much as in Turritella lentiginosa; and by carefully determining the pitch and measurements of both the peripheral spiral and the columellar spiral in a number of examples from the beechwoods of Gremsmühlen in Eastern Holstein, Professor Weldon drew various conclusions. The upper whorls of the adult shell, he found, represent the condition of the young shell, from which this adult was formed by the addition of new material, in a practically unaltered form. Specimens taken from a district which the species is known to have inhabited since pre-glacial ages are in such equilibrium with their surroundings that the mean character of the shell-spiral is the same from generation to generation, and is not being changed by selection during the growth of a young generation. The life or death of an individual is in fact determined in each case by the value of a number of correlated characters, among which differences of structure so slight as that of the measurements 
of the spirals are associated with the difference between the survival and the total extinction of a race in a particular locality.

The discovery of Neptune by Adams and Le Verrier, owing to the calculations involved by the observed aberrations of Uranus, is an instance of "scientific thought" well-known to astronomers. But another example is quoted by Professor W. K. Clifford, which is even more typical of the mental process to which I desire to draw attention. A dot on paper seen through Iceland spar shows as not one but two dots. Sir William Rowan Hamilton, late Astronomer Royal of Ireland, knowing both this phenomenon and Fresnel's explanation of it, predicted that by looking through certain crystals in a certain direction we should see a continuous circle, and Mr Lloyd did see this circle. On page 154 I have given a remarkable instance of similar foresight in Leonardo himself.

From the fact that some acids and salts, when seen by a ray of polarised light, ${ }^{1}$ show spirals which turn either to the right or left, 1 "Airy's spirals" is the name given to the peculiar coloured interference-figures seen when two sections of quartz, one of a right-handed, the other of a left-handed crystal, both cut transversely to the vertical axis, are placed one over the other, and viewed in converging polarised light. 
modern investigators have been inclined to take the occurrence of this formation as a test between organic and inorganic matter in the long argument as to the possibility of breaking down the distinction of vital force which is supposed to exist between the thing that has been "naturally" created, and the thing which is "chemically made." In his laboratory a chemist can now make a compound, such as tartaric acid, which will be optically neutral, that is to say, it will exhibit a mixture of right-handed and of left-handed spirals, whereas in Nature we find these spirals are of one kind, either right-handed or left-handed in each case. In the laboratory the one kind can be separated from the other by biological means, for there is an organism which feeds upon one sort and rejects the other. Pasteur, however, devised a process by which no such biological assistance was necessary; for by crystallising the compound he was able to pick out those salt-crystals with their hemihedral face to the right from others which exhibited the left-handed formation. In this way he approached very near the boundary which still guards the mysteries of organic life; and it was the spiral formation which enabled him to do so. 


\section{CHAPTER VIII}

\section{OF MASONRY}

"The stairs as he treads on them kiss his feet."

I $\mathrm{N}$ previous pages I have attempted to give 1 some explanation of the beautiful spiral lines upon the columella of such a shell as that shown in fig. 53, which is the fourth in a series of which Telescopium telescopium with its single spiral (fig. 27) is the beginning. In fig. 28 I reproduce the photograph of an old staircase in the Château of Blois, built long before Leonardo da Vinci came to France. The origin of the architectural lines in such a staircase as this is more easily explained than the structure either of a Telescopium or of a Voluta.

When the first great square or circular feudal fortresses or keeps were built, the walls were of such enormous thickness that the space for the living rooms was very considerably curtailed, and a staircase after the usual London pattern would have left hardly any 
room at all either for the owner's family or for his garrison. Yet it was necessary to get access quickly and easily -in some cases secretlyfrom one floor to another; and when a lady was living in the same building with a number of soldiers, she might desire, even in those rough times when dignity counted for more than decency, to have a separate staircase to herself, leading perhaps from her boudoir to the daiis of the hall, while a different stairway, at the opposite angle of the room, admitted the crowd of men-at-arms who sat below the salt. To manage these separate approaches by means of two "London staircases" would have meant a waste of room even more fatal than our own modern cramped arrangements. The problem was first solved, I imagine, by providing a shaft in the thickness of the wall from one floor to another, the entrances of which opened in the corner of each room. But it would be impossible to drop a man down this shaft like a parcel, still less to climb up without help; and a ladder, whether of wood or rope, would necessarily be at a dangerously acute angle. So they began by inserting a brick at the bottom of a shaft, just where my piece of string was attached to the base of the cylinder in my first illustration (see fig. 3) of an upward dextral helix; only you must now imagine that the cylinder has become a long hole in a 
solid body, and that into this containing circular body a slab of stone large enough to tread upon has been placed a foot above the floor. Continuing your natural spiral movement to the right, you must then place another stone in position, a foot higher than the other, and further forward-that is to say, further round this internal shaft up which you wish to ascend. Continuing in this way, you will gradually fix your slabs of stone to the inside of the shaft in constantly ascending spiral curves until you reach the top; and with a little practice you will be able so to adjust the angle of the spiral that the end of it exactly reaches the upper doorway. The wall will always be on your right as some support, but there is a dismal cavity on the left hand, and a false step would hurl you headlong through the middle of the brickbristling shaft to the bottom. 'To avoid this, in your next experiment you take rather longer slabs of stone and diminish the danger; but a time arrives when you cannot increase their length, owing to the fact that, though one end is firmly inserted in the wall, the other stretches out into emptiness, and a heavy weight might entirely displace it. This would have been a critical moment for the builder whose shaft was of a large diameter.

When Charles V. of France built the grand staircase of the Louvre (since destroyed), Ray- 
mond du 'Temple found that the Paris quarries of 1365 could not furnish big enough slabs in time, for over six feet in length was what he needed. So a selection of tombstones from the Churchyard of the Innocents was made; and I can conceive no stranger material than this "derangement of epitaphs." Surely the Devil upon Notre Dame must have chuckled; for of what else are made the steps which lead to Hell, even if the paving-stones 'are-on good authority-of a different substance?

But as the first of these primitive connecting shafts was probably quite small, I think the true solution of the whole problem rapidly made its appearance. In the case of a shaft, for instance, of six feet in diameter, if all the slabs of stepping stones projected $3 \mathrm{ft}$. 6 in. from the wall they would overlap. The first case of overlapping may have been an accident; but, at any rate, it was soon found that this method entirely covered up that dangerous hole in the middle which I mentioned; and as soon as this was effected the greatest discovery of all came simultaneously to light. For as the stairway rose, a central column was seen to be rising with it on the left hand of any person ascending the dextral helix of the stairs; and by degrees the masons learned so to cut their stepping-stones that this central column was not only built up by these stones, 
but also in its turn supported them, for they now overlapped both at their ends and at their edges. And now at last the outer wall on the right-hand side fell into its true position of a mere protective shell, while the essential feature of the whole was the central column round which the fan-like steps revolved.'

To explain this first development of the real spiral staircase (instances of which may be found in most lighthouses and in the Tower of London), I reproduce here a drawing by Viollet-le-Duc, which shows one entire revolution of the steps, and also gives the drawing (fig. 39) of a single step which contains its own portion of the central pillar, as will be found to be the case in the example I reproduced (in fig. 21) of the Palazzo Contarini. It will be noticed that the architect has not

1 This explanation of the way a spiral staircase- was evolved has high authority, and is accepted as possible in such valuable text-books as the "Century Dictionary," s.v. "Newel, . . . "in stairs where the steps are merely pinned into the wall by their outer ends, and there is no central pillar, the staircase is said to have an open newel." But it is only right to state here that some modern architects refuse to believe that any workman would pin a step into the outer wall without supporting it by a beam from beneath, and this is quite a probable deduction from the character and methods of modern masonry. I have been dealing, however, with the masons of a far older and more independent period, and I incline to the belief that the explanation given above is correct. 
yet reached the idea of a handrail, and is merely producing the simplest necessity for internal communication without any idea of decorative effect. Some kind of handrail for the left hand soon became necessary, and the first was probably a rope which was firmly attached to an iron ring at the top of the stairway and followed its curves down to the bottom, being kept at ${ }^{B}$ the right height by an occasional staple on the way. By degrees the stone of the central column got worn into a regular groove by the constant pressure of this rope, and it soon became evident that the handrail might become not merely an integral part of the stonework of the staircase
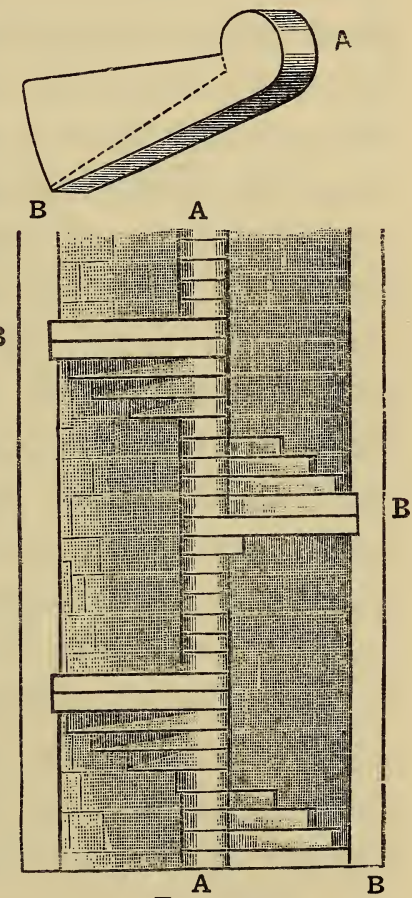

FIG. 39.

Primitive Spiral Staircase, with plan of one step.

but a very definite addition to the beauty of its decoration. Such spiral staircases were known to the Romans, who left the rough screws they filed out among the ashes of Pompeii, though they had not advanced sufficiently in mechanics to be able to make a nut that would actually 
correspond. But the conditions of mediæval life made spiral staircases peculiarly valuable to the feudal architect, for doors could open into them at any height in their spiral upward course ; they were easily lighted, and, at first, of simple and rapid construction, which could be easily repaired. They could be held by a few men against a hundred foes ; they joined the very top of the building with the very bottom, and the slope of their ascent could be made gentle or steep at will.

We have, of course, long ago rejected such useful and beautiful possibilities in London houses, which are as narrow and lofty as a feudal keep, perhaps because we could not easily get our furniture and other cumbrous living-apparatus up and down a spiral; yet, with these methods, it would be possible to construct two interior spirals where there is now scarce room for one narrow stairway and a set of useless landings. The danger of fire would certainly be reduced if one of these spirals were constructed of uninflammable materials, or even built outside the main walls of the building. At Hertford College, Oxford, the architect seems to have remembered a sixteenth-century model, but to have been unable to find workmen capable of carrying out a sixteenth-century design. At any rate, the result is a somewhat inelegant 
compromise between the old and new. One of the largest "Newel-Staircases" in the United Kingdom is at Fyvie, in Scotland.

It is strange that the daily use of this beautiful form of staircase is almost entirely restricted (in the British Islands) to lighthouse keepers; for it is only found in towers, and dwellers in the Martello Towers along the coast are rare. The Border "Peels" were built only for defence, as were probably Dacre Castle, in Cumberland, or Belsay, in Northumberland. In Ireland the form survived much later. In the old part of Blarney Castle, the stone used does not contain the full circle shown at "A," in fig 39, but only a half circle, with the result that the columns in the centre of each stair are only semi-cylindrical, and exhibit one flat surface. But a very curious fact I observed, there, is that throughout this old part of Blarney, every staircase without exception is sinistral in form, which shows that Cormack $\mathbf{M}^{\prime}$ Carthy, the Strong, fully appreciated the advantages involved in having his own right hand free to attack an ascending foe who would only be able to use his left hand in defence. There is a spiral staircase in the stronghold of the Black Douglas, Tantallon Castle, near North Berwick, and this also is sinistral, which may be for the same military reason as that suggested at Blarney. 
As the country became more settled, the tower which was first used simply for safety, was gradually built for pleasure too, as was Nunney Castle, in Somersetshire, or Friston Tower, near Ipswich, or Middleton Tower, near Lynn in Norfolk, which is of brick, and still ( $\mathbf{I}$ believe) inhabited. But by far the most interesting structure of the kind, also of brick, which I have heard of in this country is Tattershall Castle, in Lincolnshire, which was designed by no less a person than William of Waynflete, Bishop of Winchester, ${ }^{1}$ for Ralph, Lord Cromwell, Lord Treasurer of England from 1433 to 1443, who built a stately house for himself in his own country, just as Chenonceaux or Azay le Rideau were built by Financier - Generals of France. Apparently his family had no connection with the ancestors of Thomas, "malleus monachorum," or of the still more famous Oliver, both of the same name. Many of the fireplaces in the present House of Commons were modelled after the magnificent specimens at Tattershall, but the feature of the place which I now wish to emphasize is the grand staircase of one hundred and seventy-five steps, which is in the South East Turret, and givescommunication

1 See the Note on Tattershall Castle by Dr E. Mansel Sympson, in "Lincolnshire Notes and Queries," for April 1900. 
to forty-eight separate apartments, four of which are very large. Its stone handrail, sunk into the brickwork, and beautifully moulded to afford a firm hand-grasp, is original in conception, and probably unique in design. This is the only staircase in a building eighty-seven feet long, sixty-nine feet wide, and one hundred and twelve feet high, which is almost entirely constructed of small and brilliantly coloured bricks from Flanders, or, as some think, from Holland. The curve of this splendid staircase is of the rare sinistral formation, and is contained within a shaft twenty-two feet in diameter, built of enormously thick walls.

It was soon found that spiral staircases could not only be built into the interior of a house, as in the example at Blois already quoted (fig. 28), but that there was a distinct gain both in freedom of access and in methods of lighting when the whole staircase was placed outside the walls, which thus secured an admirable additional adornment, as is the case in the "Escalier à jour" of the newer wing of Francis I. at the same château (fig. 58). By the time this idea was realised, the architect had made a very distinct advance, and the mason who built for him had attained a skill which is completely lost in his profession nowadays. The delicacy of measurement implied, for instance, in the single stone and in 
the completed spiral of the next stairway I reproduce from Viollet-le-Duc (see fig. 40), can scarcely be appreciated by any one who has not endeavoured to do what is here

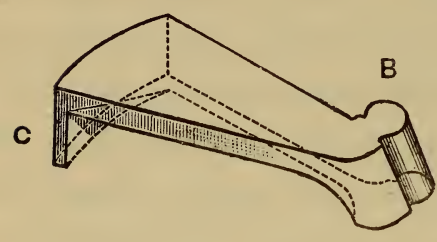
accomplished. For it will be observed that each step is light yet strong, and carries with it not only the central spiral but the handrail

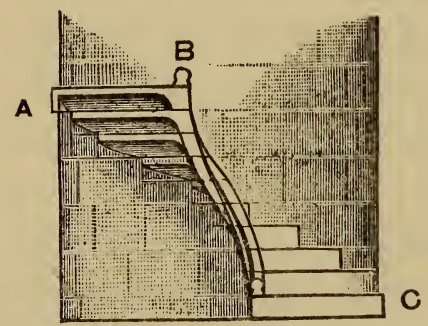
as well, while the construction is so artfully managed that the solid central column becomes lighter and stronger as a hollow cylinder, and, though every step is firmly balanced in its place, yet a stone dropped from the top of this staircase would fall to

FIG. 40.

Elaborate Spiral Staircase, with plan of improved stonework.

the bottom without touching anything.

The beautiful possibilities of this method of construction were in fact soon discovered, and, as is so often the case in other matters, men went to extremes of geometrical enthusiasm which would be the despair of modern workmen. This may partly be explained by the 



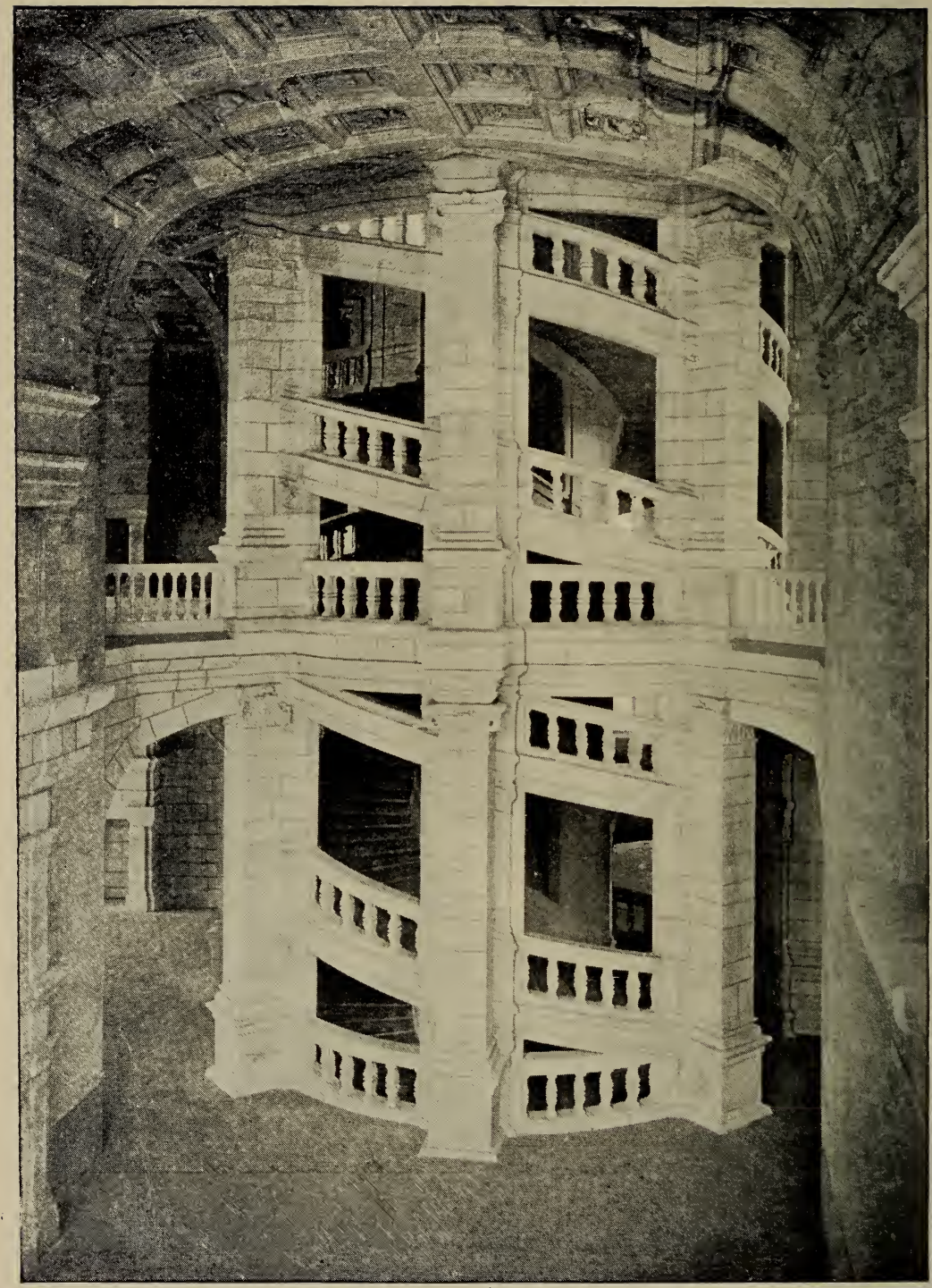

FIG. 41.

Two floors of the Chatteau of Chambord, showing the interlacing Spirals of the Double Staircase.

[To face page 143. 
fact that life in a feudal castle must have been very dull at best, and a tricky staircase like the one just mentioned may have been a godsend. Not enough of them are still in existence for me to give as many examples as I should like; but at Chambord, in Touraine, there is still a tour de force in the way of spiral staircases which would be very difficult to beat (see fig. 41). It contains two spirals, one within the other, so arranged that a man may ascend from the bottom, while the lady is tripping downwards from the top; yet they will never meet or see each other, though their steps and voices are perfectly audible. The thing is a delight to generations and armies of tourists at the present day, and the pleasure it gave the courtiers of Francis I. in that Gargantuan Abbey of Thelema, in which he combined fortress, hunting-seat, and pleasure-palace, after the dark days of Madrid, may better be described in the pleasant tales of a Brantôme or the picturesque exaggerations of a Rabelais. It is not my present purpose to go more into detail concerning such jeux d'esprit, for $\mathbf{I}$ am in search rather of the beautiful in construction than of the merely bizcorre; but they serve to show some of the possibilities of a spiral, and of the attractions which it exerted upon a constructively imaginative mind. In the parallel which I am 
seeking between the lines of architectural construction and the lines of Nature's workmanship, the central column of a spiral stair-

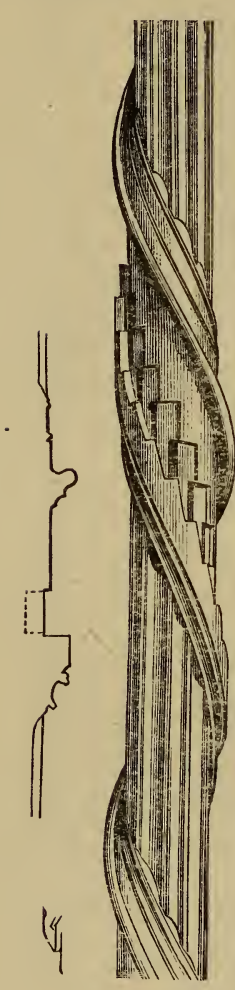

FIG. 42.

case is an integral factor, and in the older Blois staircase (fig. 28) you will observe that the decoration of this central pillar, and the carving of the single spiral line that forms its handrail, have already reached a degree of beauty which enhances the exquisite masonry of the curved flight of steps; and the colonnettes carved upon its surface give just the same pleasing contrast that we noticed in the "Prentice's Pillar" (fig. 4). This style of decoration was in use earlier still in the fifteenth century, and, in the last illustration I shall borrow from Violletle-Duc, the wooden shaft of the now vanished Collège de Central Wooden Montaigu in Paris provides an Shaft of the Stair- excellent example, not merely
case in the College de Montaigu.

of this kind of pillar, but of the rare sinistral helix (see fig. 42). It is worth observing, however, at this stage of our inquiry, that while it was easier and more natural for a right-handed architect to draw plans for a 
staircase with a right-handed spiral, this "leiotropic" formation is not invariably better; for a man ascending it and turning perpetually to the left (see fig. 28) would always have his right hand free to attack the defenders, and the garrison coming down would expose their left hands on the outside. A left-handed spiral will fit into any place where a righthanded. spiral will go as a staircase, because a door can be pierced at any point in its course, and I think it is therefore probable that righthanded spirals are more common in staircases because architects are usually right-handed, and "build up" more naturally in that formation, not because such spirals are structurally more convenient.

Evolved architecturally somewhat after the fashion I have roughly sketched, was the staircase (fig. 28) already long in use at Blois in that older wing of Louis XII., which Leonardo da Vinci saw when he first visited the château. I have now to try and imagine with what thoughts he saw it, and what effects it may have had upon his busy and speculative mind at the moment when the various problems were just being considered of that new wing in the castle for which Francis I. had ordered plans and drawings to be submitted. 


\section{CHAPTER IX}

\section{THE EXIIE}

"There are two Books from which I collect my Divinity; besides that written one of God, another of His servant Nature, that universal and publick Manuscript, that lies expans'd unto the Eyes of all : those that never saw Him in the one, have discovered Him in the other."

-Sir Thomas Browne.

W'TH the circumstances of Leonardo's sojourn in France I must not concern myself too much, but something must be said. Within the shadow of the lime-trees on the terraced garden of Amboise (some 30 kilomètres down the Loire from Blois) there is set a bust of the great Italian, and an epitaph upon the tombstone near at hand painfully records that underneath it are ashes "amongst which are supposed to be the remains of Leonardo da Vinci." It was at Amboise, at any rate, that he died on May 2, 1519; and the myth of those last moments in the arms of his royal patron at Fontainebleau becomes as shadowy and unreal as the artistic reputation of 146 

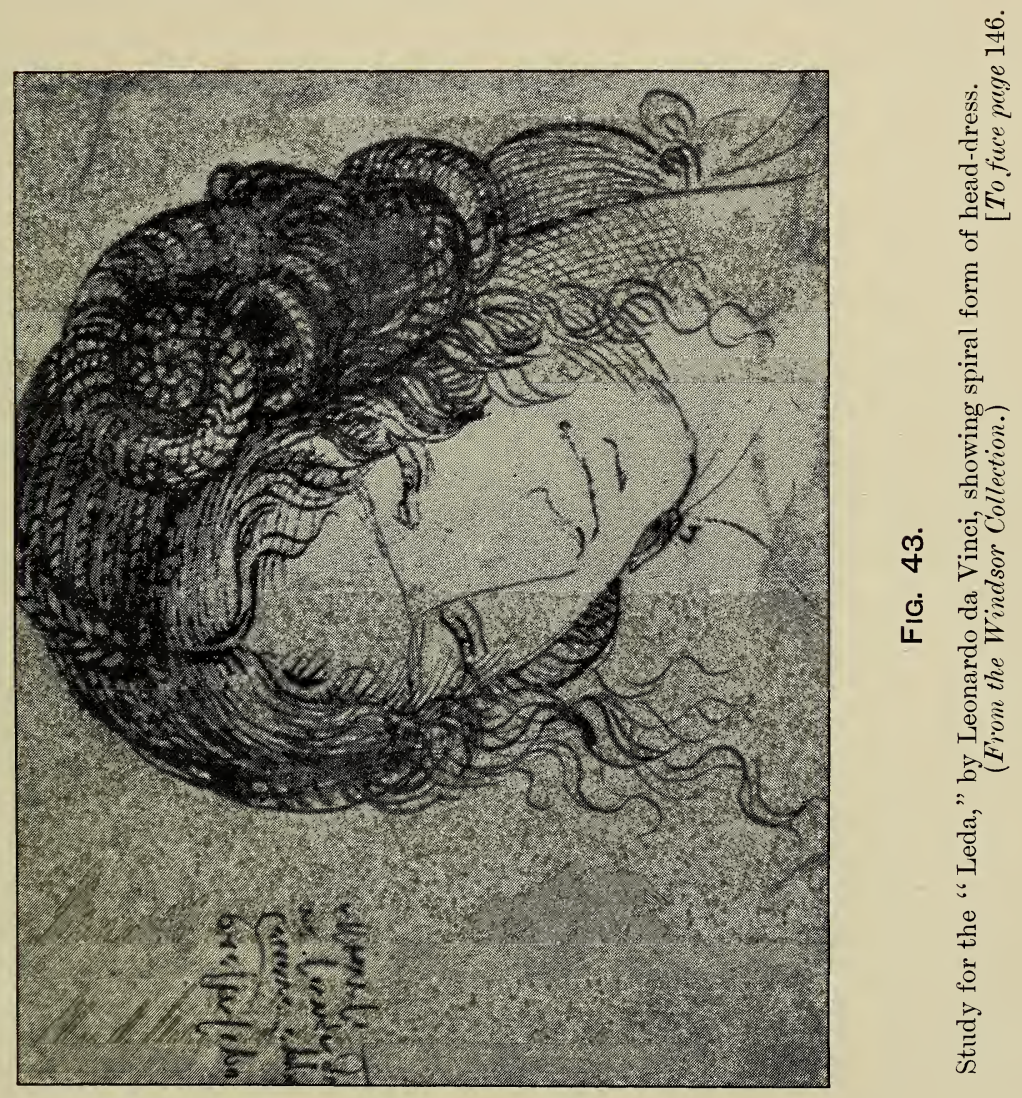

Francis I., a reputation which I have always thought to be much exaggerated. That miscellaneous grave is not calculated to increase it.

Leonardo had certainly lived in the Loire valley some time before June 1518, as a letter from him exists of that date written at Amboise; and he may well have reached there in the year before; for it was in $\mathbf{1 5 1 6}$ that he crossed the Alps at the request of Francis I., in order to live at the manor house of Cloux. If he had taken more thought of contemporary happenings, he might perhaps have remembered that the Loire valley was already full of sinister recollections of two great Italians whom he had formerly served-Ludovico Sforza, called Il Moro, and Cæsar Borgia. After taking Bayard prisoner at Milan, only to set him free again, Ludovico had been betrayed to La Trémouille by his Swiss mercenaries, and was sent to the dungeons of Loches, where he languished for nine years in a sunless subterranean cavern before he died. The pitiful frescoes and inscriptions left by Il Moro in his cell by the banks of the Indre were still fresh when Leonardo first saw the great towers of Amboise across the I Loire, which are shown in my frontispiece. At Blois, on the same stream, at Chinon on the Vienne, the 
memories of Cæsar Borgia were scarcely less vivid; for it was at Blois that Cæsar, who was created Duc de Valentinois as a reward for the Papal consent to Louis XII.'s divorce which he had brought to Chinon, had been himself married to Charlotte d'Albret. The French king made his triumphal entry into Milan with his new ally in October 1499, and saw there for the first time the fresco of The Last Supper, and the statue of Francesco Sforza. By 1501, their artist had been compelled to leave Milan, owing to the catastrophe of Il Moro, and was military engineer to Cæsar Borgia. But the career of that extraordinary adventurer was not entirely suitable to prolonged artistic patronage, and when Francis I. was in his turn making a triumphal entry into distracted Milan, in October 1515, after the Victory of Marignano, Leonardo was again there to hear another French king's praises, and by December of that same year he was preparing, with Francesco Melzi, to follow a new patron to an unknown country in the last years of his life.

His little manor, close to the castle and town, is now called Clos-Lucé, and has hardly been changed since it was built by Etienne de Loup, steward of Louis XI. It has never sheltered so many famous visitors as when the 
great Italian lived there, and in it he probably painted the St John the Baptist of the Louvre Collection, besides making plans for a canal, with locks, at the confluence of the Sauldre and the Morantin. ${ }^{1}$ It is probable, too, that his hydrographic map of the Loire and its affluents, now in the Codice Atlantico of the Ambrosian Library at Milan, was made during this same sojourn at Cloux, of which so few facts have been recorded.

His will was made in April 1519, though the written date is $1518 . \mathrm{He}$ made his pupil and faithful comrade, Francesco Melzi, his sole executor, left him all his priceless memoranda, of which I have printed a specimen page in fig. 48, and expressed the desire to be buried in the Church of the Royal Chapter of S. Florentin at Amboise. There he was laid to rest, in the next month, in the cloister, as is known from his burial certificate. The church was destroyed in 1808, and the skull found on its site by M. Arsène Houssaye cannot, it may be feared, be acknowledged as an authentic relic; though the two stones found in 1863 by M. Houssaye at Cloux, marked "LEO ... INC ..." seem a more likely

${ }^{1} \mathrm{He}$ also suggested connecting the Loire by an immense canal with the Saône at Macon, in order to open up a new route for commerce between the north and south of Europe. 
indication of the great artist's actual presence. King Francis I. was at St Germain-en-Laye at the date of Leonardo's death, and does not seem to have taken any notice of the occurrence. Descendants of Leonardo's father ${ }^{1}$ are still alive, and the successors of Maître Boreau, the Amboise Notary who drew up his will, were carrying on the business there till 1885.

The certificate of Leonardo's burial shows that he had been engaged not as the king's painter only, but as "premier peintre et ingénieur et architecte du Roy, mechanischien d'estat." His genius was of so universal a quality that I feel no necessity for proving over again that he had turned his attention, among many other studies, to those of architecture. The researches of J. P. Richter produce more than sufficient evidence of this, though no building has come down to us which has yet been recognised and agreed to have been built by him. "In peace-time,"

${ }^{1}$ In Gaye's "Carteggio Inedito d'Artisti" (quoted by E. M'Curdy), the date of Leonardo's birth is proved to have been 1452 in a list of the household of his grandfather, Antonio da Vinci, made for taxing purposes in 1457, which records "Leonardo, son of the above-mentioned Ser Piero, illegitimate, son of him and of Caterina, now the wife of Accatabriga di Piero del Vacca of Vinci, 5 years." Milanesi accepts this evidence in his edition of Vasari. 
he wrote to the Duke of Milan in 1490, "I shall be of as much service to you as any one in whatever concerns the construction of buildings": about the same time the Vice-General of the Carmelites writes to Isabella d'Este, concerning Leonardo, that "his mathematical studies have so drawn his tastes away from painting that he will scarcely hold a brush," and Sabba da Castiglione says also that "when he should have wholly consecrated himself to painting, in which he would, no doubt, have become another Apelles, he entirely surrendered himself to the study of geometry, architecture, and anatomy"; and it is significant that between 1472 and 1499 we find many important buildings in Lombardy by unknown architects, which are so good that the tradition of collaboration between Leonardo and Bramante may well be true. At Pavia Cathedral, and in the church of Santa Maria delle Grazie at Milan, this tradition was so strong that the corroboration of it lately found in Leonardo's manuscripts, preserved in Milan, was only to be expected.

By Baron Henry de Geymüller all the known architectural studies and writings of Leonardo have been collected, and among them may be pointed out his design for draining "Romolontino" (the Romorantin of Francis I.) and his sketches for a new royal 
residence at Amboise, "with a moat 40 braccia wide, and to the right of the castle a large basin for jousting in boats."

Already the best minds of his day had tried to grasp the problems of a proportion in architecture which should reflect the laws of construction and growth exemplified throughout organic life in Nature. Leonardo took up that inquiry in his usual original and thorough manner, and the investigations embodied in my former chapters were all suggested by materials in his manuscripts. He has left sketches of columns with archivolts shaped liked twisted cords, copied from interlacing branches. He has left drawings of flowers, such as Eglantine, or Cyclamen, of a delicate tenderness (see fig. 48), that is only surpassed by the loving accuracy with which he analyses and depicts the growth and structure of trees or of mountains; accumulating this infinity of observation not for its own sake merely, but in order to combine, and to create afresh; to invent with knowledge, and to design without disorder.

He studied deeply the strength and resistingpower of various materials, and was the first to produce an exhaustive theory of the fissures in walls. In fig. 44 I reproduce a careful study of the spiral forms of smoke and dust caused by the ruin of a building. He wrote much upon the 


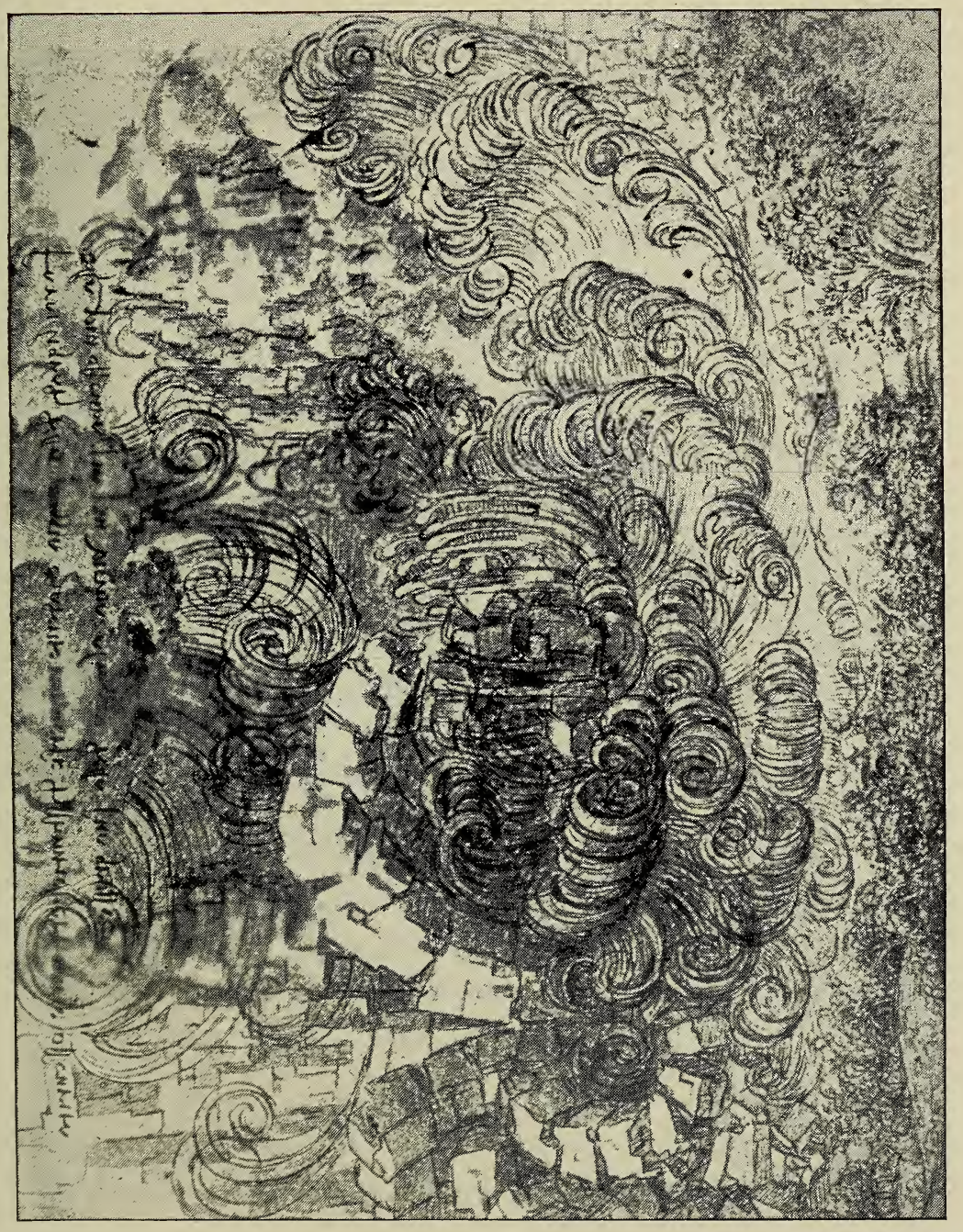

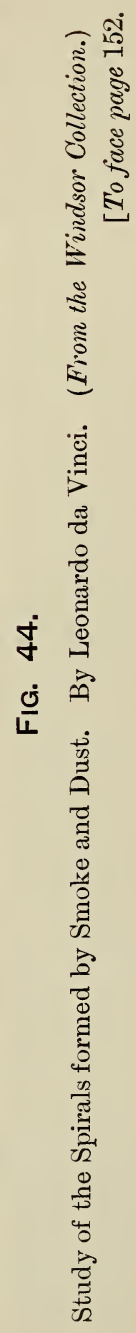



nature of the arch, and the results of pressure upon it. There was no problem of construction that came within his ken which he did not grapple and attempt to solve. The traffic in a crowded city was a difficulty in Italy long before London had become overgrown. He proposed to solve it with a system of high and low-level streets, such as may be seen to-day at Chester, and as has been suggested in these last months for the new streets near the Strand.

His notes and drawings of anatomy were highly praised by so great an authority as William Hunter, and the downward stroke of a bird's wing, which is supposed to be so new a revelation of the instantaneous camera, was noted independently by Leonardo, as it had been drawn by the quick-sighted Japanese of his own time. He observed, too, that as the tips of a bird's wings in flight go up and down as well as onwards, they make a spiral in the air (fig. 45) which is adapted to the strength of wind-resistance it has to encounter ; and he made use of this observation in his theory of flying machines. But in this figure it should be observed that if the straight line between $a$ and $p$ is the direction of the body of the bird in flight, its wing-tips would be approximately on a cylinder whose axis was ap and radius the length of a wing; 
so that a more correct description would be that the movement of each wing-tip in flight describes a line of which each portion is a portion of a spiral, though the whole line so described is not a spiral. But his keen observation of a bird's wings has received a much more striking confirmation. His brain was able to infer what no human eye could really see, and when he noted that the spiral formation of a screw was suggested by the movement of a flying bird, it was not till four hundred years afterwards that the truth of the inference could be visibly demonstrated. ${ }^{1}$ But in Pearson's Magazine for May 1902, on page 506, appeared one of Professor Marey's photographs of a flying pigeon. I have reproduced it in fig. 46, and the astonishing accuracy of Leonardo's eyesight and observation may easily be verified by a consideration of the results produced by an instantaneous camera. The prophecy he made so confidently still awaits its fulfilment, but he did much to render that fulfilment possible. "Pigliera il primo volo," he cried, "il grande ucello sopra del dosso del suo magno Cecero, empiendo l'universo del stupore, empiendo di sua fama tutte le scritture, e gloria eterna al nido dove nacque." His Essay on Flight is throughout of the

1 Compare M. Vial de Saint-Bel's argument concerning a galloping horse and its confirmation, on page 128. 


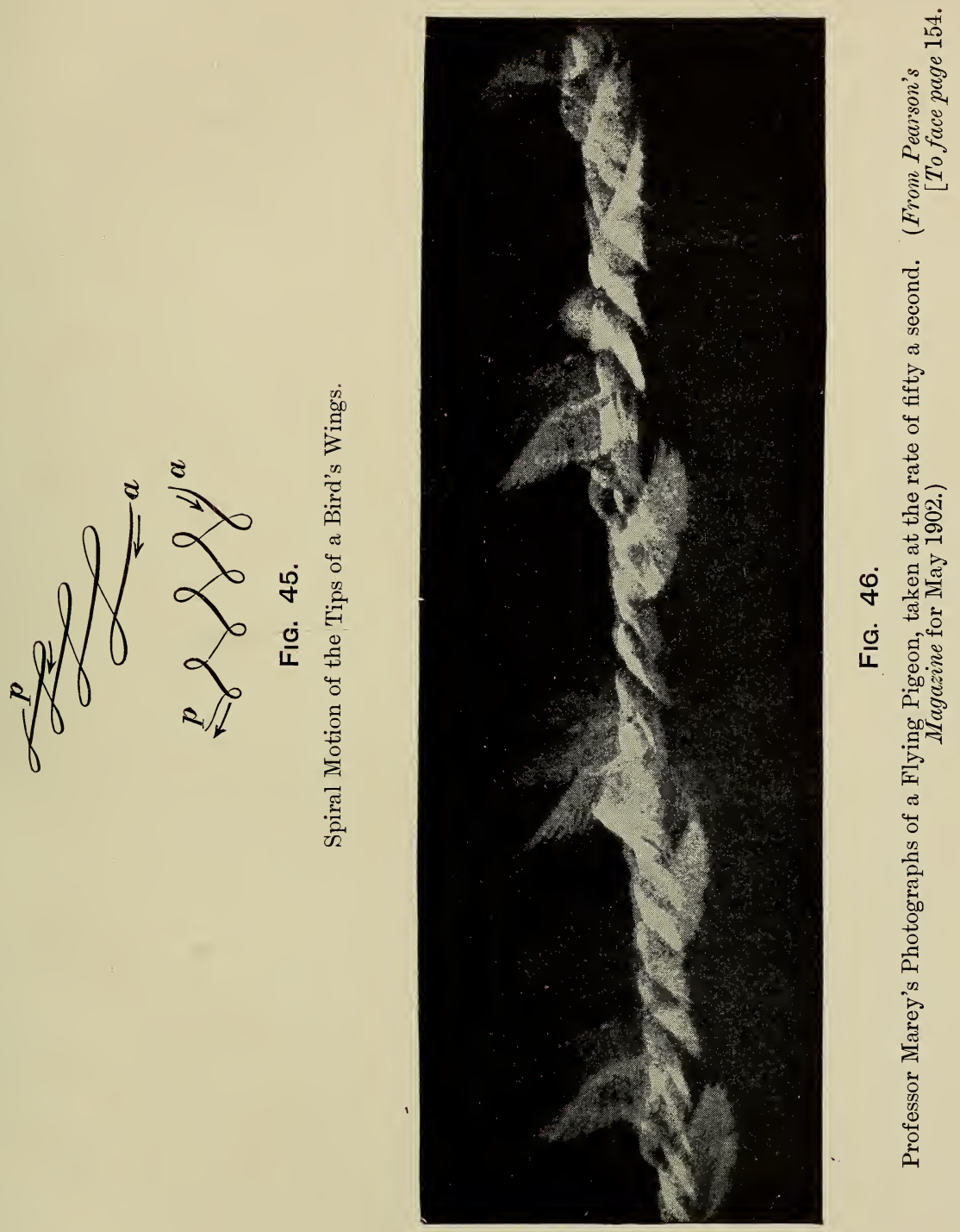





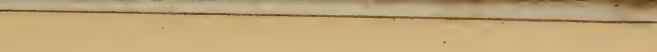




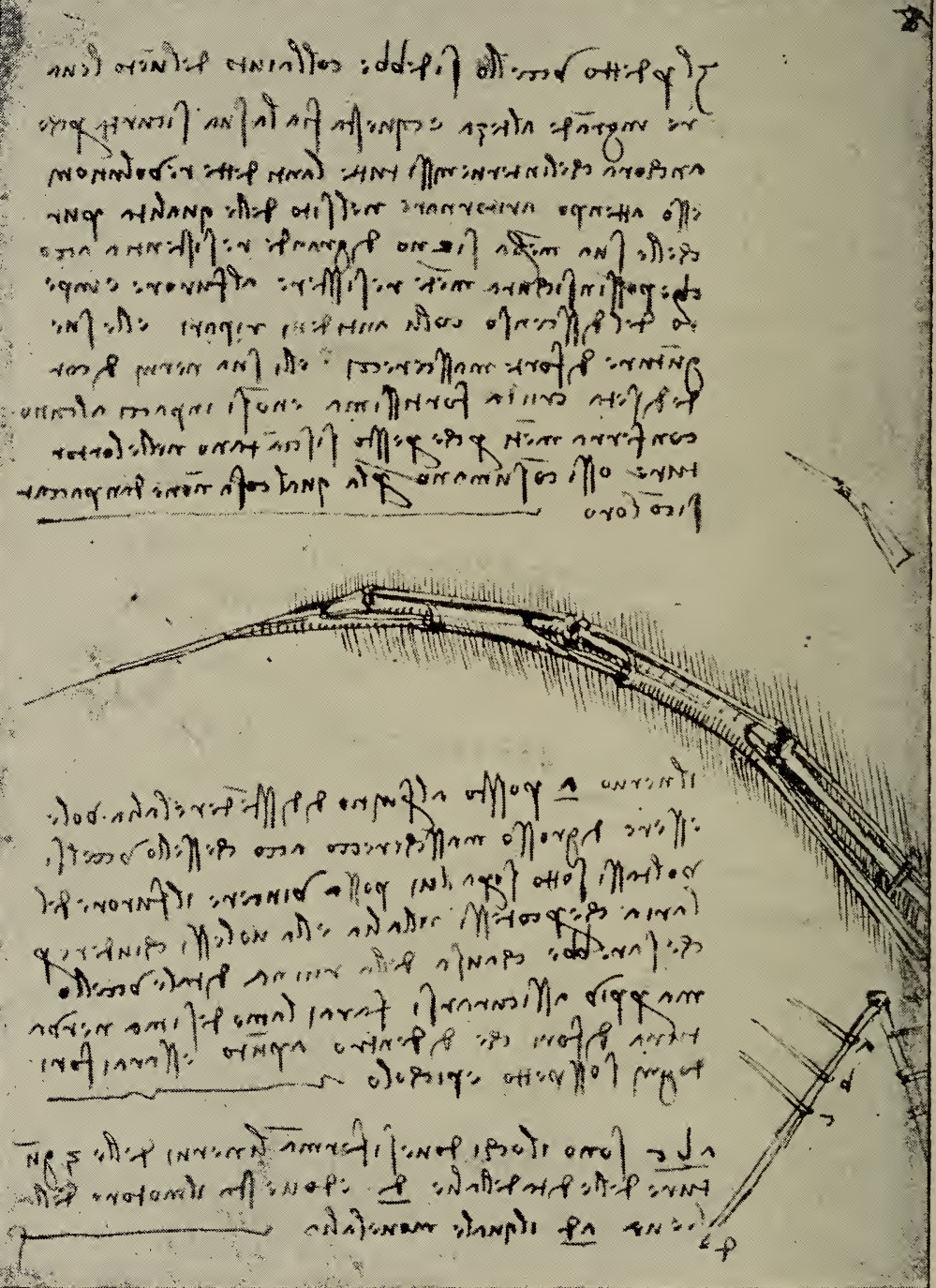

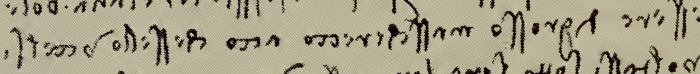

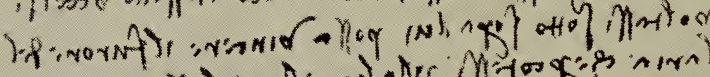

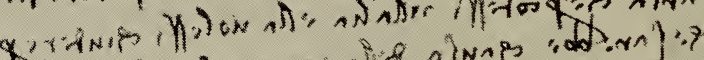

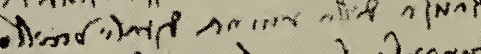

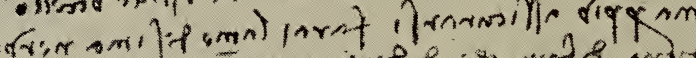

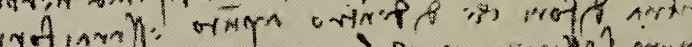

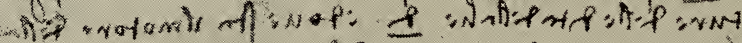
Aे)

FIG. 47.

A Page of Leonardo's Handwriting. (From Leonardo's 'Manuscript Note-book on the Flight of Birds.') 
Il predetto uccello sidebbe coll' aiuto del vento leva-re ingrande alteza, e cquesta sia la sua sicurtà ; perchè anchora che l'intervenissi tutte l'anti dette revoluzioni, esso à tenpo a ritornare nel sito dell' equalità pur-chè le sua membra sieno di grande resistenzia, accò che possin sicura mente resistere al furore e impe-to del discenso, colli anti detti ripari, e le sue giunture di forte mascherecci, e li sua nervi di corde di seta cruda fortissima; e non si inpacci alcono con ferramenti, perchè presto si schiantano nelle lor tor-ture, o si consumano, per la qual cosa non è da'npacciar-si con loro.

The bird above mentioned should, with the help of the wind, raise itself to a great height, and this will be its safety; because, although all the revolutions mentioned may happen, there is time for it to recover its equilibrium, provided its various parts are capable of strong resistance so that they may safely withstand the fury and impetus of the descent, being provided with the safeguards mentioned, with their ligaments of strong tanned leather, and their tendons of very strong raw silk; and no one need trouble to use iron joints, because they split under the strain of a twist, or wear out, so that there is no need to trouble about making them. I'ranslation by Charles Ravaisson Mollien. [To face page 155. 

highest interest, and I gladly acknowledge the debt which every reader will owe to the public spirit of its owner and preserver, Mr Theodore Sabachnikoff. The page I reproduce (fig. 47) will serve at once to show the nature of Leonardo's notes and handwriting, and to indicate the kind of material he left behind him. ${ }^{1}$

In the Windsor Collection of his drawings there are careful studies of flowers, of grass and reeds, showing the various spiral forma-

1 The Notebook on the "Flight of Birds" was written by Leonardo da Vinci at Florence in March and April 1505, and left by him in 1519 to Francesco Melzi, who died in 1570. From Melzi's Villa of Vaprio it was stolen by Lelio Gavardi, and finally given by Horace Melzi to Ambrosio Mazzenta of Milan. From him it passed to Pompeo Leoni, friend to Philip II. of Spain, and by his heir was sold to Galeazzo Arconati, who gave it, on 21st January 1637, to the Ambrosian Library in Milan, where its existence is recorded by Balthasar Oltrocchi, between 1748 and 1797, and by Bonsignori in 1791. All thirteen MSS. of Leonardo were sent to Paris by Napoleon in 1796, the Codex Atlanticus to the Bibliotheqque Nationale, the twelve others to the Institut de France. In 1815 the Codex Atlanticus went back to Milan, the rest remaining (by error) at the Institut, where the existence of this Treatise on Flight is noted by the Sub-Librarian in 1836. From there it was stolen by Jacques Libri, as Lalannes and Bordier noted in 1848, and was seen in Florence by Count J. Manzoni de Lugo in 1867, who bought it at Libri's death in 1868, and died himself in 1889. In 1892 it was bought by Theodore Sabachnikoff, and published in Paris in 1893. 
tions of their growth (see fig. 48). Water, and the forms of water, and of mountains, seem to have attracted him very strongly, as is suggested in the blue hills and streams which are the background to "La Gioconda." The Windsor Collection is full of extraordinary studies of waves for his representation of the Deluge. The great struggle of one element against another did not appeal to him merely as a Biblical dream. He examined currents, whirlpools, and ripples, until he had a host of actual facts with which to work; of true observations from which to create his vision; of laws and principles by which to guide his imagination. In fig. $49 a$ and $b$ I have reproduced two examples of the careful way in which he studied the spiral formations of water. It was for the gardens at the château of Blois that he made sketches of further improvements for the conduit, with its syphon discharging into the Loire, which was built in 1505 by Fra Giocondo, the Veronese architect. Among his drawings are studies of the curves of waves, ${ }^{1}$

1 "The waves of light and sound," said the Italian, "are governed by the same mechanical law as that governing waves of water." Though the study of waves of light, or sound, or nervous transmission, have yielded much more than Leonardo dreamt to modern research, I know of no one who has specialised so fruitfully upon the study of waves as $\mathrm{Mr}$ Vaughan Cornish, whose work on "Kumatology" stands practically alone. He is now investigating all waves that 


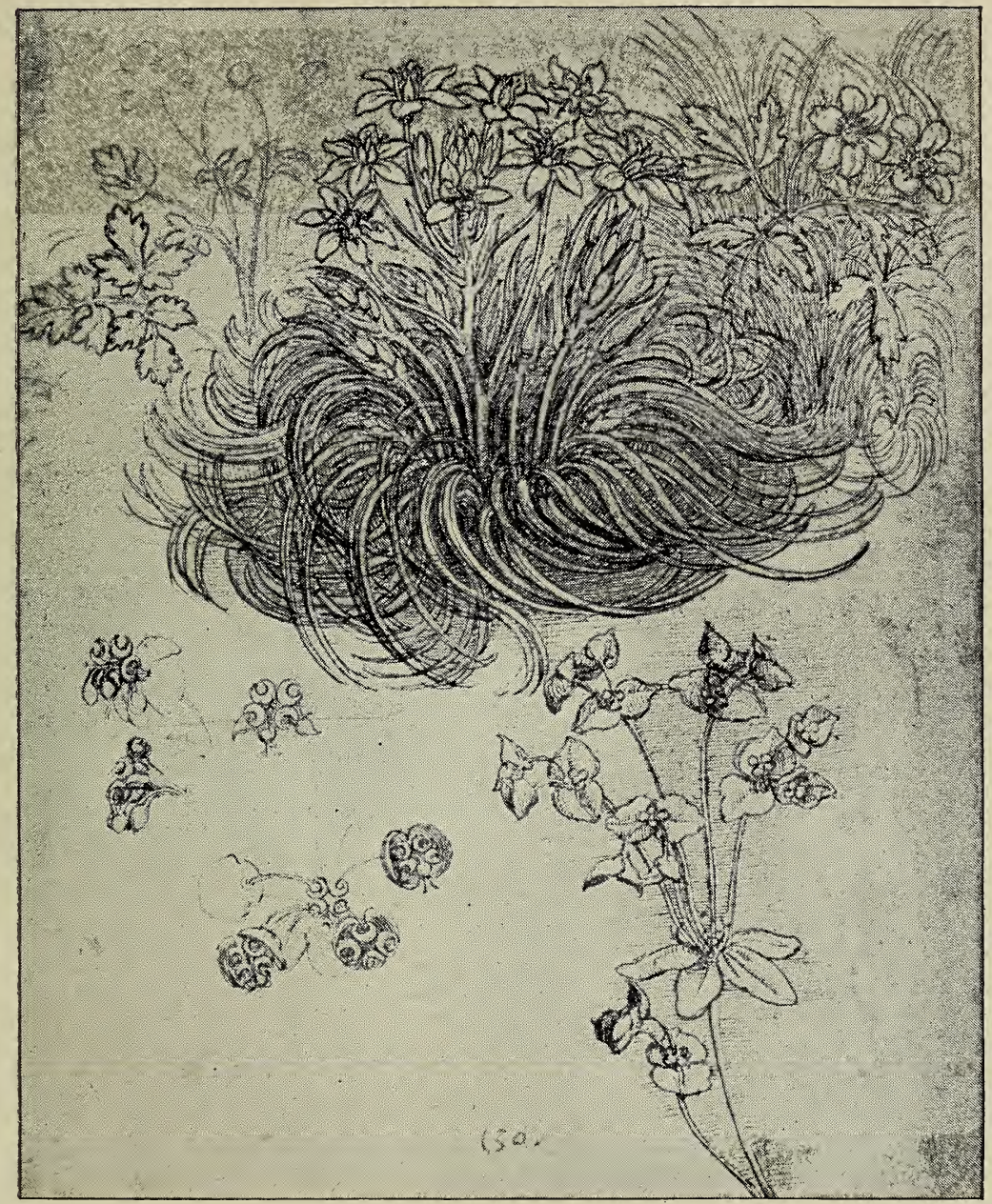

FIG. 48.

Study of the Growth of Flowers. By Leonardo da Vinci. (From the Windsor Collection.) 




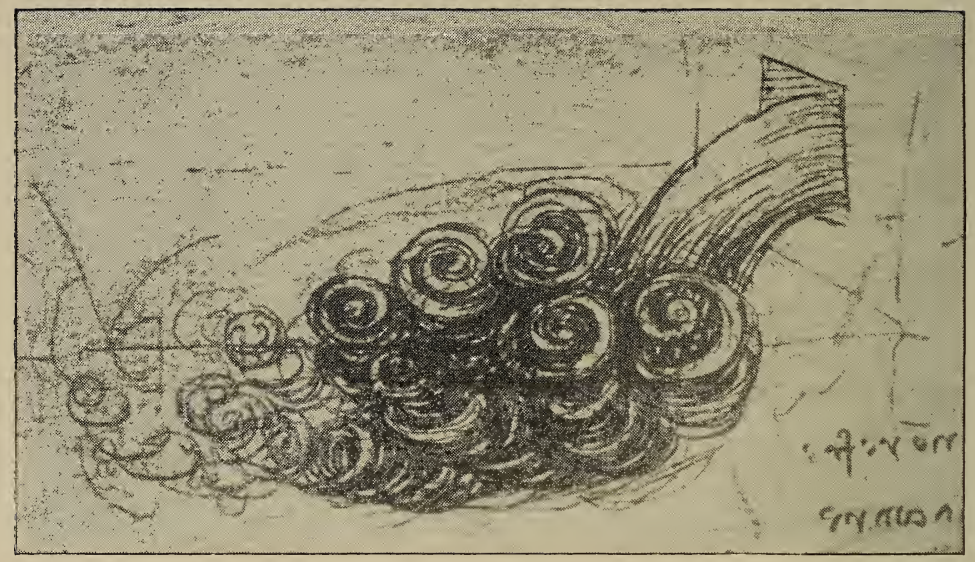

A

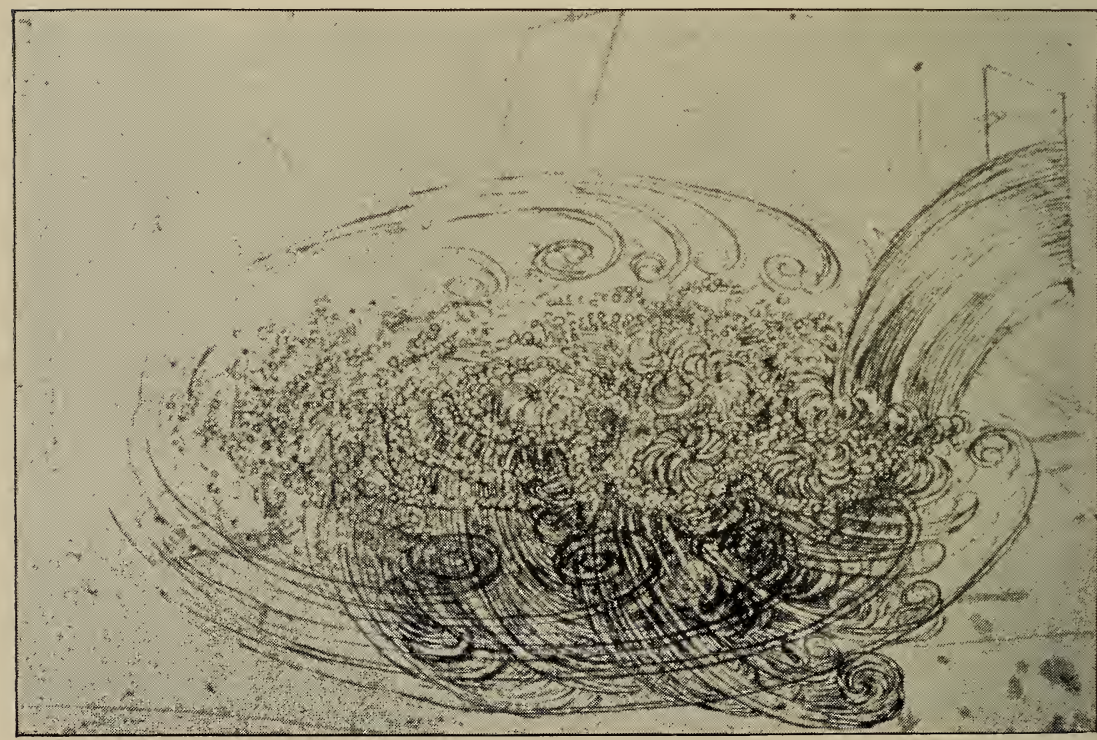

B

FIG. 49.

Study of the Spirals formed in Water. By Leonardo da Vinci. (From the Windsor Collection.)

[To face page 157. 
and of the effects of currents upon the banks of the mainland and of islands. In these studies he foresaw the scientific advance which he had no instruments delicate enough to prove, for he wrote that:- "Le onde sonore e luminose sono governate delle stesse leggi che governano le onde delle acque." The water system of the Cher and Loire he had thoroughly worked out, and recorded in a map which shows the relative position of Tours, Amboise, Blois, Montrichard, and other places in Touraine. In this connection, too, he frequently expresses his admiration of Archimedes, and of that great inventor's famous screw which raised up water by the revolution of a pipe twisted in a dextral helix round a rod.

I have already mentioned his particular interest in shells, and in the study for the head of his "Leda," which I reproduce in fig. 43 at the head of this chapter, it is impossible to avoid the parallel between the twisted coils of the Ammonite he knew (com-

occur at the common surface of two bodies which move relatively to one another, and his field is vast and fruitful, for it contains such various subjects as the sand-dunes of the Nile Delta, the ripple-marks on hills, the ice-folds of glaciers, the waves of snow, of lava, and of air (created, for instance, by a bullet), besides the waves in rivers, lakes, and seas. The results of Mr Cornish's work, beautiful as they are in themselves, will also have a most valuable indirect bearing upon important and practical inventions. 
[CHAP.

pare fig. 36) and the spiral tresses into which the woman's beautiful abundant hair is plaited. ${ }^{1}$

He even investigated the structure of intestines, and it may be noticed that the drawing in fig. 50 of the section of a shark's intestine gives a peculiarly interesting example of a dextral helix, the prime use of which is to ensure that the food passes slowly round and round the tube in order that every atom of nourishment may be extracted. ${ }^{2}$ A very beautiful parallel to this exists in the internal formation of Auricula auris-midae (fig. 52), and still more clearly in that of Turritella lentiginosa (fig. 51), a shell in which you may easily imagine yourself going up that "little tower" on a continuous inclined plane without any steps at all.

It is curious, to say the least of it, that when Leonardo was living at Amboise there existed a staircase built in the great tower by

${ }^{1}$ In another manuscript he compares the spirals of a woman's curls to the circling of a whirlpool.

2 The spirals occurring in intestines and other internal organs are numerous, and will occur to every biologist. A simple instance occurs in the cacum of the rabbit (Lepus cuniculus), one part of which, leading to the vermiform appendix, is wide in calibre, diminishing somewhat towards its termination, thin in its walls, and spirally constructed externally in correspondence with the spiral valve developed internally. 
Charles VIII. on exactly this model, and the great round tower which contained it is shown in Leonardo's drawing of Amboise which forms the frontispiece to this volume. ${ }^{1}$ You might drive a carriage and pair down its sloping

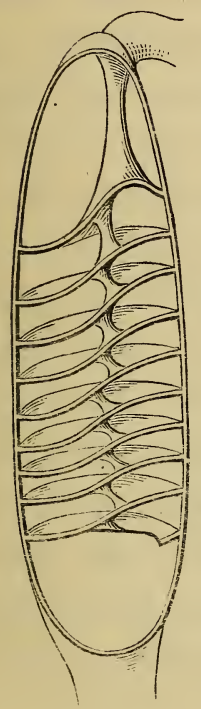

FIG. 50.

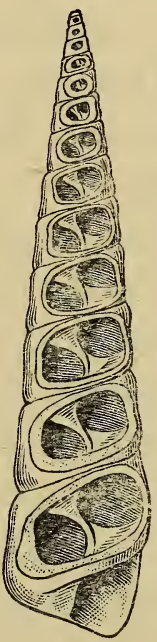

FIG. 51.

Turritella lentiginosa.

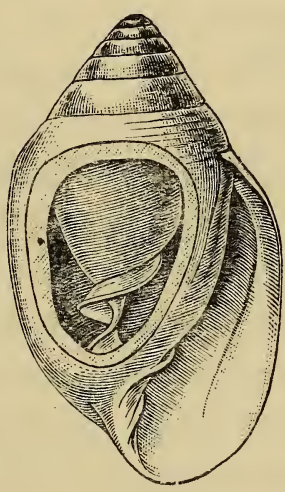

FIG. 52.

Auricula auris-midoe.

Longitudinal Section of Intestine of Raia.

circular curves to-day without meeting a single step in all the distance; and the Emperor Charles V. did, as a matter of fact, ride up it on horseback by torchlight during

${ }^{1}$ A visitor to Amboise would have to hold Leonardo's sketch before a mirror in order to recognise that this tower is drawn in its right place. 
one of his ceremonious visits to his rival Francis I.

After all this, shall I be accused of too much special pleading if I suggest that, to one who had thus investigated the secret principles of construction and of growth, and who was especially attracted by the problems of spiral formation, this inclined plane of the spiral staircase at Amboise, and this single helix of the old stair at Blois, presented a greater attraction than that of merely architectural problems skilfully surmounted? And is it too much to infer that, for one who had so carefully investigated the shells of 'Tuscany, Lombardy, and Piedmont, the comparison of the Amboise building to Turritella, and of the Blois stair to Telescopium, was no impossibility? Those two Italian staircases already mentioned, built by unknown artists in Fiesole and Venice, are both of such a period that, if Leonardo had ever studied a shell in connection with the architectural drawings for either, the names they both bear may well be the popular recognition of his skill in constructive adaptation. It is interesting, too, to find that John Bellini's Allegory of the Shell (p. 51), was painted for the Contarini family, and that their Scala del Bovolo has always been referred by tradition to a French model, which is not 
without a certain suggestiveness as to the investigations of the great Italian exile in that valley of palaces which is Touraine.

In considering the possibility of such studies in parallelism of structure having occupied the leisure of a great designer, it will be only natural to look for the evidences of any practical result towards the end of a life in which busy activity would for the most part postpone such delicate imaginations until increasing years had brought more opportunities of investigation and research. When Leonardo reached Touraine he was nearing the end of a life that had been crowded with creative action. The full fruit of one of the most strenuous and original careers ever known was in the autumn of its ripeness. Many of the problems which that fertile brain attacked have never yet been solved, and if I finally trace to its marvellous inventiveness a creation that no recorded architect has yet been found worthy to claim, it is chiefly because the beauty of that creation of man's handiwork remains unparalleled outside the realm of Nature.

As I approach this last portion of my argument, I must again refer to that series of internal spirals in shells which I mentioned before, beginning with the single line of Telescopium telescopium (fig. 27), or even 
further back with the mere inclined plane of Turritella lentiginosa (fig. 51), and ending in the eight-fold curves of Voluta musica (fig. 33). In that series I wish now especially to emphasize Voluta vespertilio (fig. 53) and the four particularly graceful lines of its dextral helix. But I must also point out the beautiful lines observable in its external shape (fig. 56), which are not quite parallel, yet satisfy the eye completely in their gradual upward ascent. You will notice, too, that the main external walls of the shell are buttressed, as it were, with little outstanding columns which hold up the first of the ascending lines in a manner that would be at once suggestive to an architectural eye.

We have already observed, both at Venice and at Chartres, the strange correspondence between the exterior arrangement of a staircase and the external shape of a shell. At Blois, in the old stairway, we have seen an internal single spiral closely corresponding to the internal single helix of the columella in a shell. I have now to point out an architectural example which combines both these correspondences, and does this although no one who only looked upon the exterior of the "Escalier à jour" at Blois (fig. 58) would dream of what it contained within, any more than a person ignorant of biology who looked 
at the outside of Voluta vespertilio could imagine the existence of the quadruple helix inside it. When it was only the outside, or only the inside of a staircase that suggested the lines of a shell, the evidence may not have been sufficient to argue any connection between the one and the other in the builder's mind. But what if the external plan be the same in both a staircase and a shell, and if the internal spiral of the stair be an exact copy of the columella within the same shell, even to the number of its revolutions round the shaft? And what if, in addition, these arrangements are in each case carefully reversed in every detail ? 


\section{CHAPTER X}

THE SHELL OF LEONARDO

"Majestati Naturæ Par Ingenium"

$\mathrm{A}^{\mathrm{T}}$ Blois there is a staircase built later than 1 the old example shown in fig. 28, built just at a time when Leonardo's presence in Touraine might have enabled him to suggest its plan, built with its external lines corresponding to the outside of a shell, while its internal spiral reproduces the helix on the columella of that shell.

In the known examples of Voluta vespertilio, about one in a million contains a sinistral helix instead of the ordinary dextral curve. I have mentioned an instance where such a rare shell at Travancore was considered to have been a manifestation of the Deity. It is therefore probable not only that travellers would try to select one of this kind to bring home, but also that in the case of shells common on the seaboard of Italy, the chief reason for the presence of one of them in the 



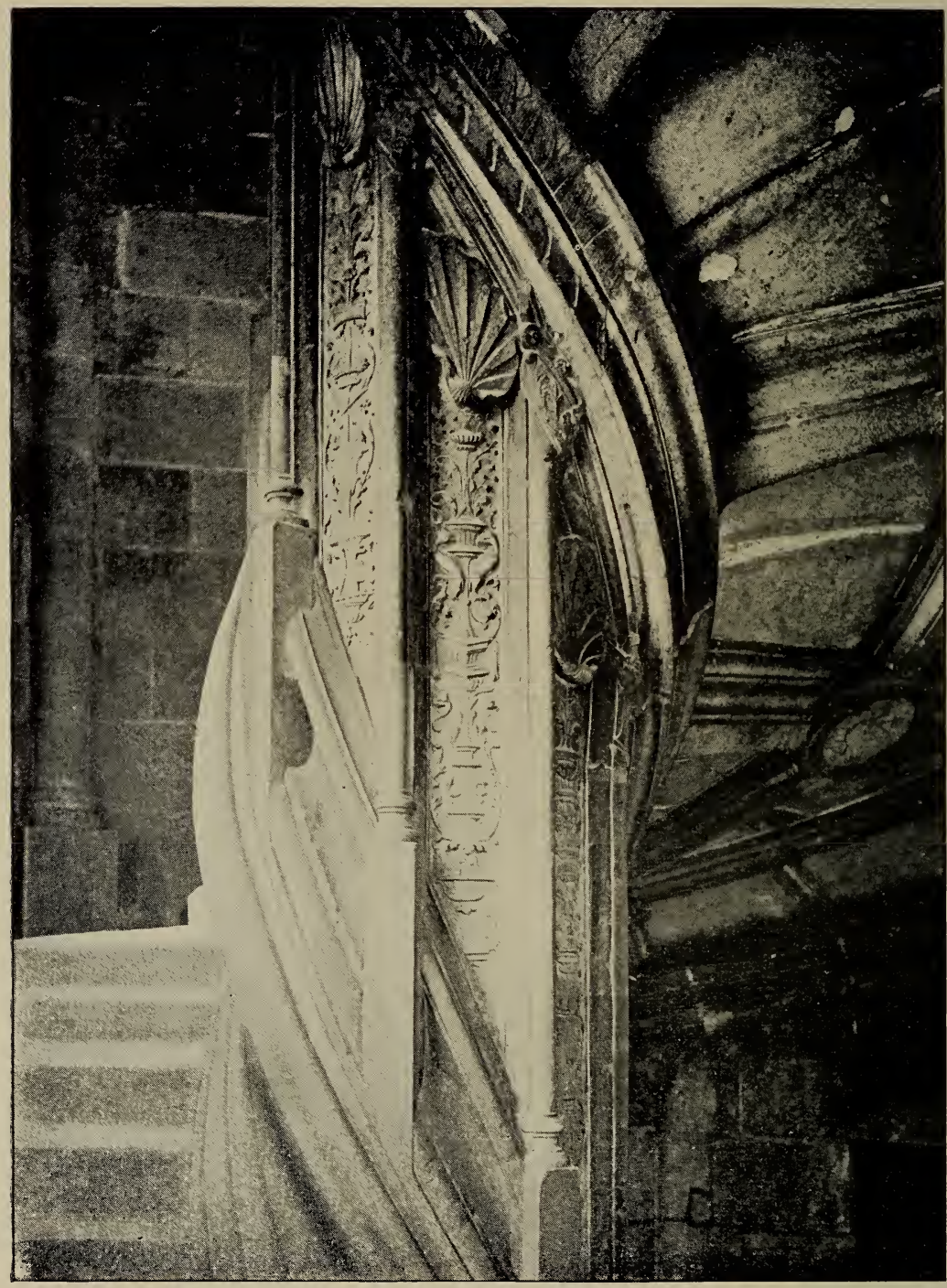

FIG. 55.

Escalier à Jour, Château de Blois, Touraine. The Central Shaft.

[To face page 165. 
cabinet of an Italian collector would be that it was distinguished above its million fellows by the possession of this rare sinistral helix.

Compare the Voluta in figs. 53 and 56 with that shown in figs. 54 and 57, and in the two latter instances you will see that the spirals are reversed, that the "entrance" is on the left instead of on the right, and that the external lines slope down from left to right

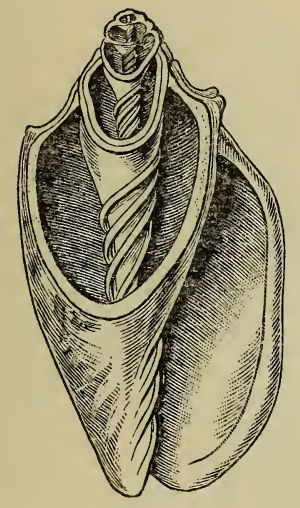

FIG. 53.

The Common Form of Voluta verpertilio (section).

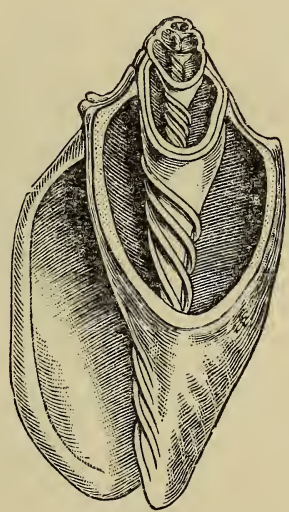

FIG. 54.

Rare Form of Voluta vespertilio (section).

instead of from right to left. Figs. 53 and 56 show the ordinary leiotropic shell with a right-handed spiral. Figs. 54 and 57 show the rare dexiotropic shell with a sinistral or left-handed spiral.

With this exceptional formation in your mind, remembering also that the ordinary 
ascending curve described by a right-handed man is to the right, compare the magnificent spiral within the staircase of the wing of Francis I. at Blois (fig. 55) with the helix in the leiotropic Voluta vespertilio (fig. 53). It is identical in form, even in the fact that it is four times repeated, but it is reversed.

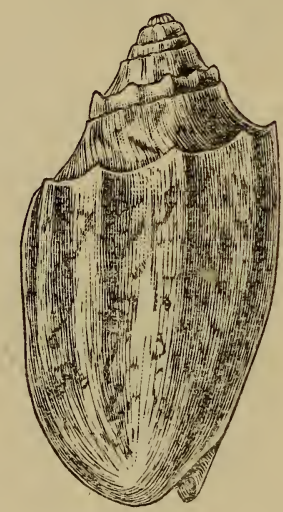

FIG. 56.

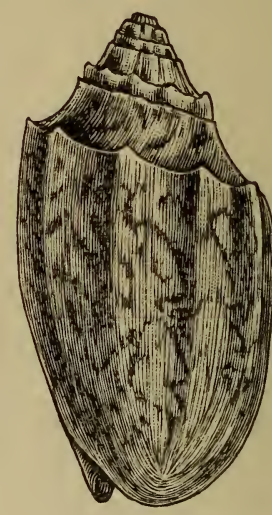

FIG. 57.

Common Form of Voluta vespertilio. Rare Form of Voluta vespertilio.

Then compare the external balustrades (fig. 58) with the lines on the outside of the same shell (fig. 56). They are arranged in the same way; they are similarly supported by slender columns; they show the same charming and curious irregularity, which seems inexplicable apart from their model; but they are reversed. Notice also that any ordinary architect would have made the lines 


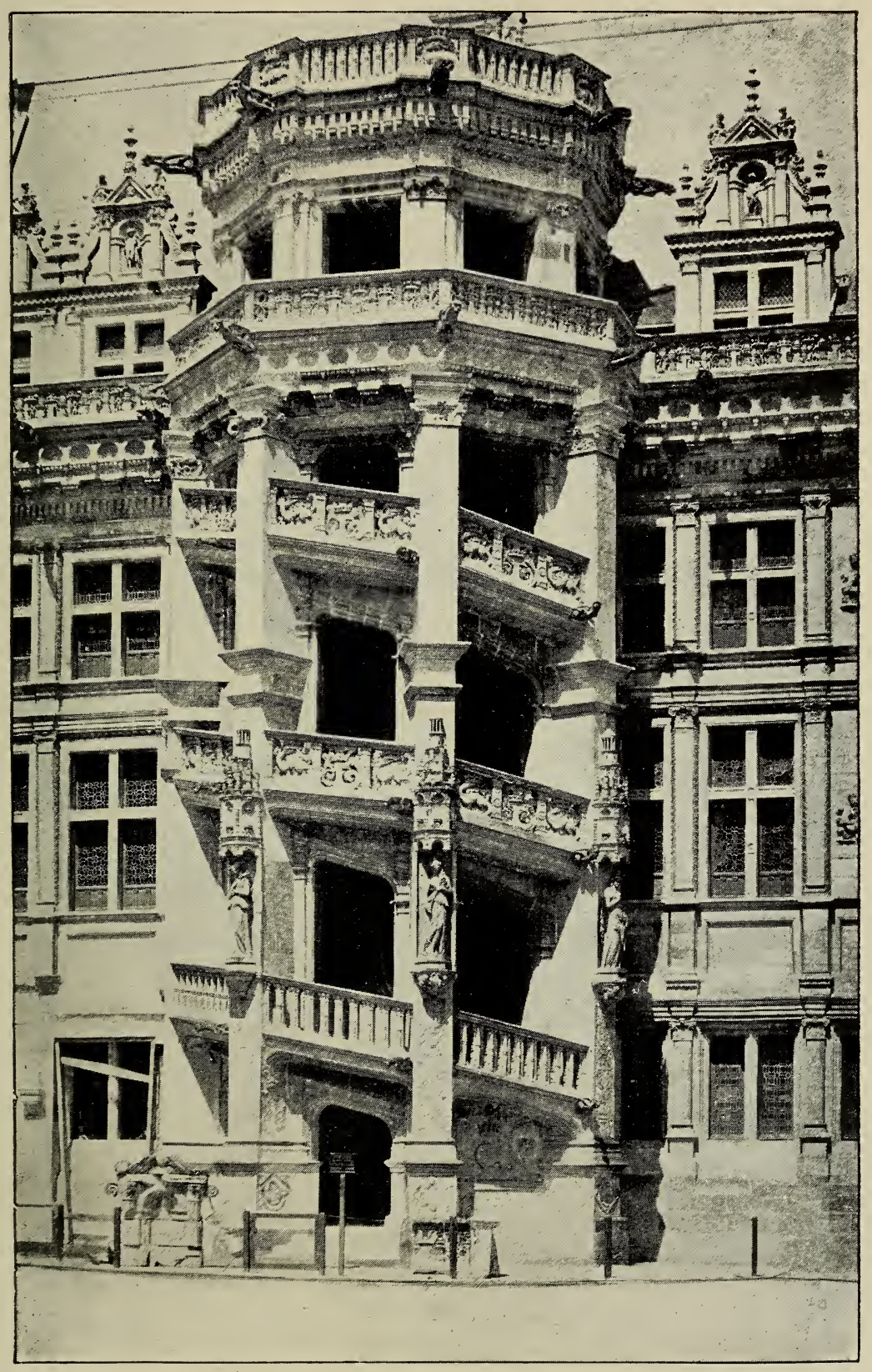

FIG. 58.

Escalier à Jour, Château de Blois, Touraine. The Exterior.

[To face page 166. 

of his external balustrades correspond with the main external lines of the floors in the building to which this open staircase was added, if the designer of the internal stairway had merely wished to build a four-fold spiral round its central column. But the designer of this staircase had not merely a quadruple mathematical line in his mind, he was thinking of a shell; and he was not thinking of Cymbium, a shell which has four plaits on its columella and an exterior quite different to that shown in fig. 56, but of Voluta vespertilio, which hides its quadruple helix behind an arrangement of sloping lines growing above slender columns, exactly as these sloping balustrades are built.

Look finally at the doorway opening to the staircase from outside. It is in the same relative position as the "entrance" of the shell; but it is reversed.

There are therefore no less than four instances of agreement with the common shell, though in any one of these four a trifling difference would not have mattered to the construction. And in all these four instances there is an invariable and exact reversal, although again there might have been trifling variations in plan made by any one who had not got the shell before him.

Can such agreements and such differences 
be chance alone? Can such lines be the result of a merely architectural solution of the problem? Can they be merely one more example of what we have seen already, of the fortuitous correspondence between perfect workmanship and the lines of Nature? Surely they must be a deliberate copy of the natural object they so closely imitate; yet not an ordinary copy, but a copy with the very striking and logical and persistent differences we have just noticed.

This, in fact, must be an example of that greatest art which imitates the greatest models with a difference that reveals the strength and personality of the designer; which discards the trivial and preserves the essential; which loves knowledge much, and is therefore unafraid of novelty; which realises the existence and the value of a studied exception here and there among all ordered things; which can unite design with fact, and originality with truthfulness; which has, in fact, discovered that the beauty of Nature is not to be found in agreement, but in difference.

Such a creation as this might well have been one of the few practical results of that philosophy which was expressed in the words: "Natural things are finite, but man's handiwork is infinite"; a saying which was not likely 
to have been uttered by one who could have permitted many such works to survive him. For this man had realised that in the perfection of Nature there is an end attained, unchanging, because perfect in its kind; but that we are "something better than the birds or bees," and in our best building, as in our best art, the confession of that superiority must always be found. Hence comes that nobler love of change which is the divine unrest of genius, which often leaves so little done behind it, because there is always so much still to do. Some faint suggestion of this feeling is to be found in the expression on the face of "Mona Lisa." Not of any mortal handiwork were the words written, "Behold, it was very good"; for labouring humanity is driven forward through the ages by the constant search for something higher that is ever hidden, yet ever to be revealed.

If then, as I believe, this staircase was copied from a shell, the man who owned the shell and used it so must have been not merely an architect but a master of construction, for the groinwork and vaulting of the stairs (fig. 59) are not the least astounding part of the whole building; and he must have been a decorative artist, too, of the very highest order. Confining your attention for a moment to the inside of the staircase only (fig. 59), you will 
see ample evidence of this in several directions. The stairs wind upwards, folding round that exquisite central shaft as the petals of a flower fold one within the other; and in the very lines of each step itself a strange and beautiful look of life and growth is produced by the double curve on which it is so subtly planned; for these steps are not straight, as in the older staircase of the château, and in most ordinary instances, but are carved into a sudden little wave of outline just where each one springs out from the supporting pillar-from the supporting stalk, as it were, of these delicately encircling leaves. Though I am more concerned with constructive lines than with mere decorative detail, it is impossible also to overlook the set of these colonnettes that move upwards with the rising shaft, and the splendidly sculptural treatment of the shells which are set between the twisted capitals of each (fig. 55). I would draw particular attention to these, because if they were placed here by the man who was inspired to take his original model from a shell, they would be treated very differently from any ornaments subsequently affixed by a lesser artist with a lesser inspiration. And this is, as a matter of fact, exactly what is to be found here. These shells are broadly carved, with light and shadow; not with a mere imitation of exact form, but with 


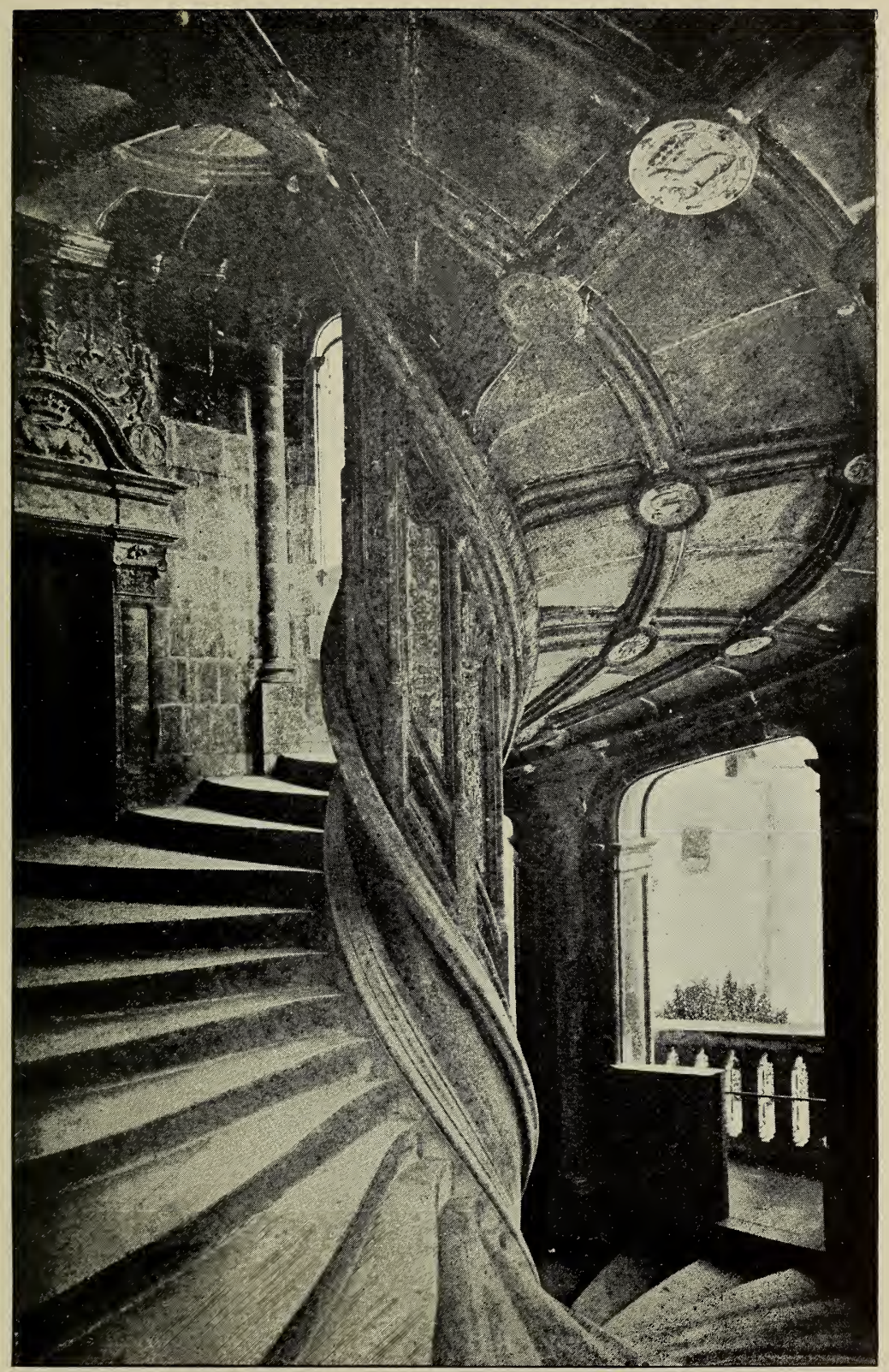

FIG. 59.

Vaulting and steps of Spiral Staircase in the wing of François I., Château de Blois.

[To face page 170. 

a fine feeling for their effect in this exact position. Beneath them are weakly conventional embroideries of later date, that are not merely meaningless, but are cut off at the bottom by the ascending spiral in a way which no one but a sculptor devoid of all structural adaptability could have permitted. They must be additions of about the same date as the statues set upon the exterior some fifteen years after the original structure had been built. They are repeated in the rooms of Catherine de Medici above, and may be seen, in exactly the same setting, on the shaft of the great stairway of Chateaudun, a structure so complicated with archways and landings that the fine righthanded spiral of the central column almost loses its effect.

Yet it is the irresistible, spontaneous, uplifting movement of the whole that remains, after all, the main impression of this marvellous piece of work at Blois. To walk up those steps is to be borne along upon a breath of beauty, and not to feel the clogging feet of human clay at all. Those waving lines rush upwards like a flame blown strongly from beneath; for there is in them a touch of that spell which is elemental; of that same Nature's mystery which curves the tall shaft of the iris upwards from the pool in which it grows, or flings the wave in curving lines 
of foam upon the rocks the rising tide will cover.

He who made all this, and who owned the shell which first suggested it, must have been an architect of powerful originality and an artist of extraordinary imagination, with a sense of harmonious proportion rarely equalled in the world, a sense which he had trained in many various arts and many branches of science, for he must have been a student of biology who collected natural objects with a determination to penetrate the secret of their beauty, just as one of the greatest of our modern sculptors, Gilbert, has studied the bony forms of fishes, and from them designed the most exquisitely curved armour and the most fantastically beautiful ornaments. Learning and taste so universal as this seems to indicate have been rare at any period of the world's history : between 1500 and 1519 there was certainly but one man who possessed them, and that was Leonardo, the artist, architect, and biologist, who devoted so much of his life to the study of the intercommunication between art and nature; who, in fact, did even more in this direction in the fifteenth century than Gilbert or any other artist did in the nineteenth; who gave this final manifestation of his constructive genius to France's ungrateful monarch just before he died; who came 
from those Mediterranean shores where Voluta vespertilio (which is not a French shell) was known.

Professor W. R. Dunstan, F.R.S., has been kind enough to give me a Voluta from the Barton Beds of the Eocene Age on the coast of Hampshire, where there are a very large number of these shells to be found in so remarkable a state of preservation that they seem scarcely fossilised at all. In the days of Leonardo, and of course long before him, Voluta had vanished, as a living form, from the English and French coasts and from all waters that were colder than Italian seas. I have not reproduced the English specimen, as it does not advance my argument, though its lines are even more beautiful than those of the Mediterranean shell known to Leonardo da Vinci.

His death occurred in May 1519, only some twenty miles from Blois, at that Amboise where he had been living for some time. The first payments recorded for the new wing at Blois containing this staircase were made by Baron de Joursanvault in July 1516, just six months after the French King had arranged for Leonardo's departure from Milan. The most cursory inspection of the plan of the whole building will show that such an external feature may well have been completed after the main lines of the building had been laid. 
Its beauty is artfully thrown into relief by the comparative simplicity of the wall from which it springs. So perfect a whole as is the staircase may well have taken many years to finish, after Leonardo had given the first masterly sketches of its plan. Some stones in it have been left untouched until this day, and a few are only roughly chiselled out. Above and around the entrance are three statues which are very characteristic of a master of a much later period, Jean Goujon, who was carving at Ecouen in 1544. His help may well have been called in to put the finishing touches to a structure which a greater than he had originated. No subsequent adornments could alter or weaken the beauty of the main conception.

The sinistral curve within it is rare in any architecture, and, as I have pointed out, it is an exact reversal of the spiral contained within the ordinary Voluta. It would have suited the internal and external arrangements of the rest of the building just as well if the drawings for this staircase had been made on the plan of the ordinary dextral helix which is exhibited in its simplest form in the staircase built at Blois (fig. 18) before Leonardo came to France. There is no constructive reason, therefore, for the reversal, and a probable reason for any designer putting a left-handed 

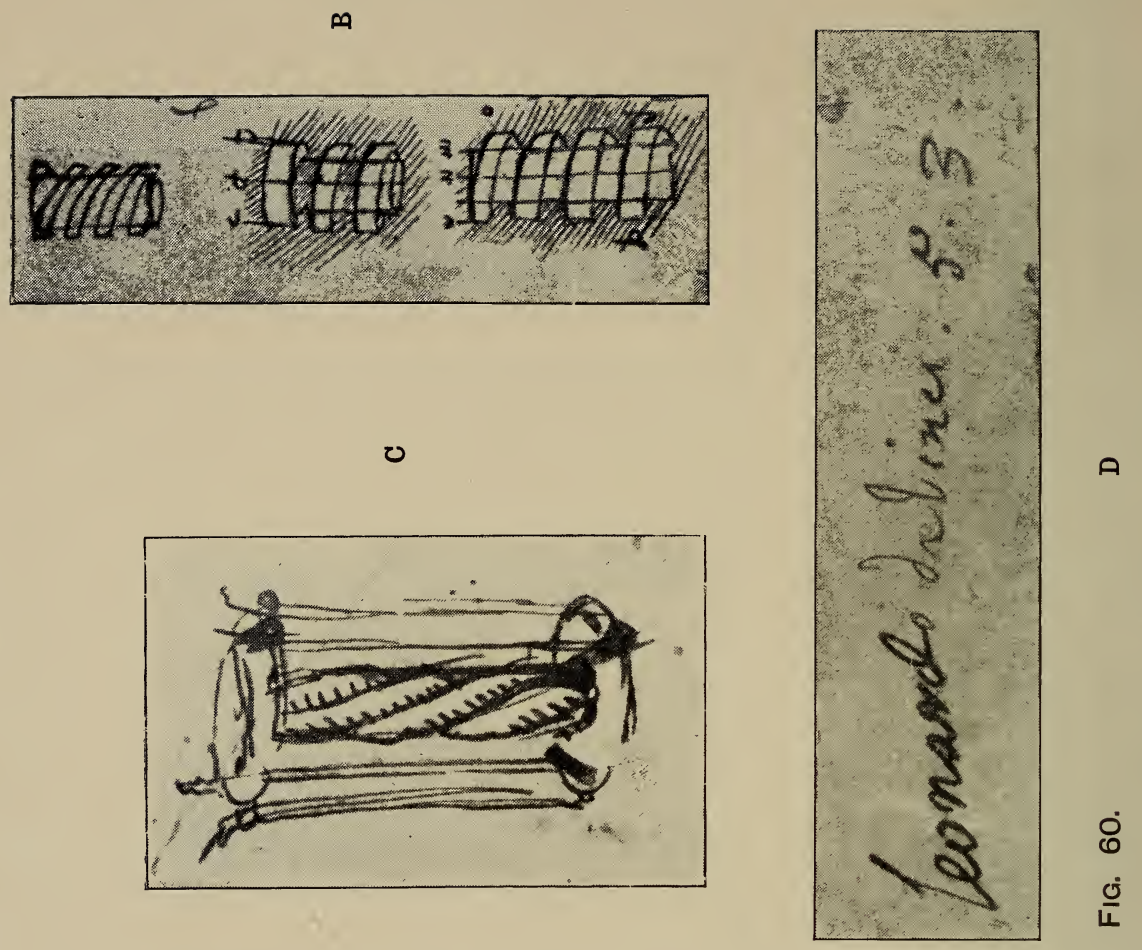

10

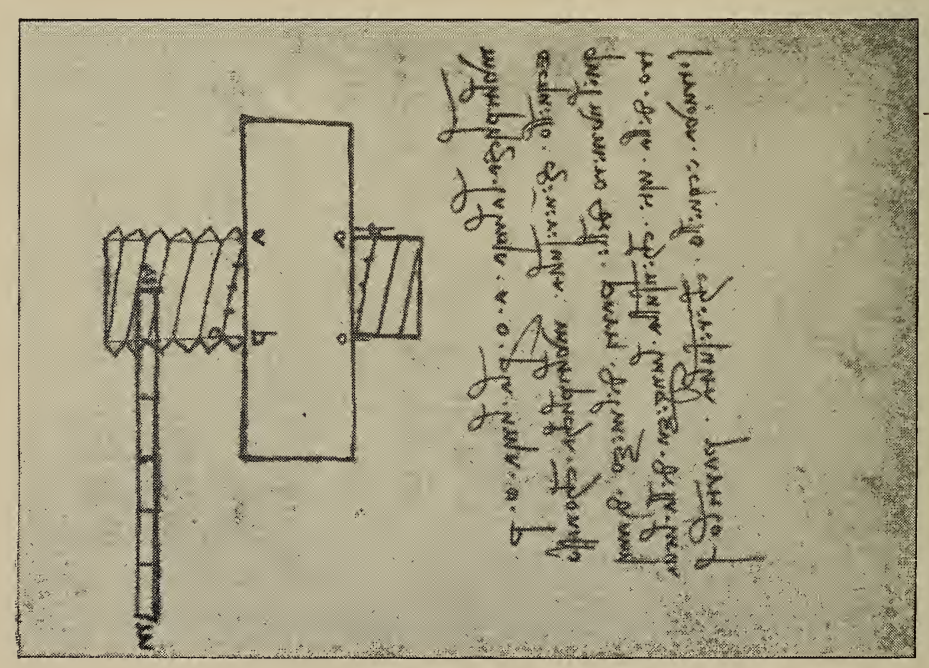


spiral into his sketches would be that he was himself left-handed.

Leonardo da Vinci was left-handed. Ninety per cent. of the screws and spirals contained in his manuscripts are left-handed spirals, and in fig. $60 \mathrm{I}$ have reproduced five of these out of a great number similarly drawn. ${ }^{1}$

It may be urged that having made his first rough sketch in the manner which came most natural to him, the architect could easily have changed it when once he had begun his working drawings. But Leonardo would not have considered the problem in that light. He was no mere slave to precedent. He had begun by drawing the left-handed spiral which came instinctively to the left-handed draughtsman. It interested him to notice the difference from the usual form, and he went on with his rarer form deliberately, carefully investigating whether it was better than the common style. As we look at the turn of the steps now, we realise that they move upward in the same direction as the hands of a watch moves forward as it lies upon a table, "through the

1 The fragments brought together on this plate show also his habitual method of shading from left to right, and I have given his right-handed signature in the same place in order that it may be contrasted with the far firmer and clearer writing done by his left hand on the opposite corner of the plate. 
buttonhole," as they say in Lincolnshire. It is after this manner, too, that fashion has decreed we should deal a hand at cards, and that superstition has ordered us to pass the Port. ${ }^{1}$ In architecture also, this arrangement produces an effect of hospitality in the curve, for a host could walk down it with welcoming right hand outstretched to the ascending guest, who was in his turn helped on his ascent by keeping his own right hand on the side-rail, just as you may see the modern athlete keep his right side inwards as he runs round the track at Queen's Club. Certainly, also, this stair is easier to walk up, a fact which may be verified by practical experience to-day.

Right-handed spirals are not only more common in Nature, they occur more often in art, because the average right-handed

${ }^{1}$ In 1690 a new "Dictionary of the Canting Crew" was published, in which the phrase "Catharpin-fashion" is defined as follows :- "When People in Company Drink cross, and not round about from the Right to the Left, or according to the sun's motion." The word "withershins," or "widdershins," also means against the sun (wither=against, shin's=sun's), and to go round a church from left to right (as you face the chancel from within) was believed to give the Devil power over so careless a traveller. The word may be connected with wiederschein = to reflect, as in Virgil's description of the rainbow, "Mille trahit varios adverso sole colores." 
architect had not cared to face the result that they involved a continual turning to the left; so he followed precedent, although on a left-handed spiral a man turns easily and naturally towards the right in his ascent. So far, then, this new arrangement must have satisfied Leonardo's practical sense of fitness. But it involved carrying out the same idea of reversal in its entirety, without the help of any previous examples in the district to guide him.

Certainly, if it was a shell before him of which he was thus reversing both the internal and external lines, he was the only architect then living who might have done so with the knowledge that Nature had, in one example out of every million, done the same before him. One of these rare examples he may have possessed and used, but it is more probable that he did not have before his eyes so uncommon a dexiotropic Voluta as that which I have reproduced in figs. 54 and 57 ; and if he did not, this rare shell, shaped by some left-handed angel of the Ocean, and worshipped as the evidence of some supernatural presence, becomes a triumphant vindication of his skill; for when its reversed lines are compared with his staircase, they will be found exactly to correspond in every case. Rare as the sinistral single spiral is in architecture, Leonardo's par- 
ticular development of the fourfold sinistral spiral is unique; and it is significant that the double interlacing staircase built by Pierre Trinqueau in 1526, close at hand in Chambord (see fig. 41), is also of this same rare sinistral form which had but just previously been built by the Loire; in tacit acknowledgment, as it seems to me, that no single stairway, even if it were similarly reversed, could ever compete for sheer beauty of construction with the older masterpiece at Blois.

To Leonardo the revelation of spirality thus so triumphantly manifested, its connection with religious doctrines, and the value of its symbolism, must strongly have appealed. As we know, he investigated many of the forms it took, and no doubt he knew far more of them than I have indicated here. He found it in such humble instances as the coil of the worm, the curve of the snailshell, the budding of the fern. Completed in the Ionic capital, arrested at the bending-point of the acanthus-leaf in the Corinthian, it became, he saw, a primal element of architectural ornament, eloquent with many meanings, representing the power of his favourite waves and winds in Greek building, typifying the old Serpent of unending Sin in Gothic workmanship. 
For him science was the handmaid of the imitative and creative arts, the tool by which he gave reality to his imaginations. His work was the healthy manifestation of a strong and subtle intellect; the mixture, and the equipoise, of all that is best in the faculties of man; and this is why his creations show that elusive quality of naturalism mingled with the ideal, of analysis with emotion, of soul with body. In him the artist and the scientist dwelt harmoniously together, worked harmoniously. No one of his time had observed so keenly; no one could express his observations with a greater realism. But his art was no mere servile form of imitation. He could both imagine and create, because he had an inexhaustible material from which to mould fresh forms. "Non è creatore se non Iddio ed il poeta" ("God and the poet are the only creators") said Tasso. But only an intellect so comprehensive as was Leonardo's could have justified the greater saying: "Natural Things are finite, but the works which the Eye can order of the Hand are infinite." One such "work" of his creative imagination did he reserve for the close of his life, and for its expression he chose that "mistress-art," architecture, to which all the other arts he knew are handmaids.

Again and again has the same search for 
the subtle and elusive causes of beauty been taken up. It has attracted minds so different as Hume, Bernouilli, Burke, and Winckelmann, among many others. Hogarth left us his idea of it. Professor Goodsir adopted the logarithmic spiral as a kind of teleological chart in Nature's beautiful designs. Taking Canon Moseley's investigations as his text, he tried to illustrate their logical corollary that the form and law of growth of an organic body being known, its form at any future time might be made a matter of mathematical elucidation. Following out with astonishing fidelity the line of investigation laid out by Leonardo da Vinci three centuries before, Professor Goodsir asked when it would be possible, by ascertaining the accurate shape, form, and proportion between the parts, organs, and whole body of any animal, to advance anatomical study geometrically. One of his most enthusiastic disciples, D. R. Hay ("On the Human Figure," 1849; "Natural Principles of Beauty," 1852 ; "The Science of Beauty," 1856), examined the geometric outline of the human body, just as Leonardo is said to have done when the Aphrodite of Praxiteles was discovered, and produced a certain harmonic proportion, by following which a correct anatomical outline could be drawn from a mathematical diagram. What Goodsir 
sought for all his life was some physiological law ruling the form and growth of organisms as gravitation is held to prevail in the physical world. If from the geometric curves of the planets' orbits Newton deduced the law of the force, said he, may we not learn "the law of the force" in natural objects also when we have got their mathematical forms? It may be very long before we do so, because very few biologists are mathematicians as well. But if ever this does come to pass, Canon Moseley's paper will be taken as the beginning of a new epoch in natural science.

Professor Goodsir considered that biology owed its progress to the study of final causes, to the study of the remarkable adaptation of structures to particular functions. This is not the most fertile mode of procedure in physical or chemical investigations, owing to the difference between organised and inorganised bodies. For each individual organism forms a system in which the reason why its parts are adapted to each other may be studied. But it is impossible to put the Solar System under our eye and examine it in order to explain the Sun. It is noticeable, however, that Newton showed in his "Principia" that if attraction had generally varied as the inverse cube instead of as the inverse square of the 
distance, the heavenly bodies would revolve, not in ellipses, but in logarithmic spirals, ${ }^{1}$ rapidly diffusing themselves and rushing off into space. If therefore, asked Goodsir, the law of the square is the law of attraction, is the law of the cube ${ }^{2}$ the law of production, and is the logarithmic spiral the manifestation of the law which is at work in the increase of organic bodies?

The process by which such results as those shown in the "Principia" must be reached may be described as two steps, the first being the hypothesis (based on the purely abstract conception of perfect motion) that the motion of a planet was like that of a ball swung on the end of a string; the second step is when Science discards the hypothesis, and uses it merely to investigate the properties of a planet's motion. This is the process that has been exemplified in the discovery of the law of light and heat, or in the hypothesis which is based upon the abstract conception of a perfect liquid. Clearly, there can be no

${ }^{1}$ It is worth considering in this connection that the growth of systems seems to be expressed in the spiral nebulæ discovered by Lord Rosse, as opposed to the circling of completed weights in the case of perfect planets which follow a fixed orbit, owing to the unvarying law of gravity.

2 "The law of the cube," that is, the law of the cell also. 
objection, as $\mathrm{Mr}$ Church points out, to the application of a mathematical conception in itself either to phyllotaxis and the arrangement of leaves upon a stalk, or to conchology and the growth of the Nautilus. Everything in nature is capable of mathematical expression if the conditions are only sufficiently well known; the real difficulty is to select a fundamental conception which will admit of modification when new factors are introduced. In other words, if the genetic spiral be regarded mathematically as winding to infinity, and being engaged in the production of similar members, it can only be represented by the logarithmic spiral which makes equal angles with all radii vectores. "Eadem mutata resurgit." This spiral, representing the laws of mathematical asymmetrical growth around a point, constitutes in Hydro-Dynamics the curves of spiral-vortex movement, and its application to magnetism has been fully investigated by Clerk Maxwell.

From this last point $\mathrm{Mr}$ Church is now working towards the proof of a hypothesis which he has not fully published; but he clearly thinks that the distribution of living energy follows identical lines with those of electrical energy, for example, and that a phyllotaxis diagram, or (as I should add) the plan of a Nautilus, is comparable to electrical 
[CHAP.

\section{lines of equipotential. ${ }^{1} \quad$ The theory, if correct, would be fundamental for all forms of growth, though it could be more easily observed in plant-protoplasm than in animals. ${ }^{2}$}

${ }^{1}$ If this hypothesis be correct, it may form a very important factor in such experiments as those reported by $\mathrm{Mr}$ A. B. Plowman in the Harvard Botanic Garden, on the relations of electricity to plant-growth, or in such researches as those of Professor Lemström of Helsingfors.

${ }^{2} \mathrm{Mr}$ Church's further statements, being somewhat too technical for the ordinary reader, though of extreme importance to the theory mentioned above, are here quoted in a footnote from his "Note on Phyllotaxis" (1901).

"The possibility that the contact parastichies may be also not only $\log$-spirals but log-spirals which intersect orthogonally, and thus plot out a field of distribution of energy along orthogonally intersecting paths of equal action, is so clearly suggested that it may at once be taken as the groundwork of a theory of phyllotaxis more in accordance with modern lines of thought. ... It is difficult to avoid the conclusion that the logarithmic spiral construction gives the true key to the problem, and that the whole subject thus becomes a question of the mechanical distribution of energy within the substance of the protoplasmic mass of the plant-apex : that phyllotaxis phenomena are the result of inherent properties of protoplasm, the energy of life being in fact distributed according to the laws which govern the distribution of energy in any other form : and that the original orthogonal planes, the relics of which survive in the contact parastichies of the system, represent the natural consequence of a mechanical system of energy-distribution directly comparable with that which produces the orthogonal intersection of cell-walls at the moment of their first formation." . . "The logarithmic spiral theory," he 
It will be seen that, in all efforts to define a natural object in mathematical terms, we come to a point at which our knowledge of the involved factors ceases. The Nautilus is almost a logarithmic spiral, but not quite. Nor can a phyllotaxis diagram, as Mr Church admits, ever show that the plant's growth is mathematically correct. All that can be said is that the logarithmic spiral is as near as we can get in mathematics to an accurate definition of the natural phenomena. To this same stopping-place the mathematician is also brought when he tries to express beauty in terms of measurement. In other words, the baffling factor in a natural object is its life, its organic growth. The baffling factor in a masterpiece of creative art is its beauty, a quality as essential and as intangible as life. This means therefore that growth cannot be wholly expressed by algebra or trigonometry,

concludes, "is so far then the logical outcome of Sachs' theory of the orthogonal intersection of cell-walls, and represents therefore another special case of the distribution of energy along planes of 'equipotential.' "'

The symbolism of the spiral form of ornament originally taken from the lotus (see p. 49) therefore receives a striking confirmation of its power and meaning; and the occurrence of the logarithmic spiral in such minute organisms as the microscopic Stentor coeruleus indicates how widely this marvellous curve can be applied to a consideration of living growth (p. 73). 
[CHAP.

though these may help us to appreciate and describe the phenomena we examine. It means also that a thing constructed merely by rule and thumb and mathematics must inevitably fall short of perfect beauty. For perfect beauty, like natural growth, implies irregular and subtle variations.

By this path we may perhaps reach some more intelligible explanation of that vague but most important quality- "good taste." It is born in some men and unknown by others. It can be widely distributed, or the life of ancient Hellas becomes an unintelligible miracle. It can be lost in just as large a measure, or most modern architecture would be a nightmare, from which our waking moments would be free. It has a definite relation to, and a keen sympathy with, the phenomena of life and growth; so it must to some extent partake of their qualities. A man whose vitality is strong, whether it be physical or intellectual, would therefore be likely to possess it, if he were keenly in touch with Nature, if he abhorred artificial rules, and mathematical or mechanical results. This would explain both its general prevalence in ancient Hellas, and its general absence in an age when machine-made productions have become paramount; when designers trust to mathematics; when the public object to any- 
thing but repetition. One of the chief manifestations of "good taste," then, is the appreciation of the truth that beauty, like life and growth, depends not on exact copying, but on those subtle variations to which the scheme of creation, as we know it, owes those great laws of the origin of species and the survival of the fittest.

A good architectural example of this deliberate and subtle variation, which was the Greek ideal of beauty, may be found in the volute of an Ionic capital. It is no more mathematically correct than the lines of the Parthenon are mathematically straight. It is beautiful because it exhibits just those variations which are observable in organic growth.

The ordinary method of drawing a " correct" volute with the help of an inverted cone is, of course, well known, and results in a mathematically exact and æsthetically vapid figure. But Mr Banister F. Fletcher (in the Building News for 22nd August 1902, p. 247) has shown that a shell can be used for the same purpose (fig. 61). Following his instructions, I took the sinistral whelk mentioned on page 90 , and wound a piece of tape, 12 inches long, round its spirals from its apex $(\mathbf{E})$ to the top of the opening, leaving a little of the tape over to hold the rest in position. A pencil was 
attached to the end of the tape touching the apex. Reversing the shell so that it stood perpendicularly upon its apex at the point marked $\mathrm{E}$ in the diagram of the volute, and keeping it fixed on that point, I drew the pencil round and round the shell in the gradually increasing curves permitted me by the gradual unwinding of the string. The volute reproduced in fig. 61 is the result. The shell used was exactly contained in a rectangular space $4 \frac{1}{16}$ inches long by $2 \frac{1}{4}$ inches wide. It produced a spiral measuring $10 \frac{5}{8}$ inches across from $\mathbf{E}$ to $\mathbf{A}$. Though both shell and volute are reduced to suit the size of these pages, the relative proportions remain the same. It will be noticed that the Chrysodomus antiquus employed is a common specimen of a sinistral shell, and has therefore produced the left-hand volute of the capital. The right-hand volute can be similarly produced from a common right-handed whelk.

This method, though mechanically performed, actually reproduces those proportions of an Ionic volute which owe none of their charm to mathematics; and whether the ancient Greeks used a shell or not in making their designs, it is very significant that the beauty of their workmanship should exhibit so exact a harmony with the lines of an organic growth that are nearly, but not quite, the 


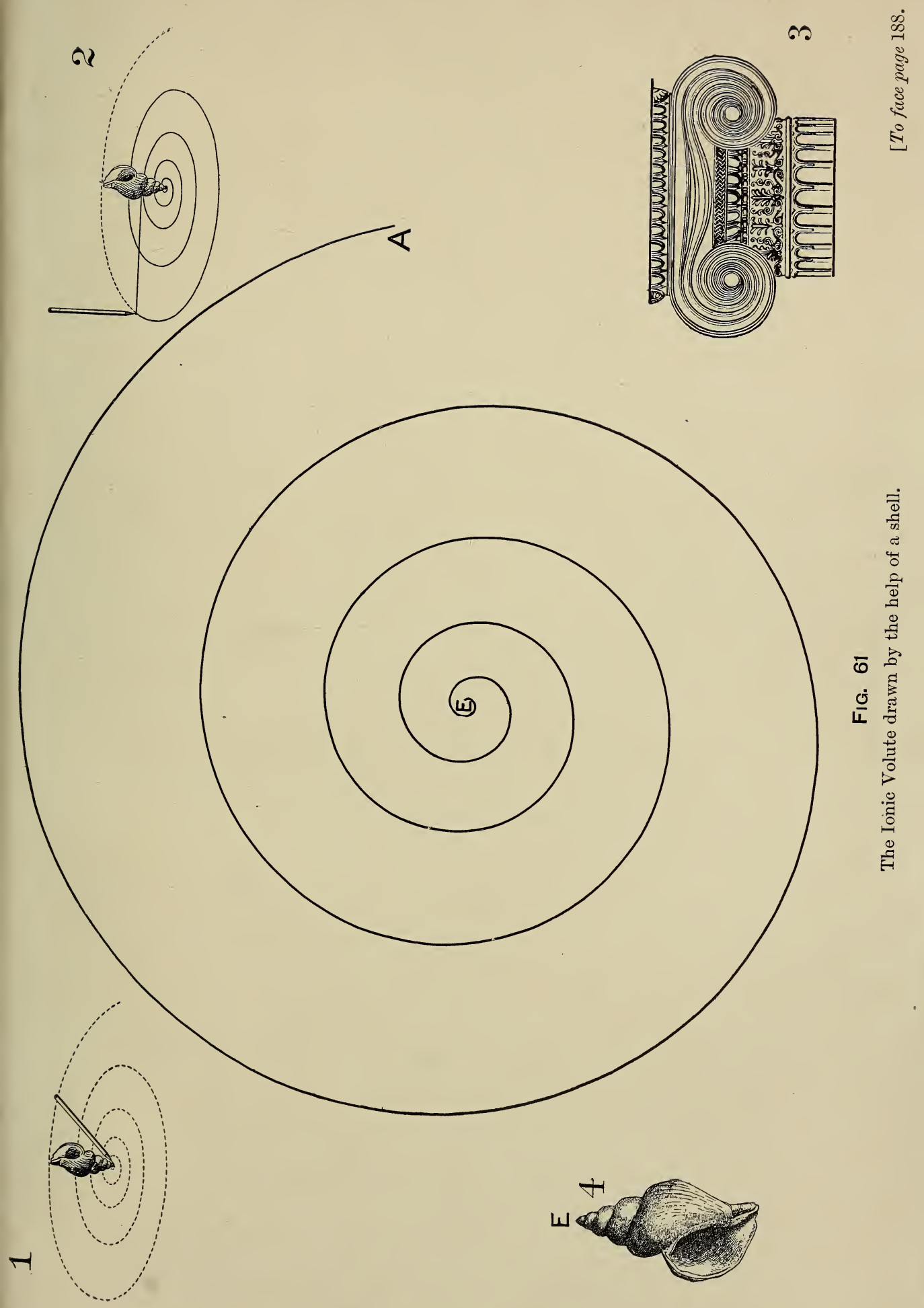



curves of a mathematical spiral. It is in this subtle difference that their charm consists.

So strongly did Goodsir himself believe in the correctness of the theory which $\mathrm{Mr}$ Church is now developing on original and progressive lines, that on his grave in Edinburgh, where a medallion portrait is now fixed, he originally ordered the logarithmic spiral to be sculptured, which represented to him the fundamental principle of beauty and of growth in nature. Pettigrew and Francis Darwin have done much towards the investigation of spiral formations in Nature; and to many another besides Professor Goodsir's pupil has the same idea appealed. But not one of all of these has left such visible monuments of insight and creative power as the Leonardo who saw the same problems both in Nature and in Art so long before them.

"Majestati Naturæ Par Ingenium." We have not yet said the last word on that theory of flight he studied from the wings of birds before the fifteenth century was gone. $\mathrm{We}$ know very little more than he has written of the mysterious forces which shape the structures of waves, of reeds, of animals, of shells. We are still groping after those fundamental laws he sought, which existed "before the fair flowers were seen, or ever the movable powers were established, before 
the innumerable multitude of angels were gathered together, or ever the heights of the air were lifted up." We, too, must look beyond, as he looked long ago towards the stars, moving in the sky " to their own natural home, which they enter unannounced as lords that are certainly expected, and yet there is a silent joy at their arrival." 



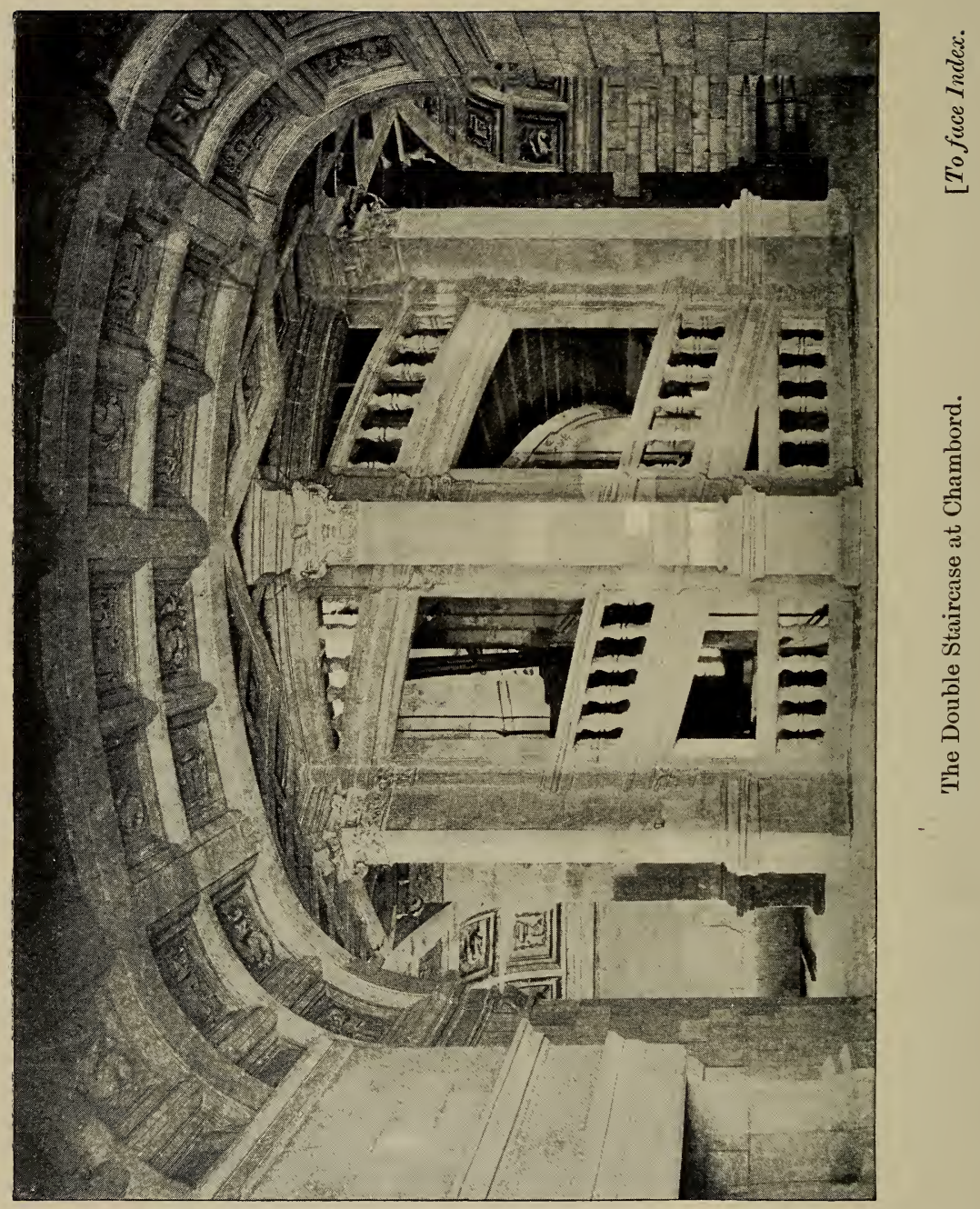


INDEX 



\section{N D E X}

ABbey of Thelema, 143

Accatabriga, 150

Accidents, 68

Africa, 48

Air tubes, 117

Airy's spirals, 130

Alaska, 48

Alaskan Bighorn, 81

Alberti (Leon Battista), 103

Aleutian Isles, 48

Amalekites, 37

Amboise, 146, 149, 152, 157, 159, 173

Ambrosian Library, 149

Ammonite, 42, 91, 93, 124, 126, 157

Amory valley, 48

Ampelopsis hederacea, 67

Amphidromus, 90

Amphidromus perversus, 89

Amsterdam, 47

Angora, 80

Antelopes, 79, 86

Antonio da Vinci, 150

Apennines, 22

Aphrodite, 180

Aploceras, 93

Arab, 48

Arbela, 36

Architecture, 8

Archimedes, 157

Arezzo, 108

Argali, 81

Argonauta Argo, 124

Arm supports, 87

Assyrian, 48

Asymmetry, 100

Atlas (Mount), 22

Augur-shell, 33

Auricula auris midæ, 158
Australasia, 125

Azay le Rideau, 140

BAIKAL (Lake), 91

Balfour, (Henry), 47

Barbour (Professor), 60

Barrande, 93

Barton beds, 6, 173

Bayard, 147

Bean, 62, 66

Bedouin, 99

Belsay, 139

Belshazzar, 35

Beltrami, 11

Bengal, 45

Benjamin of Tudela, 111

Benjamites, 37

Berkshire, 65

Bernouilli, 24, 124, 180

Bighorn, 81

Billingsgate, 89

Blarney Castle, 139

Blois, 4, 9, 98, 145, 157, 162, 173

Blois (old staircase), 144

Blois (Château), 132, 141

Bologna, 110

Bonanno, 109

Bonnet, 55, 69, 72

Boreau, 150

Borneo, 46

Brachiopods, 86

Bramante, 151

Brantôme, 143

Braun, 70

Brazil, 56

Bronze Age, 45

Browne (Sir Thomas), 19, 23, 37

Bryony, 67

Buccinum undatum, 89 
Buckland (Frank), 41

Buddhist, 48

Buffaloes, 86

Burke, 180

Bushbuck, 76

Byzantine, 48, 100, 106

CAesar Borgia, 147, 148

Calandrini, 70

Calcispongiæe, 52

Calderon (George), 49

Cambrensis (Giraldus), 34

Campanile of Pisa, 96, 108

Canterbury Cathedral, 30

Cape of Good Hope, 125

Capra falconeri, 80

Capra walie, 83

Carnauba Palm, 56

Catharpin, 176

Catherine de Medici, 171

Celts, 36

Central column (origin), 135

Ceritheum giganteum, 119

Cerithium Portlandicum, 33

Ceropegia Gardnerii, 63

Cestracion philippi, 75

Chaldee, 35

Chambord, 143, 178

Chank shell, 44

Charles V., 134, 159

Charles VIII., 159

Charlotte d'Albret, 148

Chartres, 97, 162

Chenonceaux, 140

Cher, 156

Chester, 153

Chesterfield, 96

Chestnut, 57

Chevreuil, 24

Chichly, 107

Chinon, 147

Chippendale, 113

Choanomphalus, 91

Chrysodomus antiquus, 90, 188

Church (A. H.), 70, 92, 124, 183

Clausilia laminata, 128

Clerk Maxwell, 183

Clifford (Professor), 21, 130

Climbing plants, 62

Clos-Lucé, 48

Cloux, 147, 149
Clymenia, 92

Cobus unctuosus, 78

Cochlea, 75

Cochliodus contortus, 42

Codex Atlanticus, 11

Codice Atlantico, 149

Coffin screw, 32

Cokerell, 104

Collar-day, 36

Collège de Montaigu, 144

Coloration, 85

Columella muscle, 120

Columella plaits, 115

Columna flammea, 89

Convolvulus, 59, 62

Copenhagen, 96

Copernicia Cerifera, 56

Copernicus, 23

Corea, 125

Corkscrew, 31

Cormack M'Carthy, 139

Cornish (Vaughan), 156

Cowry, 45

Crete, 45, 83

Crioceras bifurcatum, 91

Crypt of Canterbury, 31

Cumberland, 139

Curves in building, 104

Cuvier, 22, 74

Cyclamen, 55, 152

Cylindrella, 92

Cymbiola tuberculata, 120

Cymbium, 119, 167

Cypraea annulus, 45

Cypraea moneta, 45

Cypriot, 48

Cyrtoceras, 93

DACCA, 44

Dacre Castle, 139

Dæmonelix, 60

D'Alembert, 24

Darius, 36

Darwin, 16, 22, 62, 65, 67, 68, 70, 118

Darwin (Francis), 62

Date Palm, 57

Deluge (Scriptural), 12, 22, 156

Devil, 46

Devil's Corkscrews, 60

Devonshire, 55

Dexiotropic, 87 
Dexiotropic Voluta, 177

Dextral helix, 27

Diatoms, 52

Domestication 85

Donaldson, 104

Douglas (the Black) 139

Dover, 35

Driving, 27

Druids, 36

Drummond (Dr), 60

Dunstan (Professor), 173

Duval, 11

ECLIPSE (racehorse), 127

Eglantine, 152

Egypt, 45, 48, 59, 99

Elands, 78

Elasmobranch, 42

Electricity, 75

Elephant, 41

Elgin (Lord), 104

Entasis, 104

Eocene, 173

Equiangular spiral, 122

Etienne de Loup, 148

Euclid, 113

Euglena oxyuris, 74

Euglena spirogyra, 74

Evans (Arthur), 45

Evelyn, 108

Evolution, 70

Eyestone, 126

Felixstowe, 51

Fencing, 27, 38

Fiesole, 95, 160

Flanders, 141

Fletcher, Mr B. F., 187

Flight of birds, 153

Floral diagrams, 59

Florence, 109

Florence Court, 60

Flying (Treatise on), 15

Fossil twisters, 60

Fra Giocondo, 156

Framlingham, 97

Francesco Sforza, 148

Francis I., 109, 141, 143, 145, 147, 148,150

Frankfort, 96

Freeman (Professor), 121

Fresnel, 130
Friston Tower, 140

Fusus antiquus, 51

Fyvie, 139

Galileo, 17

Garisenda, 110

Gaudry (Albert), 92

Gelnhausen, 96

Geymüller (Baron de), 151

Gideon, 37

Gilbert, 172

Gioconda (La), 156

Goats, 79

Goethe, 19, 70, 110

Goodsir (Professor), 124, 127, $180,181,189$

Goodyear (Professor), 48, 101, 105,106

Goniatites, 92

Gothic, 100, 101, 108

Gothic Revival, 102

Goujon (Jean), 174

Govi, 11

Greeks, 48

Greek builders, 102

Gremsmühlen, 129

Guglielmo, 109

Gulf of Guinea, 89

Gyroceras, 93

HAIR, 39, 85

Haliotida Cunninghamii, 125

Haliotida gigantea, 125

Haliotida midæe, 125

Hamilton (Sir W. R.), 130

Hampshire, 173

Hand-rail, 141

Hand-writing, 13

Harpula fulminata, 120

Harvard, 184

Hay (D. R.), 180

Heart fibres, 75

Heart (valves of), 22

Helicoprion, 42

Helicteres ixora, 50

Hellenic art, 186

Helmholtz, 21

Helsingfors, 184

Hepplewhite, 113

Heredity, 70

Hertford College, 138 
Heteronymous, 78

Hexacoralla, 52

Highland Ram, 77, 81

Hindu, 44

Hofer, 105

Hogarth, 180

Holbein, 38

Holland, 141

Holmes (Dr O. W.), 126

Holstein (Eastern), 129

Homonymous, 78

Honecort (Wilars de), 102

Honeysuckle, 62

Hops, 49, 62, 63, 65

Horse-chestnut, 57

House of Commons, 140

Houssaye (Arsène), 149

Humboldt, 17

Hume, 180

Hungary, 83

Hunter (William), 153

Huxley, 16

IBEx, 83

Iceland spar, 130

Ile de France, 101

Il Moro, 147

Indre, 147

Infusoria, 125

Ionic Volute, 187

Ipswich, 140

Ireland, 139

Irish torques, 34

Irritability, 64

Isabella d'Este, 151

Isle of Bourbon, 57

JAFFNA, 44

Japanese, 33

Jew's ear, 50

Jones (Inigo), 103

Joursanvault (Baron de), 173

KEPLER, 4

Kew, 56

Kirchhoffer, 28, 38

Koninckina leonhardi, 87

Koodoo, 76

Kumatology, 156

LADY's TREsSES, 55

Lamarck, 70
Lamona, 22

Lanistes, 51, 90

La Trémouille, 147

Leaning Tower, 109

Leda, 157

Lee-Metford, 32

Left-handedness, 37,175

Left-handed writing, 175

Leiotropic, 32,87

Lemström, 184

Leonardo da Vinci, 4, 10, 38, 114, $132,145,146,150,151$

Lepus cuniculus, 158

Leslie (Sir John), 121, 125

Leyden, 47

Libri, 11

Limacina, 90

Lincolnshire, 140, 176

Lithuanian, 49

Lizards, 75

Loasa aurantiaca, 62

Loches, 147

Logarithmic curve, 92

Logarithmic spiral, $71,122,183$, 184

Loire, 146, 149, 156

Lombardy, ¿4, 151, 160

London, 132, 153

Lotos, 47,49

Louis XI., 148

Louis XII., 145, 148

Louvre, 134, 149

Ludovico Sforza, 147

Lyell, 22

Lyme Regis, 124

Lynn, 140

Macon, 149

Macroscaphites gigas, 92

Macroscaphites ivanii, 92

Madagascar, 57

Madrid, 143

Maison Carrée, 105

Malay, 46, 47, 48

Malpighi, 117

Mammal, 75

Manderville (John de), 21

Manlius Torquatus, 36

Mansion House, 112

Manuscripts (Leonardo's), 13

Maori, 46

Marey (Professor), 154 
Marey (E. J.), 74

Marignano, 148

Markhor, 77, 84

Martello towers, 139

Medinet Habou, 104, 105

Mediterranean, 89

Meladromus, 90

Melanesia, 46

Melia, 93

Melzi (Francesco), 148, 149

Merignac, 38

Merino Ram, 81

Metamorphosis of leaves, 70

Meyer (Hermann), 75

Michelet, 19

Middleton Tower, 140

Milan, 108, 148, 173

Milan, Duke of, 151

Milanesi, 150

Minos, 45

Miratesta, 89

Mitra papalis, 27, 97

Mohammedan, 48

Mona Lisa, 169

Montreal, 60

Montrichard, 157

Moore (Julian), 101, 107

Moore (J. E. S.), 52

Moorish, 99

Morantin, 149

Moseley (Canon), 122, 127, 180

Müntz, 11

Müller (Johann), 17

Müller-Walde, 11

Mycenae, 47

NaUtiloceras, 93

Nautilus, 91, 92, 111, 115, 122, $123,125,126,183$

Naples, 36

Narwhals, 39

Nature (finite), 18

Nebulae (spiral), 76

Neottia spiralis, 55

Nepenthes, 117

Newel, 136

New Guinea, 46

Newton, 71,181

New Zealand, 58

Nicobar Islands,

Nile, 48

Niobrara River, 60
Norfolk, 140

North Berwick, 139

North Sea, 51

Northumberland, 139

Nunney Castle, 140

Nutation, 63

Nyassa, 51

OBLIQUE plans, 106

Oncyloceras spinigerum, 91

Onion, 59

Open staircase, 166

Operculum, 90, 122, 126

Ophidioceras, 93

Optically neutral, 131

Orchid, 55

Orientals, 34

Orthoceras, 93

Orton Scar, 35

Ovis nivicola, 86

Owen, 91

Oxford, 113, 138

Pacioli (Fra Luca), 13

Palæolithic, 37

Palais de Justice, 96

Palazzo Contarini, 95, 136

Palissy (Bernard), 22

Pamir, 81

Pandanus millore, 57

Pandanus sylvestris, 57

Pandanus utilis, 57

Pandanus vandermeschii, 57

Paris, 113, 144

Parthenon, 100, 104, 105, 106

Pascal, 24

Passion flower, 62

Pasteur, 131

Patterns, 47

Pavia, 151

Peas, 62

Peels (Border), 139

Pelseneer, 90

Pennethorne, 104, 105

Penrose, 106

Penrose (F. C.), 105

Persians, 35

Peru, 46

Petersburg, 42

Pettigrew, 75

Pharaoh's serpents, 41,88

Phœnix dactylifera, 57 
Phryganeida, 74

Phyllotaxis, 69, 183, 184

Physa fontinalis, 89

Physa heterostropha, 89

Piedmont, 160

Piero da Vinci, 150

Pine Ridge, 61

Pinus smithiana, 55

Pir Panjal, 80

Pisa, 96, 108, 109

Pisa Baptistery, 110

Pisa Campanile, 111

Pisa Cathedral, 110

Piumati, 11

Plaits on columella, 118

Planorbis, 90

Plants, 54

Pliny, 21

Plowman (A. B.), 184

Po (river), 22

Polarised light, 130

Pompeii, 36, 137

Pompholyx, 91

Portland screw, 33

Poulton (Professor), 85

Praxiteles, 180

Prat, 107

Prentice's Pillar, 29, 96, 144

Pritchard (Eric), 74

QUADRUPLE helix, 163

Queen's Club, 176

RABBITS, 41, 62

Rabelais, 143

Ralph, Lord Cromwell, 140

Rata, 57

Ravaisson-Mollien, 11

Ravenna, 110,

Raymond du Temple, 135

Red Crag Sea, 51

Renaissance, 102, 108

Revett, 104

Revival (Gothic), 102

Richter, 11, 150

Rocky Mountains, 31, 61

Rodin, 20

Roman screws, 137

Rome, 47

Romorantin, 151

Rosse (Lord), 76, 182

Rosslyn, 29
Rouen, 96, 106

Rundthor, 96

Ruskin, 16, 111, 121

SABACHNIKOFF, 11, 155

Sabba da Castiglione, 151

Sabella, 74

Sabella unispira, 74

Saint-Bel (M. Vial), 127

San Domenico, 95

San Paternian, 95

Sankho, 43

Saône, 149

Santa Maria della Grazie, 151

Sant' Ambrogio, 108

Sauldre, 149

Scala del Bovolo, 6, 95, 96

Scala della conchiglia, 6, 95

Scalaria scalaris, 6, 95, 123

Schaubert, 105

Schimper, 70

Schliemann, 43, 47

Scotland, 139

Screw-like flight, 154

Screw-palm, 57

Screws, 32

Screwstone, 33

Sea-bean, 126

Séailles, 11

Septuagint, 35

Shark's egg, 75

Shark's intestine, 158

Shavings, 33

Shell growth, 87

Shells, 50

Shells (carved), 170

Sheraton, 113

Siliquaria, 91

Simroth, 90

Sinistral helix, 28

Sinistral shells, 51, 89

Sinistral spiral, 174

Sinistral spiral (fourfold), 178

Sinistral spirals (interlacing), 178

Siphuncle, 91

Situtunga, 84

Skate, 42

Smilax aspera, 66

Smoke spirals, 152

Solarium maximum, 6, 94

Somersetshire, 140 
Spencer (Herbert), 74

Spiral curve, 78

Spiral formations, 26

Spiral forms of water, 156

Spiral horns, 76

Spiral nebulae, 76

Spiral staircase (origin), 132

Spiral Theory, 69

Spiral tubes, 116

Spiral twist, 78

Spira mirabilis, 124

Spirialis, 90

Spirifer mucronatus, 87

Spirostomum ambiguum, 73

Stein, 73, 125

Stentor coeruleus, 73, 125

Stentor igneus, 73

Stentor multiformis, 74

Stentor polymorphus, 73

Stentor Roeselii, 73

Stephanoceratidae, 91

St Florentin, 149

St Germain-en-Laye, 150

St John the Baptist, 149

St Mark's, 108

Stone Age, 46

St Ouen, 106

St Paul's, 107

Strassburg, 110

Streets, 113

Stuart, 104

Style, 53

Sulieman markhor, 84

Sweden, 47

Symmetrophobia, 109

TANGANYIKa, 51

Tantallon Castle, 139

Tasso, 179

Taste, 186

Tattershall Castle, 140

Taurotragus oryx, 78

Teeth, 42

Telescopium, 91, 160

Telescopium telescopium, 98, 119,161

Tendrils, 66

Terebra maculata, 33

Terebra semiplicata, 33

Thebes, 104

Torques, 34

Torsion, 65, 68
Touraine, 143, 161

Tours, 97,157

Tower of London, 136

Tracheae, 116

Tragelaphus angasi, 79

Tragelaphus spekei, 84

Travancore, 43, 164

Trochus, 127

Troy, 43

Turbinella fusus, 120

Turbinella pirum, 44, 119

Turbinella rapa, 44

Turbine shells, 122

Turbo marmoratus, 126 *

Turbonilla, 91

Turbo olearius, 127

Turf (English), 128

Turner (Sir William), 127

Turritella, 160

Turrilites catenulatus, 89

Turrilites costatus, 89

Turritella lentiginosa, 119, 158, 162

Tuscany, 160

Tuticorin, 44

Two-fifth spiral, 69

ULTRA-DEXTRAL, 90

Ultra-sinistral, 91

Uniform growth, 71

Uzielli, 11

VASARI, 109, 150

Venice, 108, 111, 160, 162

Venturi, 11

Victoria Nyanza, 51

Vienne, 147

Viollet le Duc, 136, 142, 144

Vishnu, 43

Vitruvius, 102, 104

Voluta (dexiotropic), 177

Voluta musica, 120, 162

Voluta pacifica, 119

Voluta scalaris, 6

Voluta solandri, 119

Voluta vespertilio, 5, 89, 119, $162,164,167,173$

Volute, Ionic, 187

Von Mohl, 70

Von Thering, 90

Vorticella, 74 
WALKING-STICKS, 34

Wallachian sheep, 83

Wantage, 107

Ward (Rowland), 84

Washington, 36, 47

Waterbuck, 78

Water-lily, 58

Wax palm, 56

Weldon (Professor), 128

Westminster Abbey, 49, 107

Whelk, 90, 187

Wherry (Dr), 40, 64, 67, 76, 86

Whistler, 8

White River, 60

Wilkins, 104

William of Waynflete, 140
Wilson (Sir Daniel), 37

Winchester (Bishop of), 140

Winckelmann, 180

Windsor, 155

Withershins, 176

Wren, 108

Wren (Sir Christopher), 107

Wyndham (Rt. Hon. Geo.), 20

YAKOOTS, 48

Yew, 59

ZEUGLODON, 75

Zulus, 34

Zygospira modesta, 87 



SMITHSONIAN INSTITUTION LIBRARIES

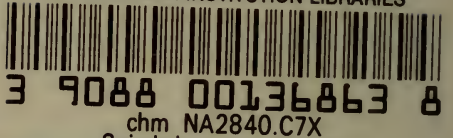

chm NA2840.C7X 